\title{
Indexação e Recuperação de Informações Utilizando Redes Neurais da Família ART
}

\author{
José Flávio Vicentini
}

Orientadora: Profa. Dra. Roseli Aparecida Francelin Romero

Dissertação aprescentada ao Instituto de Ciências Matemáticas e de Computação - ICMC-USP, como parte dos requisitos para obtenção do título de Mestre Ciências de Computação c Matemática Computacional.

USP - São Carlos

Novembro de 2002 


\section{A Comissão .Julgadora:}

Profa. Dra. Rosell Aparecida Francelin Romero

Prof. Dr. Fernando Jose Won Zuben

Profa. Dra Agma Juci Machado Traina

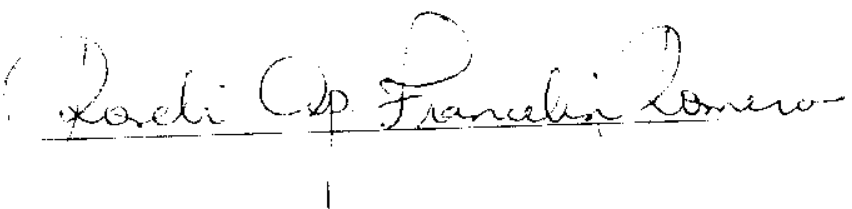

- temande fox ion jubin

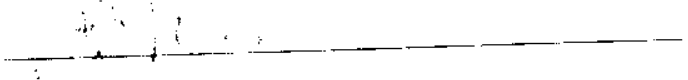


Esta dissertação foi preparada utilizando formatador de textos $\mathrm{BT}_{\mathrm{E}} \mathrm{Xe}$ o sistema de citaçōes de referẽncias bibliográficas utiliza o padrão Apalike no sistema BIBTEX. 
"Quc Deus me dê serenidade para aceitar as coisas que não posso mudar, coragem para mudar as coisas que posso e sabedoria para conhecer a diferença." [Provérbio Chinês]

“De tudo, ficaram três coisas: a certeza de que estamos sempre começando... a certeza de que é preciso continuar... a certeza de que seremos interrompidos antes de terminar... Portanto, DEVEMOS fazer da interrupção um caminho novo... da queda um passo de dança... do medo, uma escada... do sonho, uma ponte... da procura... um encontro" [Fernando Sabino] 
Dedicatória

...̀̀ MINHA FAMÍlia. 
À Profa. Dra. Roseli A. Francelin Romero pelo grande incentivo, paciência, amizade e pela oportunidade por ter desenvolvido um trabalho mediante a sua orientação segura e dedicada, que contribuiu muito para meu crescimento profissional, intelectual e moral.

À Profa. Dra. Agma Juci Machado Traina e pelos valiosos comentários e sugestōes, quando da realização do meu exame de qualificaçāo, pelos constantes esclarecimentos a respeito da estrutura Slim-Tree e paciência dedicada.

Ao Prof. Dr. Zhao Liang pelos valiosos comentários, sugestões, quando da realização do meu exame de qualificação, também pelos esclarecimentos a respeito das redes neurais ART e paciência de dedicada.

À Patricia Rufino Oliveira pela amizade, profissionalismo e incentivo durante várias etapas do desenvolvimento deste trabalho. Especialmente, pela grande ajuda prestada na revisāo final desta dissertaçāo.

Aos meus pais, pelo amor a admiração que tenho por eles, que nunca mediram esforços para incentivar minha formaçāo, e que, apesar de distantes, sempre estiveram presentes em minha vida.

Aos prof. Drs. Pedro Paulo Ayrosa, Robinson Hoto e Silvio T. Canola pelo grande incentivo na época da graduação

Aos amigos do LABIC pelos momentos vários momento de descontração. Embora o trabalho seja individual, de alguma forma há sempre a colaboração de todos, em especial Ernesto, Guillermo, Adriano, Ronaldo, Valmir, Jaque, Daniel, Claudinha e Dëbora.

Às amiga Carolina T. Ferraz (Carol), Cillene Souza Nunes (Cilla), e aos amigos Ricardo Siquieri e Marco Antônio (Marcāo) pelo incentivo e amizade.

Aos colegas do GBDI-ICMC-USP pelos esclarecimento a respeito da estrutura Slim-Tree e paciência dedicada, em especial ao Fábio, Enzo, Marcos, Josiel, Adriano e a Josiane (Jô).

Ao CNPq pelo apoio linanceiro. 
1 Introdução 12

1.1 Contexto . . . . . . . . . . . . . . . . . . . 12

1.2 Motivação e Objetivos . . . . . . . . . . . . . . . . . . . . . . . . . . . . . . .

1.3 Organizaçāo do Trabalho . . . . . . . . . . . . . 15

2 As Redes Neurais Auto-Organizáveis 17

2.1 Considerações iniciais . . . . . . . . . . . . . . . . 17

2.2 Mapas Auto-Organizáveis (Self-Organizing Maps) . . . . . . . . . . . 19

2.2.1 Arquitetura básica e funcionamento de uma rede SOM . . . . . 20

2.2 .2 Aplicaçōes da Rede $\mathrm{SOM} \ldots \ldots \ldots . \ldots . \ldots . \ldots 22$

3 Redes Neurais da Familia ART 24

3.1 Consideraçōes iniciais . . . . . . . . . . . . . . . . . . . . . . . . . . . . . .

3.2 Modelos ART . . . . . . . . . . . . . . . . . 26

3.2.1 Arquitetura básica dos modelos ART . . . . . . . . . . . . . . 27

3.2 .2 Aprendizado nos modelos ART . . . . . . . . . . . . . . 27

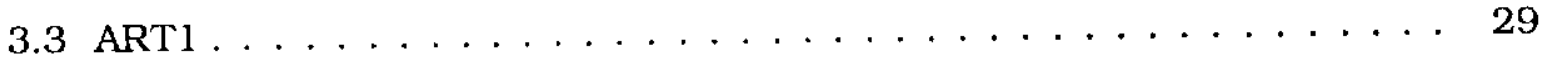

3.3 .1 Arquitetura da rede ART1 . . . . . . . . . . . . . . . . . 29

3.3.2 Algoritmo de treinamento da rede ART1 . . . . . . . . . 31

3.3.2.1 Parâmetros usados no algoritmo de treinamento da rede

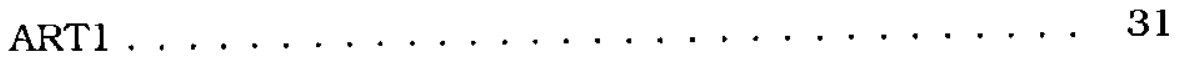

3.3.2.2 Resumo do algoritmo da rede ART1 . . . . . . . . . . 31

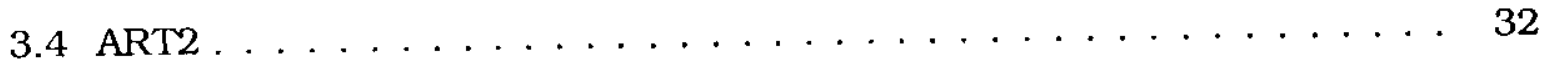

3.4 .1 Arquitetura da rede ART2 . . . . . . . . . . . . 33

3.4 .2 Algoritmo de treinamento da rede ART2 . . . . . . . . . 34

3.4.2.1 Descriçāo do algoritmo de treinamento da rede ART2 . . 35

3.4.2.2 Notaçāo e escolha dos parâmetros . . . . . . . . . . . . . . . 36

3.4 .2 .3 Resumo do Algoritmo . . . . . . . . . . . 37 
3.4.2.4 Descrição do algoritmo de treinamento da rede ART2 (modo rápido) . . . . . . . . . . . . . . . 38

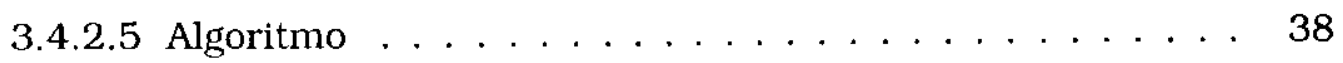

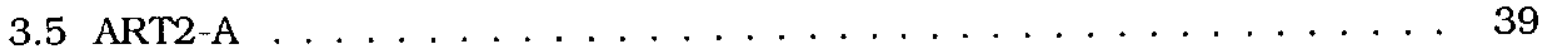

3.5 .1 Arquitetura da rede ART2-A . . . . . . . . . . . . 39

3.5 .2 Resumo do algoritmo da rede ART2-A . . . . . . . . . . . . . . 40

3.6 Fuzzy ART . . . . . . . . . . . . . . . . . . . . . . . . . . . . . . . . . . .

3.6.1 Arquitetura da rede Fuzzy ART . . . . . . . . . . . . . . . 42

3.6.2 Algoritmo de treinamento da rede Fuzzy ART . . . . . . . . . . . . 43

3.6.2. 1 Descrição do treinamento da rede Fuzzy ART . . . . . . . 43

3.6.2.2 Resumo do algoritmo da rede Fuzzy ART . . . . . . . . . . . 43

3.6.3 Consideraçōes sobre os modelos ART estudados . . . . . . . . . . . 46

3.6 .4 Aplicaçōes das redes ART . . . . . . . . . . . . . . . . . . . 47

3.7 Considerações finais . . . . . . . . . . . . . . . . 48

4 Recuperação de Informaçōes 49

4.1 Introdução . . . . . . . . . . . . . . . . . . . 49

4.2 Espaço métrico . . . . . . . . . . . . . . . . . . 50

4.2.1 Consultas por similaridade . . . . . . . . . . . . 52

4.3 Métodos de acesso a dados multi-dimensionais . . . . . . . . . . . . . 53

4.3.1 Métodos de acesso a dados espaciais . . . . . . . . . . . . 55

4.3.2 Métodos de Acessos a dados no Espaço Métricos . . . . . . . . 59

4.3.2.1 Os MAEMs dinâmicos . . . . . . . . . . . . . . 62

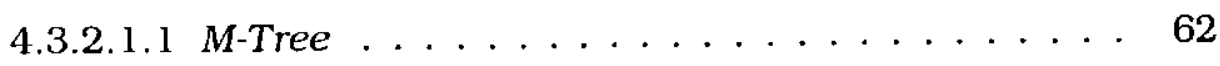

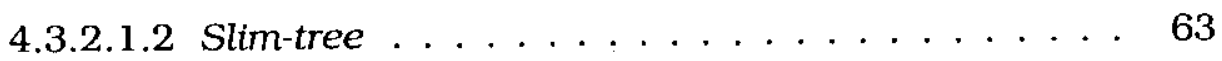

4.4 Consideraçōes finais . . . . . . . . . . . . . . . . 69

5 Recuperação de Informações Utilizando um Modelo da familia ART 71

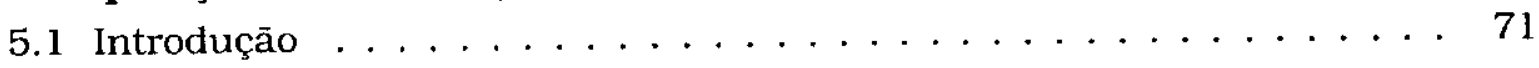

5.2 Os experimentos com os modelos da familia ART estudados . . . . 71

5.3 Construçāo de um modelo híbrido . . . . . . . . . . . . . . 75

5.4 Resultados dos experimentos . . . . . . . . . . . 76

$\begin{array}{ll}\text { Referências } & 86\end{array}$ 


\section{Lista de Figuras}

2.1 Arquitetura básica de uma rede SOM. . . . . . . . . . . . . . . 20

2.2 Atualização da vizinhança de um neurônio ganhador em uma rede SOM. 21

2.3 Clusters gerados por uma rede de SOM. . . . . . . . . . . . . . 22

3.1 Estrutura básica da Rede ART . . . . . . . . . . . . . . . . 27

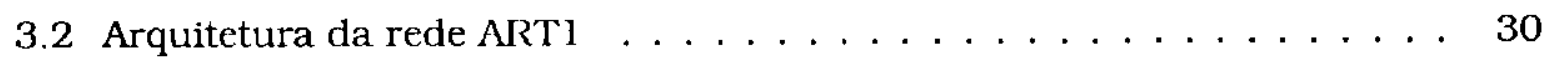

3.3 Arquitetura básica da rede ART2 . . . . . . . . . . . . . . . 34

3.4 Unidades suplementares da rede ART2 . . . . . . . . . . . . . . . . . . . . . . . . . . . . .

3.5 Arquitetura da rede ART2-A . . . . . . . . . . . . . . . . . . . 40

3.6 Arquitetura da rede Fuzzy ART. . . . . . . . . . . . . 43

4.1 Regiões de cobertura de (3) três métricas família $L_{s} \ldots \ldots \ldots \ldots$. . . . 51

4.2 Exemplo de consulta por abrangência. . . . . . . . . . . . . 52

4.3 Exemplo de consulta por $k$-vizinhos mais próximos. . . . . . . . . . 53

4.4 Critério de inserçāo em uma árvore binária de busca. . . . . . . . . . . . 54

4.5 Exemplo de uma árvore $\mathrm{B}(\mathrm{B}$-Tree $) \ldots \ldots \ldots \ldots$

4.6 Exemplo de uma estrutura K-d-B-Tree. . . . . . . . . . . . . 56

4.7 Representação de uma estrutura $R$-Tree através de MBRs. . . . . . . . 58

4.8 Representaçāo uma estrutura $R$-Tree $\mathrm{cm}$ forma árvore segundo a Figura $4.7 \ldots \ldots \ldots \ldots \ldots \ldots \ldots \ldots$

4.9 Exemplo de representação das estruturas BKT, FQT, FHGT e FGA . . . . 60

4.10 Estrutura do nó-indice da Slim-Tree . . . . . . . . . . . 64

4.11 Estrutura de um nó-folha da Slim-Tree . . . . . . . . . . . . 65

4.12 Representaçāo conceitual da estrutura Slim-Tree. . . . . . . . . . . . 67

4.13 Efeitos do algoritmo Slim-down: antes e depois. . . . . . . . . . 67

4.14 Representação de uma Slim-Tree com seus nós-índices e seus nós-folhas 70

5.1 Combinando a Arquitetura da Rede ART2-A com o MAEM Slim-Tree. . . 75 
5.2 Desempenho, em número de acessos a disco, do MAEM Slim-Tree e do modelo híbrido (ART2-A+Slim-tree), em consultas por abrangência realizadas na base de dados Iris. . . . . . . . . . . . . . .

5.3 Desempenho, em número de cálculos de distância, do MAEM Slim-Tree e do modelo híbrido (ART2-A+Slim-tree), em consultas por abrangência realizadas na base de dados Iris. . . . . . . . . . . . . .

5.4 Desempenho, em números de acessos a disco, do MAEM Slim-Tree e do modelo híbrido (ART2-A+Slim-tree), em consultas por $k$-vizinhos mais próximos realizadas na base de dados Iris. . . . . . . . . . . . . .

5.5 Desempenho, em número de cálculos de distância, do MAEM Slim-Tree e do modelo híbrido (ART2-A+Slim-tree), em consultas por $k$-vizinhos mais próximos realizadas na base de dadosIris. . . . . . . . . . . .

5.6 Desempenho, em número de acessos a disco, do MAEM Slim-Tree e do modelo híbrido (ART2-A+Slim-tree), em consultas por abrangência realizadas na base de dados Waveform. . . . . . . . . . . . .

5.7 Dcsempenho, em número de cálculos de distância, do MAEM Slim-Tree e do modelo híbrido (ART2-A+Slim-tree), em consultas por abrangência realizadas na base de dados Waveform. . . . . . . . . . .

5.8 Desempenho, em número de números de acessos a disco, do MAEM Slim-Tree e do modelo hibrido (ART2-A+Slim-tree), em consultas por $k$-vizinhos mais próximos realizadas na base de dados Waveform. . . . .

5.9 Desempenho, em número de cálculos de distância, do MAEM Slim-Tree e do modelo hibrido (ART2-A+Slim-tree), em consultas por $k$-vizinhos mais próximos realizadas na base de dados Waveform. . . . . . . . . .

5.10Desempenho, em número de acessos a disco, do MAEM Slim-Tree e do modelo híbrido (ART2-A+Slim-tree) $\mathrm{cm}$ consultas por abrangência realizadas na base de dados Eigenfaces. . . . . . . . . . . . .

5.11 Desempenho, em número de cálculos de distância, do MAEM Slim-Tree e do modelo híbrido (ART2-A+Slim-trec) em consultas por abrangência realizadas na base de dados Eigenfaces. . . . . . . . . . . . .

5.12 Desempenho, em número de acessos a disco, do MAEM Slim-Tree e do modelo híbrido (ART2-A+Slim-tree) em consultas por $k$-vizinhos mais próximos realizadas na base de dados Eigenfaces. . . . . . . . . . .

5.13 Desempenho, em número de cálculos de distância, do MAEM Slim-Tree e do modelo hibrido (ART2-A+Slim-tree) em consultas por $k$-vizinhos mais próximos realizadas na base de dados Eigenfaces. . . . . . . . . . 
3.1 Notação utilizada nos algoritmos das redes ART1 e ART2 . . . . . . . . . 31

3.2 Inicialização dos parâmetros da rede ART1 . . . . . . . . . . . . . 31

3.3 Parâmetros de ART2 . . . . . . . . . . . . . . . . . . 36

3.4 Notação e parâmetros da rede ART2-A . . . . . . . . . . . . . 41

3.5 Parâmetros da rede Fuzzy ART . . . . . . . . . . . . . . 44

5.1 Bases de dados utilizadas nos experimentos. . . . . . . . . . 73

5.2 Desempenho das redes ART2, ART2-A e Fuzzy ART. . . . . . . . . . . 73

5.3 Desempenho das redes ART2 e ART2-A, com a ativaçāo do parâmetro $\theta$ (supressão de ruído). . . . . . . . . . . . . . . . 74

5.4 Desempenho dos modelos ART2, ART2-A e Fuzzy ART. . . . . . . . . 74 
s Sistemas de Gerenciamento de Banco de Dados (SGBDs) existentes são muito sofisticados, eficientes e râpidos na recuperação de informaçōes envolvendo dados de tipos tradicionais, tais como números, texto, etc., mas existem muitas limitações em se tratando de recuperar informaçōes quando os tipos de dados sāo mais complexos, isto é, dados multi-dimensionais. Considerando os problemas existentes com a indexação e recuperação de dados multi-dimensionais, este trabalho propõe um sistema híbrido que combina um modelo de Redes Neurais da familia ART, ART2-A, com uma estrutura de dados, Slim-Tree, que é um método de acesso a dados no espaço métrico. Esta proposta é uma alternativa para realizar o processo de agrupamento de dados de forma "inteligente" tal que os dados pertencentes aos agrupamentos (clusters) possam ser recuperados a partir da Slim-Tree correspondente. O sistema híbrido proposto é capaz de realizar consultas do tipo: busca por abrangência e dos k-vizinhos mais próximos, o que nāo é característica comum das redes neurais artificiais. Além disto, os experimentos realizados mostram que o desempenho do sistema foi igual ou superior ao desempenho obtido pela Slim-Tree. 


\section{Abstract}

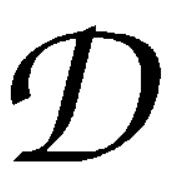

atabase Management System (DBMS) are very sophisticated, efficient and fast in the information retrieval involving traditional data sets such as numbers, strings, etc., but there are many limitations in the information retrieval when the data are more complex, i.e., high-dimensional data. Considering some existing problems in the information retrieval, this work proposes a hybrid system that combines an ART family neural network, ART2-A, with a data structure, Slim-Tree, that is a metric access method. This proposal is an alternative to perform the clustering process of data in a "intelligent" way in order the data can be recovered from the corresponding Slim-Tree. The proposed hybrid system is able to perform range queries and $\mathrm{k}$ nearest neighbor queries, that is not a inherent characteristic of artificial neural networks. Furthermore, in experiments show that the performance system was equal or superior to Slim-Tree performance. 


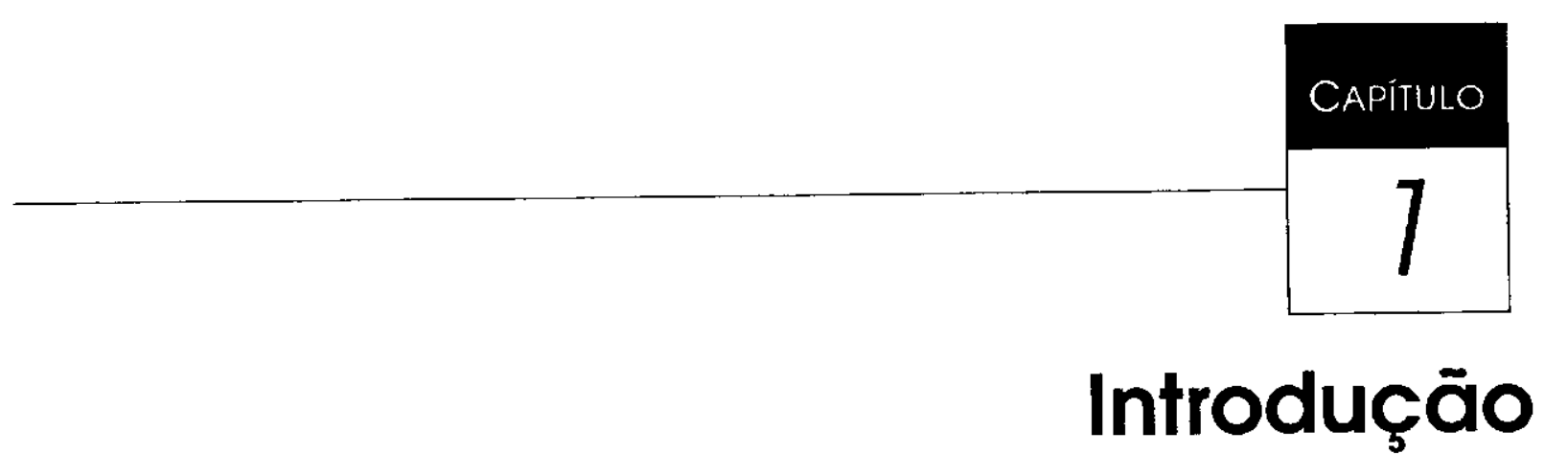

\subsection{Contexto}

s primeiros conceitos envolvendo recuperaçāo de informaçōes em bases de dados estavam relacionados à criaçāo de mecanismos de acesso direto à informaçāo. Os antigos repositórios de dados, hoje chamados de tradicionais, eram projetados de forma estruturada (através de chaves e registros) para que as consultas retornassem todas as informações, em geral textos e números, contidas em registros cuja chave era exatamente igual à chave submetida à busca.

Com a evolução dos sistemas de informação e das tecnologias de comunicação, novos tipos de dados, chamados de dados multimidia, tais como imagens, audio digitalizado, vídeo, impressōes digitais, e moléculas de DNA estāo sendo armazenados em repositórios nāo-estruturados de dados. Esta tendência, se deve ao fato de que é muito dificil, tanto manualmente quanto computacionalmente, armazenar e recuperar esses tipos de dados em repositórios estruturados, uma vez que as operaçōes de busca mais sofisticadas, bem como a aplicação de ferramentas de data mining, ficam comprometidas nestes repositórios (Chávez et al., 2001).

Dados multimídia podem ser como considerados vetores $k$-dimensionais, i.e., pertencentes a um espaço vetorial multi-dimensional. Muitas estruturas de dados foram propostas aproveitando a natureza deste conceito e incorporando a noção de similaridade (Gaede and Gunther, 1998). Tais estruturas são amplamente abordadas na literatura como Métodos de Acesso a dados Espaciais (MAEs) ${ }^{1}$. Neste contexto, o trabalho pioneiro refere-se ao desenvolvimento da estrutura $R$-Tree (Guttman, 1984).

\footnotetext{
${ }^{1}$ Do original em inglês, Spatial Access Methods (S $\Lambda$ M).
} 
Mais tarde, surgiram algumas variaçōes e adaptaçōes deste trabalho (Sellis et al., 1987), (Papadias et al., 1995), (Hellerstein et al., 1995) e (Gaede and Gunther, 1998). Este último trabalho é um resumo de vários métodos de acesso espacial em bases de dados existentes na literatura.

Entretanto, apesar de os MAEs terem sido projetados para o tratamento de dados multi-dimensionais, a maioria destes nāo são bem adaptados a aplicações em bancos de dados multimídia envolvendo dados com altas dimensōes. Devido à natureza espacial destas estruturas, as operações de busca, ou até mesmo a de inserçāo de objetos (neste caso, vetores $n$-dimensionais), acabam sendo muito custosas, com ordem de complexidade exponencial, se a dimensāo $n$ dos vetores aumenta. Isto é chamado na literatura de "Maldição da Alta Dimensão" 2 (Weber, 1998) (Chávez et al., 2001).

Diante do cenário descrito acima, foi verificado que os tipos de dados multimidia freqüentemente não são bem adaptados, se forem considerados como pertencentes ao espaço vetorial. Foi constatado, portanto, que estes dados são melhor aproveitados se forem considerados como pertencentes a um espaço métrico (Chávez et al., 2001). As técnicas para tratamento de dados no espaço métrico utilizam o conceito de similaridade para organizar os dados em uma estrutura, de modo a facilitar o processo de recuperaçāo de informações. O trabalho pioneiro, relacionado à indexação e recuperaçāo de informaçōes no espaço métrico, refere-se ao desenvolvimento da estrutura $B K T$ (Burkhard and Keller, 1973). Mais tarde, surgiram trabalhos envolvendo outras estruturas, tais como query fuxed tree (Baeza-Yates et al., 1994), VP-tree (Vantage-Point tree) (Chiueh, 1994), GNAT (Brin, 1995) e MVP-tree (Multi-Vaniage Point tree) (Bozkaya and Ozsoyoglu, 1997), e as estruturas dinâmicas M-Tree (Ciaccia et al., 1997) e Slim-Tree (Traina Jr. et al., 2000a). Tais métodos surgiram na tentativa de abranger um maior número de aplicações e de melhorar o desempenho com relação à resposta a consultas por similaridade, tais como consultas por abrangência ${ }^{3} \mathrm{e} k$-vizinhos mais próximos ${ }^{4}$. Estas estruturas sāo amplamente abordadas na literatura como Métodos de Acesso a dados no Espaço Métrico MAEMs ${ }^{5}$.

Considerando os diversos MAEMs disponiveis na literatura, aqueles que implementam estruturas dinâmicas, isto é. que permitem novas inserções de dados depois que estas tenham sido construídas, mostram-se mais adequados a aplicações de dados multimídia, onde o volume de informações a serem processados nāo é previamente definido. Dentre os MAEMs dinâmicos, a estrutura Slim-Tree apresentou melhor desempenho em relaçāo à $M$-Tree nos experimentos realizados por Traina em (Traina Jr. et al., 2000a), considerando consultas realizadas em várias bases de dados.

\footnotetext{
${ }^{2}$ Do original em inglês, Curse of Dimensionality.

${ }^{3}$ Do original em inglês, range queries.

${ }^{4}$ Do original em inglês, $k$-Nearest Neighbors.

${ }^{5}$ Do original em inglês, Metric Access Methods (MAM).
} 
Uma outra tecnologia que se apresenta como uma alternativa na tentativa de melhorar o desempenho no tratamento de dados multi-dimensionais sāo as Redes Neurais Artificiais (RNAs) (Laaksonen et al., 1999) (Aghbari et al., 2002) (Vargas and Romero, 2002). No contexto deste trabalho, a utilização deste tipo de abordagem visa encontrar similaridades em conjuntos de dados de modo a detectar agrupamentos de dados, com o objetivo de reduzir os recursos computacionais em relação à capacidade de armazenamento e rapidez na recuperaçāo de informações.

\subsection{Motivação e Objetivos}

Modelos de RNAs apresentam características semelhantes às estruturas métricas, no que diz respeito à capacidade de comparar dados por medidas de similaridade e reconhecer padrōes $\mathrm{em}$ grandes conjuntos de dados. Uma caracteristica conhecida das RNAs é a sua tolerância a falhas, isto é, a capacidade de associar um padrão que possui ruido ${ }^{6}$ à classe com que este tem maior grau de semelhança. Isto reforça o conceito de similaridade incorporado às RNAs no processo de classificaçāo (Rumelhart et al., 1986). Outra caracteristica importante das RNAs, mais especificamente do grupo de redes neurais conhecidas como auto-organizáveis ${ }^{7}$, é a capacidade de realizar agrupamentos de dados, ou seja, de extrair informaçōes do conjunto de dados apresentados para separá-los em grupos distintos, onde cada grupo deve ser constituído por um conjunto de padrōes com características semelhantes. Alguns modelos de RNAs que possuem estas características, são : Os Mapas Auto-Organizáveis ${ }^{8}$ (Kohonen, 1990), e os modelos de redes neurais da familia (ART) ${ }^{9}$, tais como ART-1 (Carpenter and Grossberg, 1987b), ART-2 (Carpenter and Grossberg, 1987a) ART2-A (Carpenter et al., 1991b) e Fuzzy ART (Carpenter et al., 1991c).

Considerando aplicações em bancos de dados multimídia, as RNAs da família ART, apresentam algumas caracteristicas peculiares que podem ser consideradas como vantagens em relação às redes SOM para este propósito. Dentre estas caracteristicas, as principais referem-se ao tipo de aprendizado implementado por esses modelos e à arquitetura. O aprendizado implementado por estes modelos é incremental e fundamentado na Teoria da Ressonância Adaptativa (Carpenter and Grossberg, 1987b). Esta caracteristica permite que a rede incorpore novo conhecimento, sem perder aquele previamente adquirido, o que nāo acontece, por exemplo com o modelo SOM. Outra característica está relacionada à arquitetura dos modelos ART, nos quais cada neurônio da camada de saída, juntamente com seu conjunto de pesos, representa um cluster (Peper et al., 1993). Esta propriedade é importante, pois permite que uma estrutura de dados, com capacidade de armazenamento e recuperação de informaçôes, possa ser naturalmente incorporada na arquitetura dos modelos ART.

\footnotetext{
${ }^{6}$ Isto pode ser compreendido como uma pequena deformaçăo nos dados.

${ }^{7}$ Do original em inglês, Self-Organizing

${ }^{8}$ Do original em ingless, Self-Organizing Maps (SOM).

${ }^{9}$ Do original em em inglês, Adaptive Resonance Theory.
} 
Esta característica nāo é facilmente identificada no modelo SOM clássico, que tem sua arquitetura projetada em uma matriz, em que cada elemento é um neurônio que representa um determinado padrão de entrada.

O objetivo principal deste trabalho é desenvolver um sistema hibrido, combinando um modelo da familia ART com o MAEM Slim-Tree, de modo que este novo modelo possa responder a operações de consultas por similaridade, com desempenho melhor se comparado, nas mesmas condições, diretamente com o MAEM Slim-Tree.

Pela prôpria característica da arquitetura dos modelos da família ART estudadas neste trabalho, ou seja, as arquiteturas ART-2, ART2-A e Fuzzy ART, a combinação de qualquer uma destas com a estrutura Slim-Tree pode ser feita naturalmente, isto é, sem mudanças drásticas tanto na arquitetura do modelo ART escolhido quanto no método Slim-Tree.

Para identificar qual dos três modelos poderia ser o melhor utilizado para realizar a combinação com o MAEM Slim-Tree, foram considerados, neste trabalho, vários estudos realizados a respeitos destas RNAs (Hussain, 1993), (Peper et al., 1993), (Fausett, 1994), (Upal and Neufeld, 1996), (Frank et al., 1998) e (Baraldi and Alpaydin, 2002a). Além disso, neste presente trabalho também foram realizadas anâlises e comparaçōes entre os três modelos ART, quanto às suas capacidades para detectar agrupamentos de dados, considerando diferentes bases de dados.

Uma vez que o desempenho e a aplicabilidade dos modelos estudados foram avaliados, um destes modelos foi utilizado para compor um modelo híbrido com o MAEM Stim-Tree. Para avaliar os resultados obtidos a partir dos experimentos realizados com o modelo híbrido, as mesmas operações de consultas foram realizadas com o MAEM Slim-Tree, considerando os mesmos conjuntos de dados. Os resultados destes experimentos foram considerados satisfatórios, em termo de acesso a disco e de número de cálculos de distância.

\subsection{Organizaçāo do Trabalho}

Este trabalho está organizado da seguinte forma. No próximo capítulo, os sistema auto-organizáveis sāo apresentados, destacando-se suas principais características, bem como o principal modelo de RNA não-construtivo, a rede SOM. No capítulo 3, as RNAs da família ART são analisadas, ressaltando-se suas características, e destacando alguns de seus modelos ART-2, ART2-A e Fuzzy ART. No capítulo 4, é apresentado um levantamento a respeito dos principais métodos existentes para recuperação de informaçōes, destacando-se o MAEM Slim-Tree. No capitulo 5, as redes neurais, analisadas com um maior grau de detalhe no Capítulo 3, são avaliadas quanto à capacidade de agrupamento de dados. Um modelo híbrido, que combina um dos modelo ART escolhidos, é proposto, descrito e comparado com o MAEM Slim-Tree quanto a capacidade de recuperação de informações. Além disso, no final deste 
capítulo há uma descriçāo a respeito das contribuiçōes deste trabalho e de trabalho futuros. 


\section{As Redes Neurais Auto-Organizáveis}

\subsection{Considerações iniciais}

$\mathcal{U}$ ma das principais características das RNAs (Redes Neurais Artificiais) é a capacidade de aprender através de exemplos e melhorar seu desempenho através do aprendizado. Uma RNA aprende através de um processo iterativos de ajustes aplicados aos seus pesos sinápticos, tornando-se mais conhecedoras (ou adaptadas) ao ambiente em questāo.

O que determina a arquitetura da rede e a forma como os pesos das conexōes serão atualizados é o algoritmo de treinamento (ou aprendizado). São dois os tipos mais comuns de paradigmas de algoritmos de treinamento: o paradigma de aprendizado supervisionado e o nāo-supervisionado (Haykin, 1994). O primeiro paradigma citado utiliza um agente externo que indica a resposta desejada ${ }^{1}$ para o padrão que está sendo apresentado à rede, assim o aprendizado acontece através da atualização dos pesos das conexōes utilizando o erro produzido a partir da diferença entre a resposta desejada e a resposta na camada de saída da rede. O objetivo deste tipo de treinamento é diminuir o erro da camada de saida, em relaçāo à resposta desejada . No segundo paradigma de treinamento citado, não existe um agente externo avaliando as respostas da rede, esta deve extrair as característica dos dados e criar novos agrupamentos (ou grupos) ${ }^{2}$ automaticamente.

\footnotetext{
${ }^{1}$ Isto pode ser compreendido como o protótipo que melhor representa uma determinada classe de padrōes.

${ }^{2}$ Aqui terá o mesmo significado que clusters, do original em inglês.
} 
Hâ muitas aplicações em que não se dispōe de informaçōes prévias a respeito dos dados ou da resposta desejada para cada conjunto de padrōes ${ }^{3}$. Nestes casos, a informação a respeito das características dos dados está no próprio conjunto de padrões apresentados à rede, e o modelo de RNA, mais adequado à estas aplicaçōes deverá utilizar o paradigma nāo-supervisionado (Haykin, 1994) (Kohonen, 1989b). As redes auto-organizáveis sāo baseados na idéia central do paradigma de aprendizado não-supervisionado, e dessa forma definem parâmetros por si próprios.

De acordo com Barlow (Barlow, 1989), para que seja desenvolvida uma função de processamento útil durante o processo de aprendizagem, é necessário que haja redundância e ruídos nos padrões de entrada. Isto permitirá que a rede detecte as semelhanças e diferenças entre os dados. Parte deste tipo de conhecimento incorporado à rede pode ser medido por parâmetros estatísticos (ex: média, variância e matriz de correlação do vetor de entrada).

O processo de auto-organização incorporado às redes neurais é aquele através do qual a rede neural agrupa padrões de entrada dentro de grupos (clusters) de padrões semelhantes.

Diversos modelos de RNAs auto-organizáveis foram desenvolvidos. Um dos primeiros modelos de redes neurais foi proposto por Von der Malsburg (der Malsburgs, 1973). Era um modelo simples, que reproduzia as propriedades funcionais de algumas células encontradas no córtex visual.

As RNAs auto-organizáveis são mais semelhantes às estruturas neurobiológicas que as redes neural que utilizam o paradigma de aprendizado supervisionado, como por exemplo a rede MLP (MultiLayer Perceptron) (Rumelhart et al., 1986). A arquitetura padrāo dos modelos auto-organizáveis é formada por uma camada de entrada, ou fonte, e uma camada de saîda, ou de representaçāo. Há também modelos multi-camadas (Fukushima, 1975) (Fukushima, 1980).

O paradigma de aprendizado nāo-supervisionado, e pode ser dividido em dois grandes grupos: aprendizado competitivo e aprendizado hebbiano (Hebb, 1949). No aprendizado competitivo, os neurônios da rede competem entre si pelo direito de atualizar seus pesos e apenas um neurōnio é ativado por vez. Tais algoritmos normalmente são utilizados em classificação, extração de características, compressão de dados e formação de clusters. Exemplo de redes que utilizam este tipo de aprendizado são os modelos da familia ART (Carpenter and Grossberg, 1987b) (Carpenter and Grossberg, 1987a) (Carpenter and Grossberg, 1990) (Carpenter et al., 1991c) (Carpenter et al., 1991b) e SOM (Kohonen, 1989b). O aprendizado Hebbiano, por outro lado, é baseado no postulado proposto pelo neurofisiologista Hebb (Hebb, 1949):

"Quando um axônio da célula A está suficientemente próximo para excitar uma célula B e repetidamente tenta excitá-la, algum processo crescente ou mudança metabólicas ocorrem em ambas as células."

\footnotetext{
${ }^{3}$ Pode ser compreendido como exemplos de treinamento.
} 
Transformando a declaração acima em duas regras (Stent, 1973) (Changeoux and Danchin., 1976), segue-se que:

1. Se dois neurônios ligados por uma sinapse são ativados simultaneamente (sincronamente), a intensidade desta sinapse (conexão) é aumentada.

2. Se dois neurônios ligados por uma sinapse são ativados assincronamente, a intensidade desta sinapse (conexão) é diminuída ou eliminada.

Ao contrário do aprendizado competitivo, no aprendizado Hebbiano, vários neurônios podem ser ativados ao mesmo tempo. As principais aplicações deste algoritmo sāo para extração de características de dados de dados, memórias associativas. Exemplos de modelos de redes que utilizam este tipo de aprendizado sāo: modelos de Hopfield (Hopfield, 1982), Linsker (Linsker, 1986) e RNAs PCA (Principal Component Analisys) (Baldi and Hornik, 1989).

Nas próximas seçōes serāo apresentado um outro modelo de RNA auto-organizável: a rede de Kohonen SOM (Self-organizing Maps) (Kohonen, 1984) (Kohonen, 1989b), que por sua vez têm a capacidade de detectar clusters em conjuntos de dados (conceito de "similaridade").

\subsection{Mapas Auto-Organizáveis (Self-Organizing Maps)}

As redes SOM, também chamadas de SOFM (Self-Organizing Features Maps, foram desenvolvidas por Teuvo Kohonen (Kohonen, 1984) (Kohonen, 1989b). Em contraste com os modelos propostos como (Rumelhart et al., 1986) e (Hopfield, 1982), este modelo de RNA possui uma forte inspiração neurofisiológica. Isto é, este modelo foi baseado no mapa topológico presente no córtex cerebral. O cérebro humano talvez seja a estrutura mais interessante da fisiologia humana. Mesmo sendo muito complexo do ponto de vista microscópico, ele tem uma estrutura uniforme à escala macroscópica. Os centros responsáveis por atividades tais como o pensamento, visão, audiçāo, etc. sempre se desenvolvem na mesma posição em todos os seres humanos. As áreas individuais apresentam uma ordenação lógica em relação a sua funcionalidade. Um exemplo conhecido desta ordenação é o mapa tonotôpico das regiōes auditivas (Woolsey, 1958) (Celsia et al., 1968) (Celsia, 1976). Neste mapa, os neurônios próximos entre si respondem a freqüências similares de sons. Também é conhecida a existência do mapa somatotópico (Kohonen, 1982) (Amari, 1983) (Kohonen, 1984) (Kohonen, 1989b) (Schieber and Hibbard, 1993) (Matsuoka, 1995), que é o mapa dos nervos motores responsáveis por cada parte do corpo humano. Neste tipo de mapa, as regiōes fisicamente próximas são responsáveis por membros do corpo fisicamente próximos.

Regiōes tais como o mapa Tonotópico e o mapa Somatotópico são também conhecidas como: correspondências ordenadas de características. Como definição simplificada pode-se dizer que numa correspondência que respeite a topologia, as 
unidades que estiverem fisicamente próximas umas das outras responderão analogamente a vetores de entrada similares. A seguir será apresentada a rede SOM, que representa de forma natural esses mapas de características.

\subsubsection{Arquitetura básica e funcionamento de uma rede SOM}

Nestas redes, os neurônios se organizam em uma grade ou reticulado e, geralmente, estāo dispostos em uma camada bidimensional e organizados em linhas e colunas (Figura 2.1). Portanto, a rede apresenta duas camadas, uma de entrada (que é utilizada para apresentar os padrōes ${ }^{4}$ ) e a saída que corresponde a todos os neurônios da matriz . Uma hierarquia de camadas bidimensionais pode também ser utilizada (Haykin, 1994). Cada neurônio da camada de saida possui conexões com cada uma

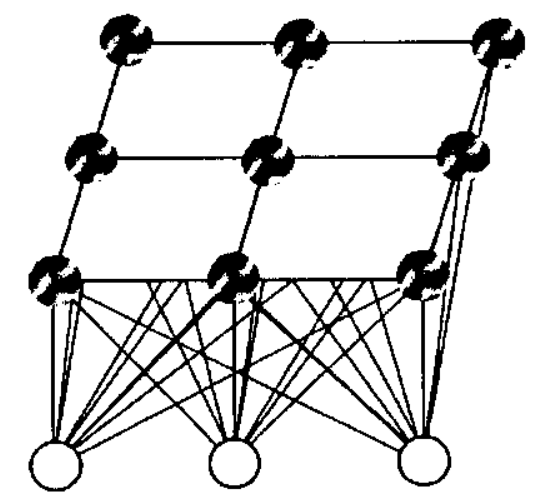

Figura 2.1: Arquitetura básica de uma rede SOM.

das entradas, e existe um vetor de pesos associado a cada uma destas conexōes. $O$ tamanho do vetor de pesos, contido em cada neurônio, corresponde ao tamanho do vetor de entrada que terá o seu sinal propagado a todos os neurônios.

O treinamento é competitivo e segue o paradigma de aprendizado nāo-supervisionado (embora utilize uma fase supcrvisionada para rotular os neurônios na saida). Cada vez que um vetor (ou padrão, ou exemplo) de treinamento é apresentado à rede, os neurônios competem entre si e apenas um ganhador é escolhido, já que cada neurônio terá um valor de ativação. A escolha do ganhador acontece da seguinte forma: o neurônio que tiver a menor distância em relação ao padrão que está sendo apresentado será ativado. Em geral, a distância utilizada é a distância Euclideana, veja a Equaçāo 2.1.

$$
d_{j}=\sqrt{\sum_{i=1}^{n}\left(\mathbf{w}_{j}-x_{i}\right)^{2}}=\sum_{i=1}^{n}\left\|\mathbf{x}-\mathbf{w}_{j}\right\|
$$

onde $\mathrm{x}$ é o vetor de entrada e $\mathrm{w}_{j}$ é o vetor de pesos associado ao neurônio $j$. Em outras palavras, o neurônio ganhador é aquele que satisfaz a Equação 2.2. Isto está

\footnotetext{
${ }^{4}$ exemplos de treinamento
} 
rclacionado com a semelhança entre a entrada e a saída da rede.

$$
\left\|\mathbf{x}-\mathbf{w}_{c}\right\|=\min \left\{\left\|\mathbf{x}-\mathbf{w}_{i}\right\|\right\}
$$

onde $c$ é o índice do neurônio ganhador $\mathrm{e}_{c}$ é o seu vetor de pesos. Neste contexto, uma vez escolhida a unidade ganhadora, só ela tem o direito de atualizar suas conexōes (pesos) e as dos seus vizinhos através da Equaçāo 2.3:

$$
w_{j i}(t+1)= \begin{cases}w_{j i}(t)+\eta(t)\left[x_{i}(t)-w_{j i}(t)\right], & \text { se } j \in \Lambda(t), \\ w_{j i}(t), & \text { caso contrário, }\end{cases}
$$

onde $t$ é o tempo discreto indexado que aumenta de uma unidade a cada variaçāo de vizinhança, $\Lambda(t)$, e a cada nova entrada apresentada. Um critério para atualizaçāo da vizinhança pode ser, por exemplo, escolher regiōes retangulares (mais comum), ou as hexagonais em volta da unidade ganhadora, como pode ser observado na Figura 2.2. Após cessar o treinamento, a rede poderá representar vários clusters. Cada cluster corresponde a um grupo de padrōes similares, sendo que o centro de cada grupo corresponde ao padrāo que melhor representa aquela classe. Na Figura 2.3, o centro corresponde aos locais de pico.

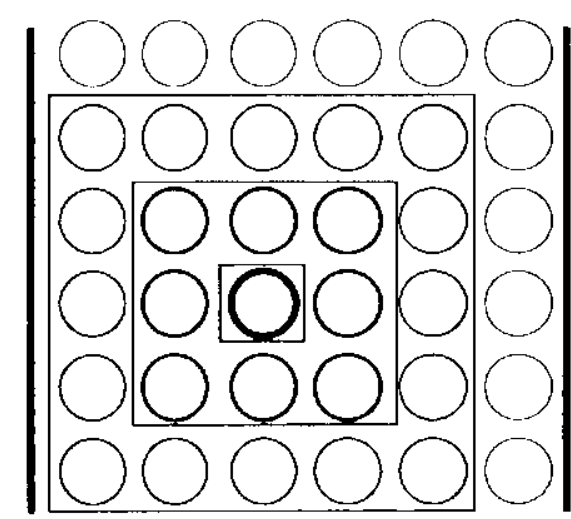

Retangular

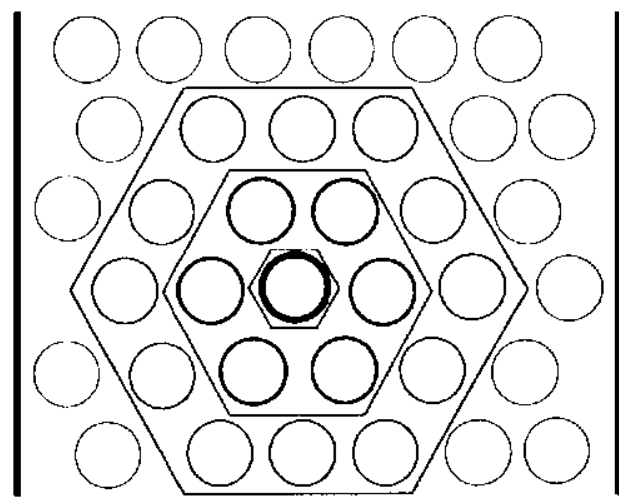

Hexagonal

Figura 2.2: Atualização da vizinhança de um neurônio ganhador em uma rede SOM.

O critério de convergência é assegurado, satisfazendo os requisitos:

1. $0<\eta(t)<1 \rightarrow \forall t$, considerando $\eta(t)$ (taxa de aprendizagem) uma função decrescente;

2. o tamanho da vizinhança $\Lambda(t)$ deve satisfazer às condições: $1<\Lambda(t)<\max ($ lin, col $)$, $\forall t$, considerando $\Lambda(t)$ uma função decrescente.

O algoritmo de treinamento para as redes do tipo SOM está resumido a seguir.

Após ter alcançado a condição de parada para a execuçāo do algoritmo, o treinamento termina e cada vetor do conjunto de treinamento será rotulado no neurônio 


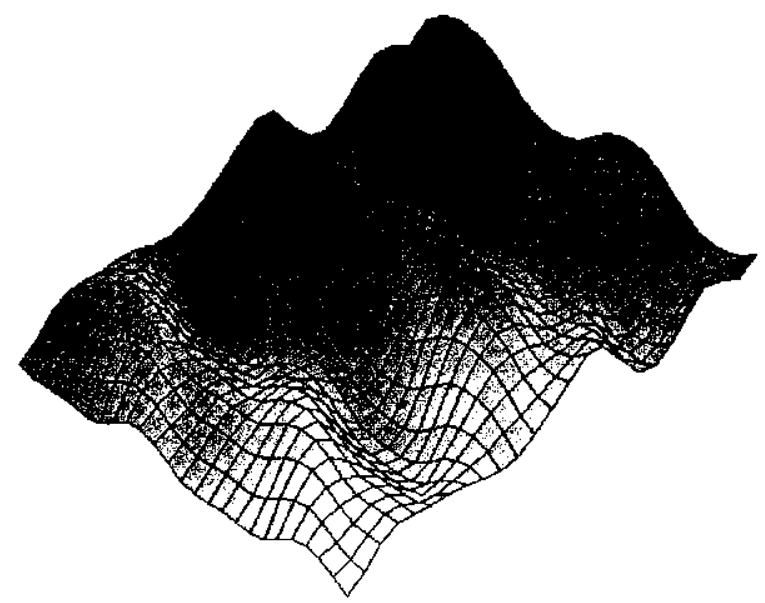

Figura 2.3: Clusters gerados por uma rede de SOM.

Algoritmo 1: - Treinamento da rede SOM

1: Inicialize os parâmetros de entrada e os pesos (criação da da matriz da rede SOM)

2: Enquanto Condição de parada é falsa faça

3: $\quad$ Para todo vetor de entrada $x$ faça

4: Encontre o neurônio vencedor (mais próximo (menor distância) do padrão de entrada\}

5: $\quad$ Atualizar os pesos do neurônio vencedor e de sua vizinhança $\Lambda(t)$

6: $\quad$ Enquanto Raio da vizinhança $\geq 0$ faça

7: $\quad$ Atualizar o neurônio vencedor $e$ vizinhança

8: $\quad$ reduzir raio da vizinhança

9: $\quad$ Fim-Enquanto

10: Fim-Para

11: Reduzir taxa de aprendizagem

12: Fim-Enquanto \{A condição de parada pode ser, por exemplo, o número de ciclos, ou verificar se certo valor limite é atingido por $\eta(t)\}$.

que melhor o representa. Assim, a representaçāo dos clusters pode ser visualizada na própria arquitetura da rede SOM.

\subsubsection{Aplicaçōes da Rede SOM}

A rede desenvolvida por Kohonen e suas variaçōes, tais como (Kohonen et al., 1992), (Bezdek, 1992), (Bose and Murthy, 1996) e (Blonda et al., 1997), têm sido amplamente aplicadas nas mais diversas áreas, como por exemplo: recuperaçāo de informaçōes (Kaski, 1999), (Koskela, 1999), (Laaksonen et al., 1999), (Aghbari et al., 2002) e (Vargas and Romero, 2002); reconhecimento de linguagem falada (Kohonen, 1989a) e (Kohonen and Somervuo, 1997); exploração de grandes bases de dados textuais (Kohonen, 1997); estimativa de posiçāo para robôs móveis (Ulrich Nehmzow and Hallam, 1991); segmentaçāo de imagens (Haring et al., 1994); rcconhecimento de manuscritos (Schomaker and Teulings, 1990); reconhecimento de face (Serratosa 
et al., 1999); Data Mining (Vesanto, 2000); Text Mining (Albrecht and Merkl, 1999); reconhecimento de estilos e estruturas musicais (Hrönel and Ragg, 2000). 


3

\section{Redes Neurais da Família ART}

\subsection{Consideraçöes iniciais}

Dentre as várias habilidades inerentes à mente humana, uma das mais interessantes e fundamentais para o individuo é capacidade aprender e de continuar aprendendo assuntos novos sem esquecer o que já foi aprendido no passado. Um exemplo, bastante comum, é a capacidade de um individuo conhecer seus pais, mesmo se nāo os tenha visto por algum tempo e, durante este periodo, ter conhecido milhares de rostos (ou pessoas) diferentes. Os sistemas complexos, tais como o cérebro, com arquitetura paralela devem ter algum meio de manter a estabilidade em todos os niveis para desempenhar bem suas tarefas. Seria, portanto, de grande interesse que um sistema computacional tivesse esta característica (Freeman and Skapura, 1991).

Quando se projeta um sistema computacional neural para que este desempenhe tarefas de classificação de padrōes, primeiramente cria-se um conjunto de exemplos (ou padrōes) para ser utilizado no treinamento do sistema. Durante o treinamento, as informações apresentadas ao sistema em questão serão incorporadas a este, através do processo de ajuste dos pesos sinápticos associados aos neurônios da rede. Uma vez terminado o processo de treinamento, o sistema está pronto para ser colocado em prática e, a partir de então, nenhum ajuste adicional é permitido no conjunto de pesos. Este tipo de situaçāo é aceitável em um ambiente estável, ou seja, que possui limites bem definidos. Em ambientes estáveis, é possivel definir um conjunto de treinamento adequado para qualquer que seja o problema a ser resolvido.

Infelizmente, o que acontece na maioria das situaçōes do mundo real é que o ambiente é dinâmico (não-estável) e, na maioria dos casos, seus limites sāo desco- 
nhecidos. Como exemplo de ambiente dinâmico, pode-se considerar a situaçāo em que se tenha que reconhecer silhuetas (formas) de algumas classes de aeronaves. As imagens apropriadas podem ser usadas para treinar o sistema neural. e esta tarefa, dependendo da arquitetura deste sistema, consumirá algum tempo. Após o processo de treinamento, nenhuma outra modificação nos pesos é permitida. Se em algum momento no futuro, um outro modelo de aeronave de uma mesma classe já conhecida tornar-se operacional, e se os usuários do sistema desejarem adicioná-lo ao conjunto de exemplos de treinamento que já possuem, é necessário que se faça um novo treinamento do sistema utilizando os exemplo que já foram utilizados anteriormente, mais os exemplos do novo modelo. O novo treinamento deve ser feito desta forma, pois caso seja feito somente com o novo modelo de aeronave, o sistema neural assimilará muito bem este, mas, em contrapartida, os outros padrōes que foram usados no primeiro treinamento ficarāo perdidos, talvez, em sua totalidade.

Esse tipo de situaçāo acontece porque o sistema computacional neural, não possuindo nenhum conhecimento a respeito da nova entrada, e não dispondo de um mecanismo de generalizaçāo capaz de reconhecer o novo padrāo de entrada, tenta ajustar-se à nova situação "esquecendo" o conhecimento previamente adquirido. Essas caracteristicas sāo mais bem observadas em sistemas computacionais, tais como em redes neurais MLP (Multilayer Perceptron) (Rumelhart et al., 1986) e SOM (Self-organizing Maps) (Kohonen, 1984).

Carpenter e Grossberg (Carpenter and Grossberg, 1987b), preocupados com a estabilidade em sistemas auto-organizáveis, desenvolveram a Teoria da Ressonância Adaptativa (ART) ${ }^{1}$ a partir do que eles chamaram de dilema estabilidade-plasticidade. Esse dilema pode ser compreendido a partir de uma série de questōes:

- Como um sistema (capaz de aprender) pode continuar sendo adaptativo (plástico) em resposta a uma entrada significativa (noval e, ao mesmo tempo, manter-se estável em resposta uma entrada irrelevante (conhecida)?

- Como o sistema será capaz de alternar entre os modos plástico e estável ?

- Como o sistema poderá reter as informaçōes aprendidas anteriormente e continuar aprendendo novas informaçōes?

Quando um sistema "inteligente" aprende novas informações sem perder aquelas previamente aprendidas, este sistema é dotado de plasticidade, ou é plástico. Por outro lado, quando não há perdas significativas de informações, ou seja, não há diferentes interpretaçōes para um mesmo padrão durante diferentes estágios de treinamento, o sistema em questão é dotado de estabilidade, ou é estável. A idéia central, para resolver o dilema estabilidade-plasticidade, é adicionar entre a camada de saída (competitiva) do sistema computacional neural e a camada de entrada, um mecanismo de retorno (feedback) para facilitar a adaptação a uma situação nova, sem perder o

\footnotetext{
${ }^{1}$ Do original em inglès, (Adaptive Resonance Theory)
} 
conhecimento anterior, permitindo que seja possivel alternar entre os modos estâvel e plástico.

O primeiro resultado desta abordagem foram duas arquiteturas de redes neurais capazes de agrupar padrões de entrada em ambientes reais e dinâmicos. Estas arquiteturas de redes neurais são chamadas de ARTl (Carpenter and Grossberg, 1987b) e ART2 (Carpenter and Grossberg, 1987a).

Neste capítulo, são discutidos e apresentados o modelos ART que são considerados relevantes para este trabalho. Na Seçāo 3.2 é apresentada uma visão geral e resumida a respeito dos modelos ART mais comuns. Nas Seçōes 3.3, 3.4, 3.5 e 3.6 são apresentados, respectivamente, os modelos ART1, ART2, ART2-A e Fuzzy ART, com suas características, arquiteturas e resumos de algoritmos de treinamento.

\subsection{Modelos ART}

Desde o surgimento da teoria da ressonância adaptativa, vários modelos fundamentados nesta teoria foram desenvolvidos. O primeiro modelo da família ART foi o ART1 (Carpenter and Grossberg, 1987b), que reconhece agrupamentos (clusters) de padrōes em seqüèncias arbitrárias de valores binários. A rede ART2 (Carpenter and Grossberg, 1987a), foi desenvolvida com o objetivo de abranger um número maior de situaçôes do mundo real, para isso aceitando seqüências arbitrárias de valores reais.

Tanto o modelo ART1 quanto o ART2 foram projetados para funcionar com algoritmo de aprendizado não-supervisionado. Um outro modelo, também de paradigma não-supervisionado, é o ART3 (Carpenter and Grossberg, 1990). Este, diferente dos dois citados anteriormente, é fundamentado no processo de sinapses complexas, que inclui um modelo de neurotransmissores químicos, e fornece um mecanismo de busca paralela para reconhecimento distribuído em uma rede neural hierárquica multi-nivel.

A primeira rede da familia ART a realizar aprendizado supervisionado e incremental foi a rede ARTMAP (Carpenter et al., 1991a). Esta, por sua vez, foi projetada para reconhecer agrupamentos em resposta a vetores de entrada binários. Os modelos ART2-A (Carpenter et al., 1991c), bem como o modelo Fuzzy ART (Carpenter et al., 1991b) serāo abordados com mais detalhes em breve neste capítulo. Há também o modelo Fuzzy ARTMAP (Carpenter et al., 1992), que é uma versão análoga ao ARTMAP para padrōes de entrada com valores reais.

Existem muitas outras variações, tais como: CALM (Murre et al., 1989), ARTSTAR (Hussain, 1993), SMART (Bartfai, 1994), HART (Bartfai, 1995). Há também os novos modelos: ART-C (He et al., 2002), Gaussian ART (GART) (Williamson, 1997), Simplified ART (Baraldi and Alpaydin, 1998), Self-Organizing SART (FOSART) e Fuzzy ART simétrica (S-Fuzzy ART), que implementa melhoras no modelo Fuzzy ART. Esses quatro últimos modelos foram analisados com detalhes por Baraldi (Baraldi and Blonda, 1999), (Baraldi and Alpaydin, 2002a), (Baraldi and Alpaydin, 2002b). 
Este presente trabalho limita-se apenas a alguns modelos específicos da família ART, ou seja, aqueles que recebem como dados de entrada valores reais e que possuem paradigma de aprendizado nāo-supervisionado e incremental.

\subsubsection{Arquitetura básica dos modelos ART}

A arquitetura das redes da família ART pode ser representada de por um esquema geral (ver Figura 3.1), que envolve três grupos de neurônios:

- camada $F_{1}$ : constituida das unidades de entrada e de interface;

- camada $F_{2}$ : constituida das unidades de cluster representadas pelas unidades $y_{j}$;

- unidade de Reset: implementa o controle do usuário sobre o grau de similaridade entre os padrōes classificados em um mesmo cluster.

Todas as unidades da camada $F_{1}$ estão unidas, através pesos adaptativos top-down e bottom-up, à camada $F_{2}$. Deve-se notar, na arquitetura apresentada, que a camada $F_{1}$ recebe como entrada um vetor s e, como saída, um vetor $\mathrm{x}$, o que significa que poderá ocorrer algum pré-processamento nos dados de entrada. Para facilitar o entendimento, pode-se fazer uma divisão da camada $F_{1}$ em duas ${ }^{2}$ (Fausett, 1994): $F_{1(a)}$, que incorpora o vetor de entrada $s_{i}$, e $F_{1(b)}$, sub-camada interface, constituida pelas unidades $x_{i}$ (ver Figura 3.2).

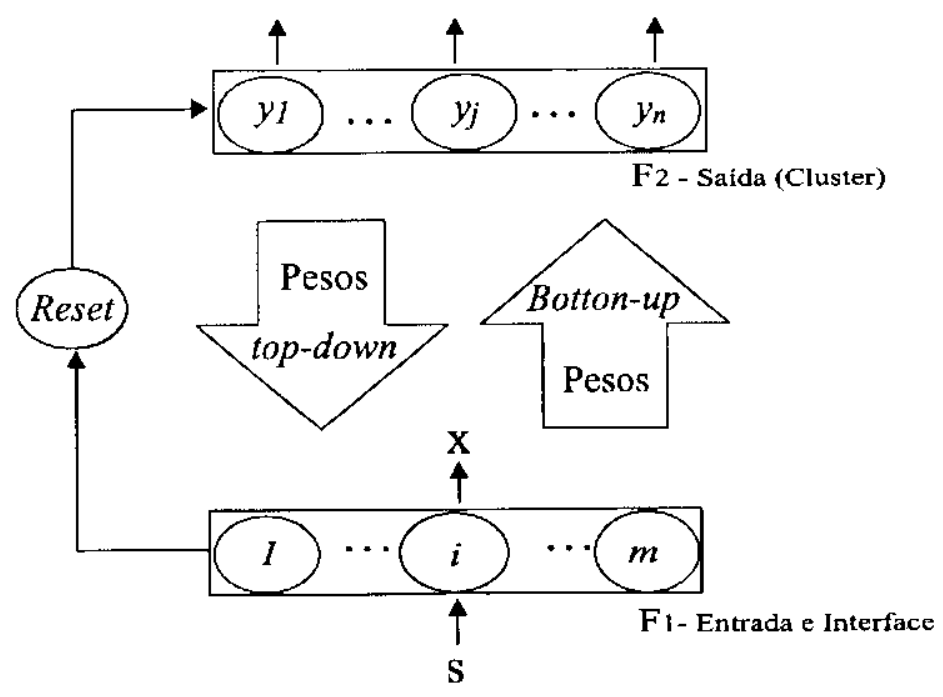

Figura 3.1: Estrutura básica da Rede ART

\subsubsection{Aprendizado nos modelos ART}

Os modelos ART podem implementar tanto o paradigma de aprendizado supervisionado quanto o nāo-supervisionado. Além disso, são sistemas de aprendizado

\footnotetext{
${ }^{2}$ Isto foi feito por conveniència a partir do modelo original (Carpenter and Grossberg, 1987b).
} 
competitivo, isto é, os neurônios da camada de saida vão competir entre si pelo direito de aprender o dado de entrada submetido à rede. Outra característica è que o tipo de aprendizado implementado por esse modelos é incremental, isto é, o sistema está apto a entrar no modo de treinamento a qualquer momento, possibilitando que a rede incorpore conhecimento novo, mantendo sua plasticidade e estabilidade (ver a Seção 3.1).

As redes neurais da familia ART levam este nome devido à maneira como aprendem e reconhecem a informação submetida a sua entrada. Em Física, a ressonância ocorre quando há transferência de energia de um sistema (elétrico ou mecânico) oscilante para outro, isto é, quando oscilações, de pequenas amplitudes, de um sistema, com a mesma freqüência própria (natural) de outro são transferidas a este causando vibrações de alta amplitude.

$\mathrm{Na}$ rede ART, o periodo de ressonância corresponde a um processo adaptativo do sistema, que ocorre de duas formas. A primeira destas, acontece se a rede aprendeu o suficiente para reconhecer os padrōes submetidos à entrada. Neste caso, o processo de ressonância é realizado rapidamente reforçando seus pesos (ou memória). A segunda maneira de o sistema entrar no estado de ressonância, ocorre quando o padrāo de entrada não é imediatamente reconhecido. Neste outro caso, a rede faz uma busca dentre seus padrões armazenados, na tentativa de encontrar um equivalente; caso nāo seja encontrada nenhuma equivalência, o sistema entra em estado de ressonância para aprender o novo padrāo.

Normalmente, há dois modos de treinamento para as redes ART, considerando um mesmo modelo: modo de aprendizado rápido (fast learning) e modo de aprendizado lento (slow learning). No modo de aprendizado rápido, os vetores de pesos são direcionados para seus valores ótimos em poucos ciclos ${ }^{3}$ de treinamento, por exemplo em um ou dois ciclos. No aprendizado lento, os pesos sāo ajustados lentamente, em vários ciclos de treinamento, por exemplo em dez ciclos.

As redes da familia ART foram projetadas para permitir que o usuário tenha a possibilidade de controlar o grau de similaridade entre os padrōes agrupados em um mesmo cluster. Esse parâmetro de similaridade, nas redes ART, é o threshold $(\rho)$, ou parâmetro de vigilância, que, por sua vez, controla a resoluçāo do processo de classificaçāo (i.e., o grau de similaridade entre os padrōes colocados em um mesmo cluster). O parāmetro de vigilância é o mais crítico dentre os parâmetros dos modelos ART, assumindo valores entre 0 (zero) e 1 (um). Se $\rho$ assume um valor baixo (por exemplo, < 0.3), a resoluçāo do processo de classificaçāo será baixa, criando poucos clusters. Se, para a mesma aplicação, $\rho$ assumir um valor alto (por exemplo, $>0.9$ ), uma pequena variaçāo nos padrōes de entrada levará à criaçāo de novos clusters.

A condição de parada do treinamento nos modelos ART pode ser estabelecida de duas formas: a primeira, quando não ocorrer mudança nos pesos após um determinado número de ciclos, ou melhor, quando não ocorrer nenhuma inibiçāo por Reset. A

\footnotetext{
${ }^{3}$ Um ciclo significa uma apresentaçāo completa do conjunto de padrōes.
} 
segunda condição é satisfeita, quando há um número máximo de ciclos a ser atingido. Caso todos os padrōes apresentados à rede não forem agrupados quando terminar os ciclos de treinamento, é preciso aumentar o número de clusters em $F_{2}$, ou reduzir o valor de $\rho$, e reiniciar o algoritmo. Isso serve para os modelos que serão apresentados nas próximas seçōes.

Nas próximas seções, serão apresentados os modelos ART1, ART2, ART2-A e Fuzzy ART. Para facilitar o entendimento dos seus algoritmos, o processo de treinamento de cada um deles foi dividido nos seguintes estágios:

- Inicialização: os parâmetros e os pesos da rede são inicializados;

- Entrada: apresentaçāo dos padrōes;

- Busca: o neurônio com maior ativação é escolhido;

- Comparaçāo (ou Reset): o neurônio, escolhido no estágio anterior, tem seus pesos avaliados com relaçāo a similaridade com o padrão de entrada:

- Adaptaçāo: a regra de aprendizado é aplicada (processo de ressonância).

\subsection{ART 1}

O modelo ART1 foi projetado para agrupar vetores de entradas binários, utilizando para isto, o paradigma de aprendizado nāo-supervisionado e incremental. Além disso, o processo de aprendizado não exige que os padrōes de entrada possuam uma ordem fixa, ou que o número de padrōes seja pré-definido para treinamento, i.e., mais padrōes podem ser adicionados durante o processo de treinamento.

\subsubsection{Arquitetura da rede ARTI}

A arquitetura da rede AR'l'l consiste de unidades computacionais, denotadas por $F_{1}, F_{2}$ e Reset, e de unidade suplementares, denotadas por $G 1$ e $G 2$ (ver Figura 3.2). Assim como descrito anteriormente, na Seção 3.2.1, a camada de entrada $F_{1}$ pode ser dividida em duas partes: $F_{1(a)}$ e $F_{1(b)}$. A sub-camada de interface $F_{1(b)}$, constituída pelas unidades $x_{i}$, combina sinais provenientes da camada $F_{1(a)}$, constituida pelas unidades $s_{i}$, e da camada $F_{2}$, constituida pelas unidades $y_{j}$, e isto é feito para comparar o sinal de entrada com a entrada ponderada (reforçada) pelo vetor de peso da unidade que foi selecionada para adaptaçāo (aprendizado). Para comparar o grau de similaridade entre padrões existem dois conjuntos de conexões (cada um com seus próprios pesos), conectando as unidades de interface $x_{i}$ com as unidades de clusters $y_{j}$. As conexōes que partem de $F_{1(b)}$ e vāo em direçāo à $F_{2}$ são reforçadas pelos pesos bottom-up e assumem valores reais $b_{i j}$. As conexōes que partem da camada $F_{2}$ em direçāo à camada $F_{1(b)}$ são reforçados pelos pesos top-down que assumem valores 
binários $t_{j i}$. A camada $F_{2}$ é competitiva, ou seja, a unidade de cluster que possuir maior valor de ativaçāo será escolhida para aprender o padrāo de entrada.

Para cada camada dos modelos ART1 e ART2 existem unidades externas de controle, que sāo chamadas de unidades suplementares. No modelo ART1, estas unidades são representadas por $G 1$ e $G 2$. A função destas unidades é controlar o fluxo de dados através das camadas em cada fase de um ciclo de treinamento. Estas unidades sāo chamadas de unidades de controle de ganho (Gain Control Unit) e serão descritas mais adiante, juntamente com a finalidade dos sinais “+" e "-". Entre a camada de entrada e a camada de saída há também a unidade de Reset, que é responsável por calcular uma medida de similaridade relativa entre o vetor de entrada e o protótipo armazenado no vetor de pesos associado ao neurônio vencedor, com o objetivo de comparar essa medida com o parâmetro de vigilância $(\rho)$.

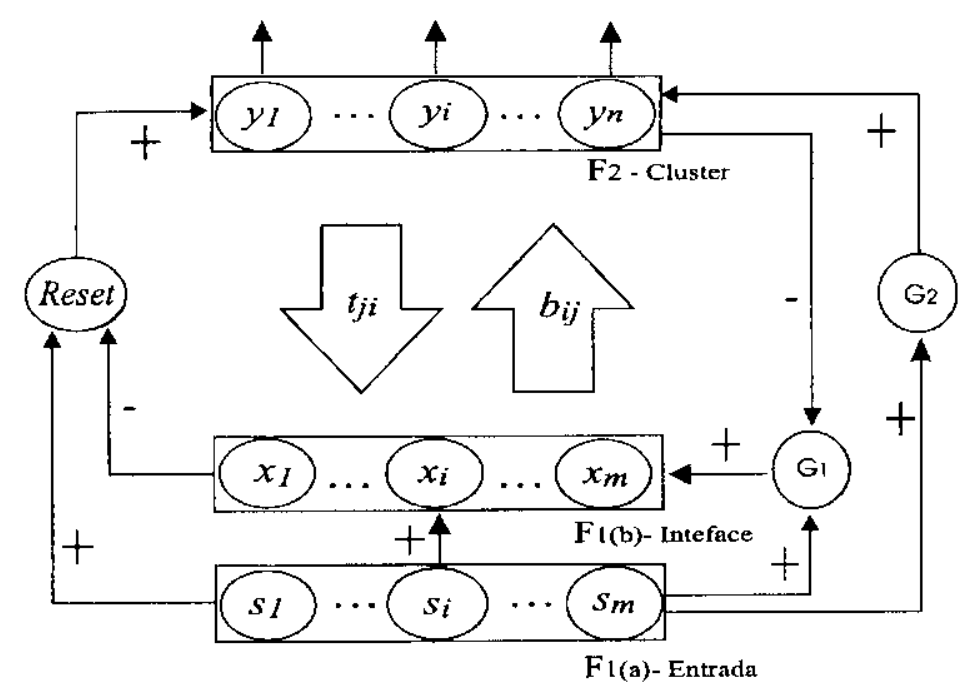

Figura 3.2: Arquitetura da rede ART1

Uma dificuldade inerente à arquitetura do modelo ART1, é que as unidades que a compõem têm que responder de forma diferente aos diversos estágios do processo neural. Por exemplo, as unidades de $F_{1}$ devem estar ativas sempre que o sinal é percebido na entrada $F_{1(a)}$ e nenhuma unidade de $F_{2}$ está ativa. As unidades de $F_{1(b)}$ devem estar ativas, se e somente se, recebem sinais de $F_{2}$ e da camada de entrada. A operaçāo da unidade de Reset também possui um papel importante dentro do sistema de processamento neural, uma vez que essa unidade também deve inibir a unidade $F_{2}$, sob certas condiçōes, e reativá-la em uma etapa mais adiante. Estes dois problemas podem ser compreendidos e resolvidos quando são adicionadas as unidades suplementares $G 1$ e $G 2$.

Dessa forma, as unidades suplementares sāo importantes sob o ponto de vista teórico, uma vez que estas fornecem um mecanismo para o qual o algoritmo apresentado na Seçāo 3.3.2 possa ser implementado usando princípios de redes neurais.

Na Figura 3.2 os sinais excitatórios são representados por “+”, e os sinais inibitórios são representados por “-”. Um sinal, seja este qual for, é enviado sempre que 
uma unidade está ativa. Cada unidade das camadas $F_{1(b)}$ e $F_{2}$ recebem três sinais que vêm de outras unidades. Por exemplo, $F_{1(b)}$ pode receber sinais de $F_{1(a)}, F_{2}$ (através dos pesos top-down) e $G 2$. Da mesma forma, $F_{2}$ pode receber sinais de $F_{1(b)}$, Reset e $G 1$ (ver Figura 3.2). Cada uma das camadas $F_{1(b)}$ (através dos pesos bottom-up) e $F_{2}$ devem receber pelo menos dois sinais excitatórios para se tornar ativa, considerando três possiveis fontes de sinais. Esta situação é conhecida por "regra dos $2 / 3$ (dois terços)".

\subsubsection{Algoritmo de treinamento da rede ARTI}

A Figura 3.2 pode ajudar a entender o algoritmo de treinamento da rede ART1. Para melhor compreensāo deste algoritmo, a seguinte notação será usada:

\begin{tabular}{ll}
\hline \hline Variáveis & Descrição \\
\hline$m n$ & número de componentes do vetor de entrada \\
$n$ & número máximo de clusters que podem ser formados \\
$b_{i j}$ & pesos bottom-up \\
$t_{j i}$ & pesos top-down \\
$\rho$ & parâmetro de vigilancia \\
$\mathbf{s}$ & vetor de entradas binárias \\
$\mathbf{x}$ & vetor de ativaçāo de $F_{1(b)}$ \\
$\|\mathbf{x}\|$ & norma do vetor $\mathbf{x}$, calculado pela Equação 3.1 \\
\hline \hline
\end{tabular}

Tabela 3.1: Notação utilizada nos algoritmos das redes ART1 e ART2.

$$
\|\mathbf{x}\|=\sqrt{\sum_{i} x_{i}^{2}}
$$

\subsubsection{Parâmetros usados no algoritmo de treinamento da rede ART1}

A Tabela 3.2 mostra os parâmetros que sāo definidos pelos usuários e suas respectivas restriçōes (Carpenter and Grossberg, 1987b).

\begin{tabular}{ll}
\hline \hline Parâmetros & Restriçōes \\
\hline$L$ & $L>1$ \\
$\rho$ & $0<\rho \leqslant 1$ \\
$b_{i j}$ & $0<b_{i j}(0)<\frac{L}{L-1+n}$ \\
$t_{j i}$ & $t_{j i}(0)=1$ \\
\hline \hline
\end{tabular}

Tabela 3.2: Inicialização dos parâmetros da rede ART1

\subsubsection{Resumo do algoritmo da rede ARTI}

O algoritmo de treinamento que será apresentado aqui é o de modo rápido.

- Inicialização: determine o tamanho das camadas $F_{1}$ e $F_{2}$, e os valores para os demais parâmetros da rede, sendo que para cada vetor de entrada, é preciso 
ajustar toda unidade $F_{2}$ para zero, ou seja, $y_{j}=0$, para todo $j$;

- Entrada: compute $\|$ s $\|$ com a Equação 3.1 e para todos os elementos de $F_{1(b)}$ faça $x_{i}=s_{i}$.

- Busca: compute a ativaçāo de cada neurônio da camada $F_{2} \operatorname{com} y_{j}=\sum_{i} b_{i j} x_{i} \mathrm{e}$ encontre o neurônio $J$ com a maior ativação:

$$
y_{J}=\max \left\{y_{j}, j=1 \ldots n\right\} \text {. }
$$

Se houver mais que um $y_{J}$, entāo utilize o menor indice $j$, mantendo-se a ordem de $j=1,2,3 \ldots n$. Caso todos os $y_{j}$ sejam iguais a -1 , significa que os neurônios estão inibidos, e aquele padrão de entrada nāo será aprendido durante aquele ciclo de treinamento.

- Comparação (ou Reset): compute o sinal de ativação das unidades de $F_{1(b)}$ com $x i=s_{i} t_{J i}$, calcule a norma $\|\mathbf{x}\|$ e teste a unidade de Reset com:

$$
\frac{\|\mathbf{x}\|}{\|\mathbf{s}\|}>\rho
$$

Se a desigualdade for verdadeira, entāo vá para o próximo estágio. Caso contrário, faça $y_{J}=-1$ (i.e., o neurônio ficará inibido durante a apresentação daquele padrāo), sendo necessário que se repita o estágio de Busca;

- Adaptação: atualize os pesos da rede de acordo com a seguinte regra:

$$
\left\{\begin{array}{l}
b_{i J}^{(N o v o)}=\frac{L \mathbf{x}}{L-i+\|\mathbf{x}\|}, \quad e \\
t_{J i}^{(N o v o)}=x_{i} .
\end{array}\right.
$$

Nesta seção, foram apresentados detalhes sobre o modelo ART1, por se tratar de um modelo pioneiro e que inspirou outros modelos também importantes, tal como o modelo Fuzzy ART (ver Seçāo 3.6). Na próxima seção, será apresentado o modelo ART2, sendo este, o primeiro modelo ART adaptado para trabalhar com entrada de valores reais.

\subsection{ART2}

O modelo ART2 foi projetado para receber entradas de valores reais, da mesma forma que o modelo ARTl o faz com os valores binários. As diferenças entre estes dois modelos refletem as modificaçōes necessárias para acomodar os vetores de entrada 
com valores reais e, por isso, a camada $F_{1}$ do modelo ART2 é mais complexa. Esta complexidade se deve justamente às normalizaçōes e supressāo de ruídos presentes na camada $F_{1}$, além da comparação dos sinais bottom-up e top-down necessários ao mecanismo de Reset.

\subsubsection{Arquitetura da rede ART2}

A arquitetura da rede ART2 pode ser encontrada com detalhes, como também outras arquiteturas alternativas, em (Carpenter and Grossberg, 1987a). Uma arquitetura ART2 típica é apresentada na Figura 3.3. A camada $F_{1}$ consiste de seis tipos de unidades computacionais $\left(w_{i}, x_{i}, u_{i}, v_{i}, p_{i}\right.$ e $\left.q_{i}\right)$. Há $m=i$ unidades ${ }^{4}$ de cada um desses tipos, mas somente uma unidade de cada tipo é mostrada na Figura 3.3. Além disso, existem mais cinco unidades suplementares (ver Figura 3.4). Entre $w_{i}$ e $x_{i}$ existe uma unidade suplementar que recebe sinais de todas as unidades $w_{i}$, computa a norma (Equaçāo 3.1) do vetor $w_{i}$ e envia estes sinais para cada das unidades $x_{i}$. Cada uma destas unidades, $x_{i}$, também recebe sinais de unidades $w_{i}$ correspondentes.

Outras unidades suplementares executam a mesma tarefa entre $v_{i}$ e $u_{i}$ e entre $p_{i} \mathrm{e}$ $q_{i}$, também havendo unidades suplementares entre $u_{i}$ e Reset, e entre $p_{i}$ e Reset. Desta forma, o mesmo papel das unidades suplementares no modelo ART1 foi incorporado ao modelo ART2. Cada uma das unidades $x_{i}$ está conectada com a sua correspondente unidade $v_{i}$, e cada unidade $q_{i}$ está conectada com sua correspondente unidade $v_{i}$.

Os simbolos em algumas conexōes na camada $F_{1}$ indicam a transformaçāo de sinal de uma unidade para outra, e não uma multiplicação por uma dada quantidade (ou peso). A conexāo entre as unidades $p_{i}$ (da camada $F_{1}$ ) e $y_{j}$ (da camada $F_{2}$ ) mostram que os pesos multiplicam o sinal naqueles caminhos.

A ativação do neurônio vencedor da camada $F_{2}$ é denotada por $d$, sendo $0<d<1$. A ação das unidades de $F_{2}$ acontece da mesma forma que no modelo ART1, ou seja, as unidades $y_{j}$ competem entre si e apenas uma ganha o direito de atualizar seus pesos.

Como ocorre na rede ART1, diz-se que o modelo aprendeu somente se os pesos top-down da unidade vencedora forem suficientemente similares ao padrāo de entrada. O teste da condição de Reset no modelo ART2 é análogo ao realizado no ART1. Desta forma, as unidades $u_{i}$ desempenham um papel similar aos componentes de $F_{1(a)}$ no modelo ART 1 , e as unidades $p_{i}$ desempenham um papel similar aos componentes de $F_{1(b)}$ nesse mesmo modelo.

O sinal proveniente de $v_{i}$ corresponde ao vetor de entrada que sofreu algum pré-processamento. Este pré-processamento é feito pelas unidades $x_{i}$ e $q_{i}$, que aplicam uma ativação em suas entradas. A funçāo de ativação (Equaçāo 3.5) suprime qualquer componente do vetor de ativação a níveis que estão abaixo do valor de supressāo de ruído selecionado pelo usuário, ou seja, o valor de $\theta$. As conexões das unidades $w_{i}$

\footnotetext{
${ }^{4} m$ representa o tamanho do padrão de entrada.
} 
para as unidades $u_{i}$ e das unidades $q_{i}$ para as unidades $v_{i}$ possuem valores fixos $a \mathrm{e}$ $b$, respectivamente, que reforçam estas conexōes.

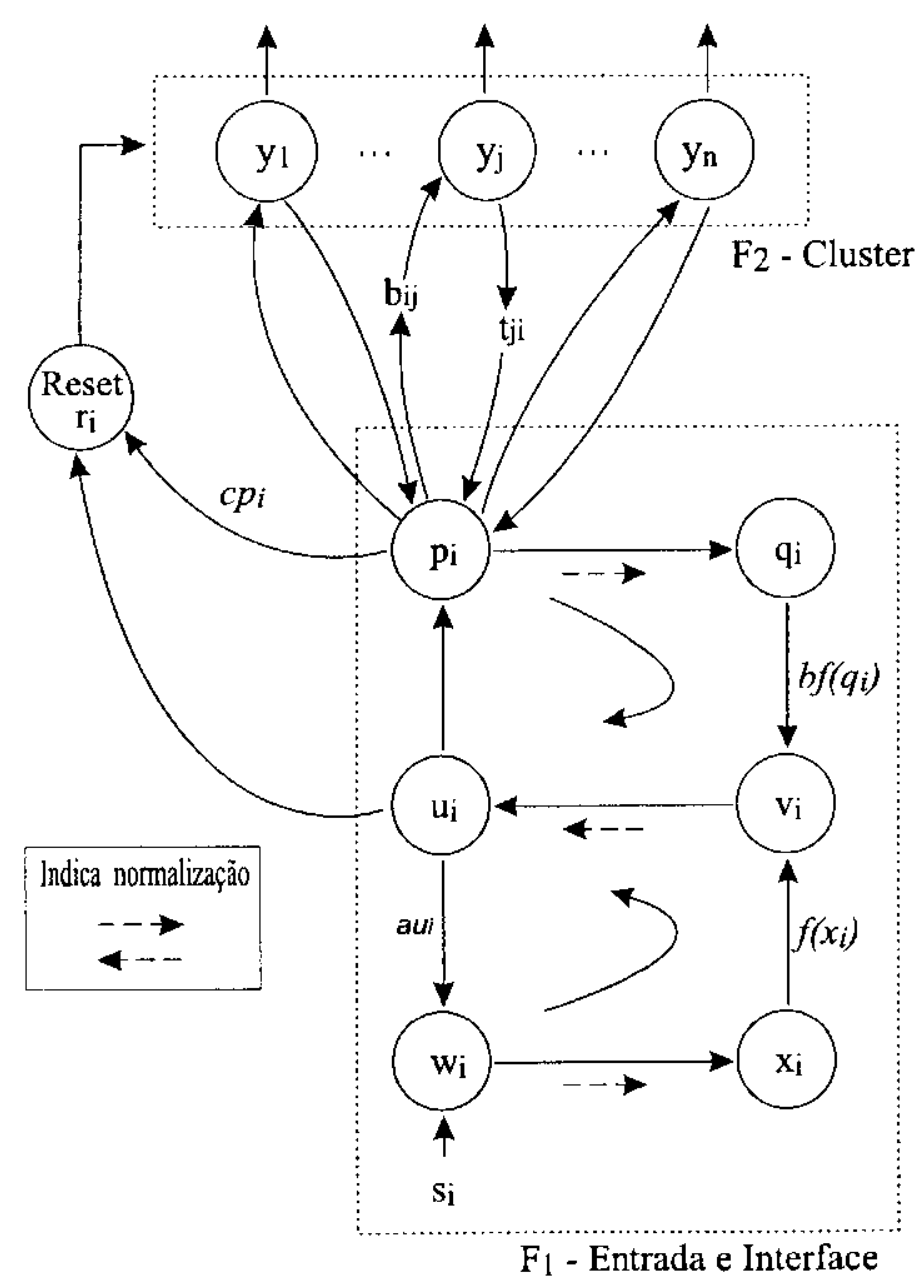

Figura 3.3: Arquitetura básica da rede ART2.

$$
f(x)= \begin{cases}x & \text { se } x \geq \theta \\ 0 & \text { caso } x<\theta\end{cases}
$$

\subsubsection{Algoritmo de treinamento da rede ART2}

Nesta seção, são apresentados, de forma resumida, os algoritmo de treinamento no modo lento e no modo rápido do modelo ART2 (Carpenter and Grossberg, 1987a). Primeiramente, será apresentada uma descrição do algoritmo no modo lento e dos seus parāmetros utilizados. A Figura 3.3 pode ser usada para melhor entendimento do algoritmo. 


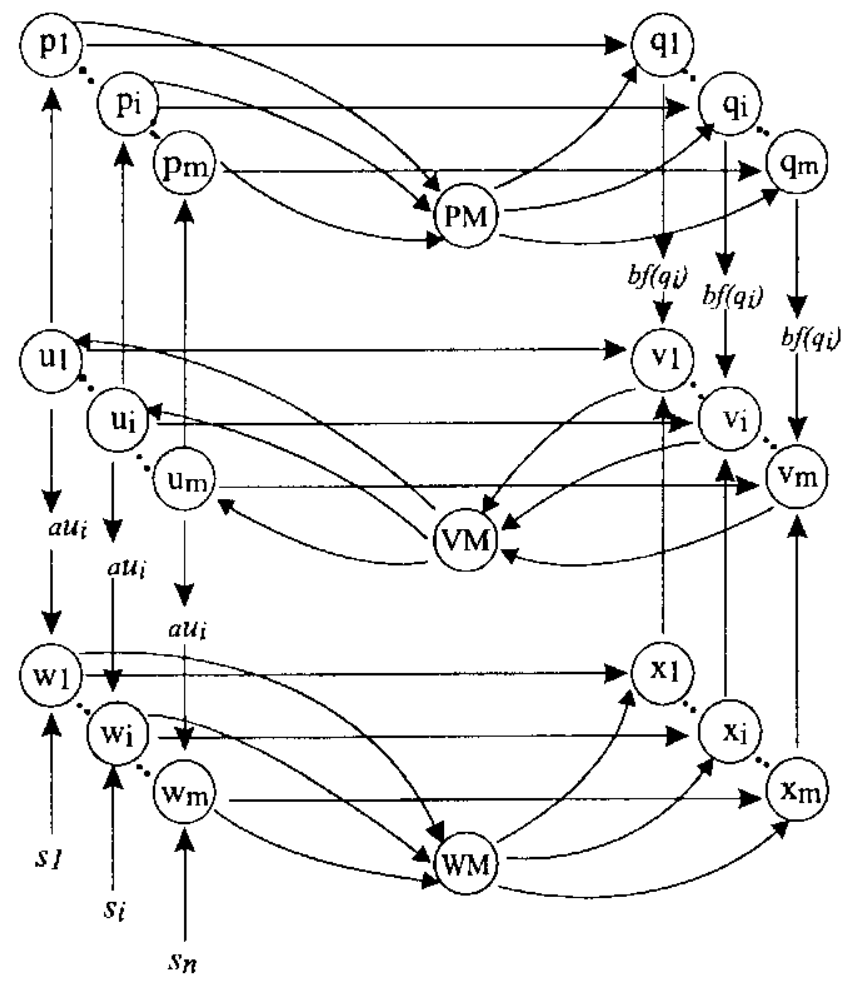

Figura 3.4: Unidades suplementares da rede ART2.

\subsubsection{Descrição do algoritmo de treinamento da rede ART2}

A etapa inicial do processo de aprendizado consiste em apresentar à rede um sinal de entrada $s=\left(s_{1}, \ldots, s_{i}, \ldots, s_{n}\right)$ de valores reais. No início do treinamento, todas as unidades possuem valores iguais a zero, e o ciclo computacional pode ser melhor compreendido como tendo início nas unidades $u_{i}$. O sinal partindo de cada unidade $u_{i}$ em direção às unidades $w_{i}$ e $p_{i}$ são, então, computados.

As unidades $w_{i}$ somam os sinal que recebem das unidades $u_{i}$ e das entradas em $s_{i}$. As unidades $p_{i}$ computam o sinal que recebem de $u_{i}$ e dos pesos top-down. que recebem de uma unidade ativa em $F_{2}$. A ativação de $x_{i}$ e $q_{i}$ são versões normalizadas de $w_{i}$ e $p_{i}$, respectivamente, sendo que uma funçāo de ativação (Equaçāo 3.5) é aplicada em cada uma destas unidades antes de o sinal ser enviado às unidades $v_{i}$. Em seguida, as unidades $v_{i}$ somam o sinal que recebem e completam o ciclo, atualizando a camada $F_{1}$. Com a função de ativação, as unidades $u_{i}$ e $p_{i}$ buscam o equilíbrio depois de duas atualizações da camada $F_{1}$.

As unidades $p_{i}$, após receberem os sinais de unidades da camada $F_{1}$, enviam sinais para as unidades de cluster $y_{j}$ em $F_{2}$, onde acontece a competiçāo. As unidades $u_{i}$ e $p_{i}$ também enviam sinais para as unidades de Reset $\left(r_{i}\right)$, que se tornam ativas para verificar a possibilidade de inibir, ou não, o vencedor em $F_{2}$. Isto acontecerá somente quando as unidades $p_{i}$ receberem os sinais dos pesos top-down. Depois que a condição de Reset foi verificada, uma unidade de cluster $y_{J}$ será rejeitada se o padrão de entrada não for suficientemente similar ao protótipo deste cluster. Então, 
uma outra unidade de cluster, que nāo está inibida, deverá ser escolhida e testada na unidade de Reset.

A estabilidade da rede é atingida quando, entre um ciclo e outro, nāo ocorrer qualquer mudança nos clusters formados, ou ainda, quando não ocorrer sinal de Reset na unidade de cluster que havia classificado um determinado padrão de entrada anteriormente.

\subsubsection{Notação e escolha dos parâmetros}

Os parâmetros que estão definidos na Tabela 3.3 são usados no algoritmo de treinamento do modelo ART2, sendo estes parâmetros definidos pelos usuários.

\begin{tabular}{|l|l|}
\hline \hline Parâmetros & Descriçāo \\
\hline$m$ & Número de componentes do vetor de entrada. \\
\hline$n$ & Número máximo de clusters que podem ser formados. \\
\hline$a, b$ & $\begin{array}{l}\text { Pesos fixos da camada } F_{1} ; \text { exemplo de valores são } \\
a=10, \text { e } b=10 . \text { Se } a=0 \text { ou } b=0 \text {, a rede poderá } \\
\text { ficar instável; com exceção deste caso, a rede não é } \\
\text { particularmente sensivel a outros valores escolhidos. }\end{array}$ \\
\hline$c$ & $\begin{array}{l}\text { Pesos fixos que sāo usados nos testes de Reset. Um } \\
\text { exemplo é } c=0.1 . \text { Um valor pequeno proporciona } \\
\text { uma grande cficácia do parâmetro de vigilância ( } \rho \text { ). }\end{array}$ \\
\hline$d$ & $\begin{array}{l}\text { Ativação da unidade vencedora em } F_{2} . \text { Os parâmetros } \\
c \text { e } d \text { deve ser escolhido de modo a satisfazer a } \\
\text { inequação: } \frac{c d}{1-d} \leq 1 . \text { Isto evita a ocorrência de Reset } \\
\text { durante o treinamento. }\end{array}$ \\
\hline$e$ & $\begin{array}{l}\text { Parâmetro de valor próximo a 0 (zero). Isso evita a } \\
\text { divisão por zero. }\end{array}$ \\
\hline$\beta$ & $\begin{array}{l}\text { Parâmetro de supressão de ruído. Um exemplo de } \\
\text { valor é } \theta=\frac{1}{\sqrt{n}} .\end{array}$ \\
\hline$\rho$ & $\begin{array}{l}\text { Taxa de aprendizagem. Um valor pequeno vai as- } \\
\text { segurar que os pesos encontrem o equilíbrio no } \\
\text { algoritmo de treinamento (modo lento). }\end{array}$ \\
\hline \hline
\end{tabular}

Tabela 3.3: Parâmetros de ART2

Inicialização dos Pesos: os pesos top-down são inicializados em zero,

$$
t_{j i}(0)=0
$$

para assegurar que nāo ocorra sinal de Reset para o primeiro padrão a ser colocado em qualquer uma das unidade de cluster. Os pesos bottom-up devem satisfazer a desigualdade:

$$
b_{i j}(0) \leq \frac{1}{(1-d) \sqrt{n}} .
$$


Além disso, isto evita a possibilidade de um novo vencedor ser escolhido durante a ressonância. Ativação da camada $F_{1}$ : abaixo seguem as equaçōes de ativação e pré-processamento dos dados de entrada da camada $F_{1}$.

$$
\begin{gathered}
u_{i}=\frac{v_{i}}{e+\|\mathbf{v}\|}, \\
w_{i}=s_{i}+a u_{i}, \\
p_{i}=u_{i}+d \mathbf{t}_{\mathbf{J}}, \\
x_{i}=\frac{w_{i}}{e+\|\mathbf{x}\|}, \\
q_{i}=\frac{p_{i}}{e+\|\mathbf{p}\|}, \\
v_{i}=f\left(x_{i}\right)+b f\left(q_{i}\right) .
\end{gathered}
$$

\subsubsection{Resumo do Algoritmo}

- Inicialização: determine o tamanho das camadas $F_{1}$ e $F_{2}$, bem como os valores para os demais parâmetros da rede: $a, b, c, d, e, \beta$ e $\rho$, de acordo com as restrições da Tabela 3.3. Além disso, inicialize os pesos top-down e bottom-up utilizando as Equações 3.6 e 3.7. Para cada vetor de entrada na rede é preciso ajustar toda unidade $F_{2}$ para zero, ou seja $y_{j}=0$, para todo $j$.

- Entrada: compute para cada padrão $s_{i}$ as ativaçōes:

$$
\left\{\begin{array}{l}
u_{i}=0, w_{i}=s_{i}, p_{i}=0 \\
x_{i}=\frac{s_{i}}{e+\|\mathbf{s}\|} \\
q_{i}=0, v_{i}=f\left(x_{i}\right),
\end{array}\right.
$$

e atualize a camada $F_{1}$ com as Equaçōes 3.8, 3.9, 3.10, 3.11 e 3.12.

- Busca: compute a ativação de cada neurônio da camada $F_{2} \operatorname{com} y_{j}=\sum_{i} b_{i j} p_{i}$, e encontre o neurônio com maior ativação:

$$
y_{J}=\max \left\{y_{j}, j=1 \ldots n\right\}
$$

Se houver mais que um $y J$, então utilize o menor indice $j$, mantendo-se a ordem de $j=1,2,3 \ldots n$. Caso todos os $y_{j}$ sejam iguais a -1 , significa que os neurônios estão inibidos, e aquele padrão de entrada nāo será aprendido durante aquele 
ciclo de treinamento.

- Comparação: compute o sinal que vem de $F_{2}$ para $F_{1}$ através de Equação 3.10, e compute a Equaçāo 3.8 para validar o sinal de Reset com:

$$
r_{i}=\frac{u_{i}+c p_{i}}{e+\|\mathbf{u}\|+c\|\mathbf{p}\|}
$$

Se $\|\mathbf{r}\|>\rho-e$ for verdadeiro, o processo de adaptaçāo inicia-se e os pesos da unidade $J$ vencedora em $F_{2}$ são atualizados; caso contrário, $y_{J}=-1$, (i.e., o neurônio ficará inibido durante a apresentaçāo daquele padrāo de entrada), sendo necessário que se repita o estágio de Busca;

- Adaptação: atualize os pesos da rede de acordo com a seguinte regra:

$$
\left\{\begin{array}{l}
b_{i J}^{(\text {Novo })}=\beta d u_{i}+\{\beta d(d-1)\} b_{i J}^{(\text {Velho })} \\
t_{J i}^{(N o v o)}=\beta d u_{i}+\{\beta d(d-1)\} t_{J i}^{(V e l h o)}
\end{array} e\right.
$$

Em seguida atualize as ativaçōes em $F_{1}$ com as Equaçōes 3.8, 3.9, 3.10, 3.11 e 3.12 .

\subsubsection{Descriçāo do algoritmo de treinamento da rede ART2 (modo rápido)}

$\mathrm{O}$ algoritmo de treinamento no modo rápido também é chamado de Instant ART2. Neste algoritmo, não é necessário verificar o Reset para a unidade de cluster que está sendo selecionada pela primeira vez. Isto pode ser feito verificando se os pesos top-down desta unidades de cluster são iguais a zero, uma vez que estes tenham sido inicializados em zero.

\subsubsection{Algoritmo}

A notação utilizada no algoritmo descrito abaixo é a mesma utilizada até agora. $\mathrm{O}$ algoritmo de aprendizado no modo rápido do modelo ART2 é semelhante ao algoritmo de aprendizado no modo lento. A diferença entre os dois modos de treinamento está no estágio de adaptação, por isso, somente este estágio é descrito a seguir:

- Adaptação: a regra de atualização dos pesos ê dada por uma situação condicional: se o neurônio escolhido para aprender aquele padrāo já foi escolhido alguma vez, ou seja, $t_{J} \neq 0$, então, as unidades do conjunto de pesos top-down do neurônio vencedor que são diferentes de zero, isto é. $t_{J i} \neq 0$, devem ser atualizadas com a seguinte regra:

$$
\left\{\begin{array}{l}
b_{i J}=\frac{1}{1-d} u_{i} e \\
t_{J i}=\frac{1}{1-d} u_{i} .
\end{array}\right.
$$


Por outro lado, se todas as unidades do conjunto de pesos top-down do neurônio vencedor nảo foram atualizadas nenhuma vez, ou seja, $t_{J}=0$, entāo, estas devem ser atualizadas com a seguinte regra:

$$
\left\{\begin{array}{l}
\mathbf{b}_{J}=\frac{1}{1-d} \mathbf{u} e \\
\mathbf{t}_{J}=\frac{1}{1-d} \mathbf{u} .
\end{array}\right.
$$

Neste estágio, diferente do modo de aprendizado lento, não é necessário atualizar as ativaçōes da camada $F_{1}$.

Na próxima seção, será apresentado o modelo ART2-A. Este, por sua vez, tem a mesma finalidade do modelo ART2, mas com velocidade de processamento duas ou très vezes maior que este último.

\subsection{ART2-A}

A RNA ART2-A é um sistema computacional simples, com arquitetura paralela semelhante à ART1, e com características análogas à ART2. Entretanto, seu processamento é da ordem de magnitude de duas ou três vezes mais rápido que a ART2 em simulaçōes com computadores convencionais (Carpenter et al., 1991c). A rapidez apresentada pelo algoritmo deve-se, em parte, à especificação de variáveis de estado fixo com a composição de um pequeno número de operaçōes nāo-lineares. As equações de estado fixo substituem um consumo de tempo gasto por um sistema multi-camadas iterativo, tal qual aquele apresentado pelo modelo ART2. Outra caracteristica do modelo ART2-A, diz respeito ao seu modo de treinamento. Este modelo apresenta um modo de treinamento rápido e um modo intermediário, que captura as principais propriedades do algoritmo ART2 em modo de treinamento lento. $\mathrm{O}$ treinamento no modo intermediário oferece uma opção de fast commitment $t^{5}$ e slow recode $^{6}$, que permite ao sistema maior estabilidade, tolerância a ruidos, e também menor sensibilidade à ordem de entrada. Este processo será discutido com mais detalhes na Seção 3.5.2, no resumo do algoritmo.

\subsubsection{Arquitetura da rede ART2-A}

A arquitetura deste modelo apresenta as principais caracteristicas do modelo básico das redes ART (ver Figura 3.1) (Carpenter et al., 1991c). Os componentes desta arquitetura são: a camada $F_{1}$ (dividida em duas sub-camadas, entrada e interface, respectivamente, $F_{1(n)}$ e $F_{1(b)}$ ); a camada $F_{2}$ (cluster); a unidade de Reset e o conjunto

\footnotetext{
${ }^{5}$ Isto significa que o padrão de entrada será copiado, de forma idêntica, como primeiro protótipo para o conjunto de pesos do neurônio que está sendo escolhido, pela primeira vez, para o estágio de adaptaçāo.

${ }^{6}$ Isto significa que o padrāo de entrada será parcialmente copiado, como forma de incrementar o protótipo armazenado conjunto de pesos. Neste caso, o neurônio já foi, pelo menos uma vez, escolhido para o estágio de adaptaçāo.
} 
de pesos, representados pela matriz $\mathbf{W}$, que conecta a sub-camada $F_{1(b)}$ com a camada $F_{2}$. Entre as unidades da sub-camada $F_{1(a)}$ e as unidades da sub-camada $F_{1(b)}$ ocorre o pré-processamento dos dados de entrada. As unidades da sub-camada $F_{1}(b)$ também estāo conectadas com a unidade de Reset. Isto está de acordo com a Figura (3.5).

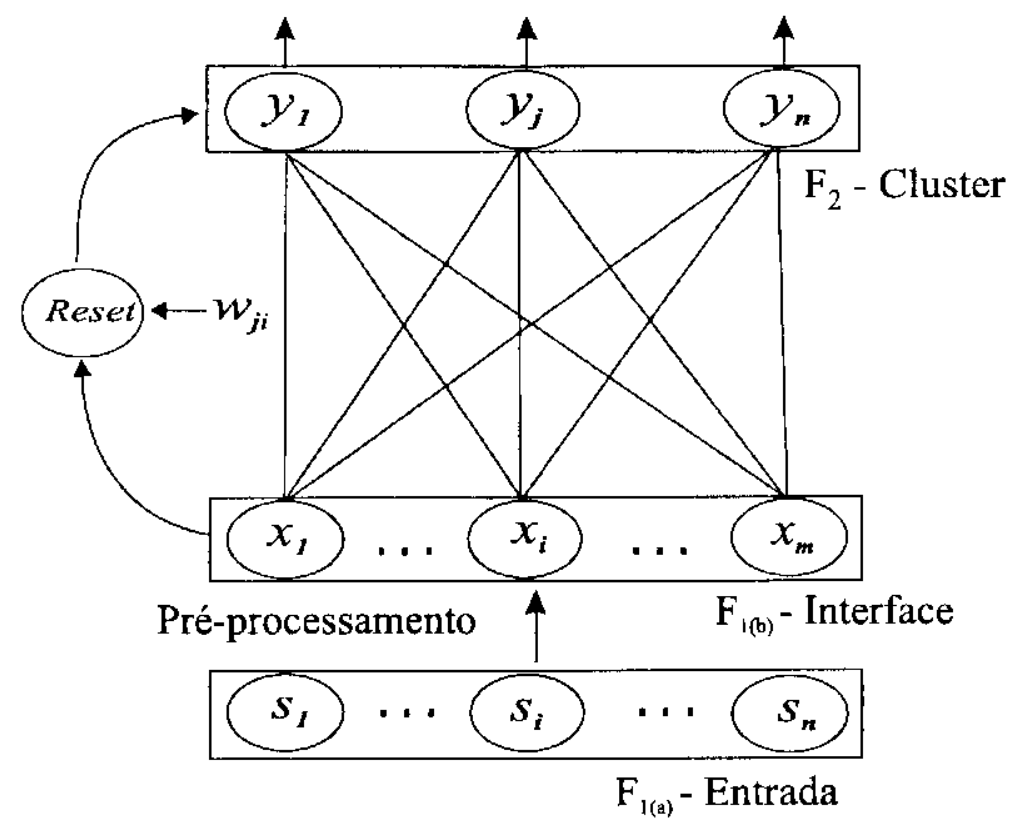

Figura 3.5: Arquitetura da rede ART2-A

\subsubsection{Resumo do algoritmo da rede ART2-A}

O algoritmo de treinamento da rede ART2-A possui dois modos de treinamentos: o modo rápido e o intermediário. A notação utilizada, bem como os parâmetros e suas restriçōes são apresentadas na tabela 3.4 .

- Inicialização: determine o tamanho das camadas $F_{1}$ e $F_{2}$, bem como os valores para os demais parâmetros da rede. Além disso, para cada vetor de entrada, é preciso ajustar todas unidades de $F_{2}$ para zero, ou seja $y_{j}=0$, para todo $j$;

- Entrada: realize o pré-processamento da entrada com $x=\aleph(\wp(\aleph(s))$, onde

$$
\aleph(\mathbf{s})=\frac{\mathbf{s}}{\|\mathbf{s}\|},
$$

com s representando o vetor de entrada, e

$$
\wp(\mathbf{x})=\left\{\begin{array}{l}
x_{i}, \text { se } x_{i}>\theta \\
0(\text { zero }), \text { caso contário. }
\end{array}\right.
$$

Os valores de $\theta$ satisfazem a propriedade descrita da Tabela 3.4. 


\begin{tabular}{|l|l|}
\hline \hline Parâmetros & Descrição \\
\hline$m$ & Número de componentes do vetor de entrada. \\
\hline$n$ & Número máximo de clusters que podem ser formados. \\
\hline$\theta$ & $\begin{array}{l}\text { Parâmetro de supressão de ruído; seus valores estão } \\
\text { no intervalo } 0<\theta \leqslant \frac{1}{\sqrt{m}} .\end{array}$ \\
\hline$\alpha$ & $\begin{array}{l}\text { Parâmetro de supressão de ruído; seus valores estāo } \\
\text { no intervalo } 0<\alpha \leqslant \frac{1}{\sqrt{m}} .\end{array}$ \\
\hline$\beta$ & $\begin{array}{l}\text { Taxa de aprendizagem, sendo seus valores no inter- } \\
\text { valo }[0,1] . O \text { valor } 1 \text { determina treinamento no modo } \\
\text { rápido; valores } \beta<1 \text { determinam treinamento no } \\
\text { modo intermediário. }\end{array}$ \\
\hline$\rho$ & $\begin{array}{l}\text { Parâmetro de vigilância. Determina quantos clusters } \\
\text { serāo formados durante o treinamento. }\end{array}$ \\
\hline $\mathbf{W}$ & $\begin{array}{l}\text { Representa a matriz de pesos. Neste modelo, os pesos } \\
\text { top-down e bottom-up são iguais. Portanto, apenas } \\
\text { um destes conjuntos é usado. }\end{array}$ \\
\hline \hline
\end{tabular}

Tabela 3.4: Notação e parâmetros da rede ART2-A

- Busca: compute a ativação de cada neurônio da camada $F_{2}$ com:

$$
y_{j}=\left\{\begin{array}{l}
\alpha \sum s_{i}, \text { se } j \text { for uncommitted } e \\
\mathbf{x}_{\mathrm{i}} \mathbf{w}_{j}, \text { se } j \text { for committed }
\end{array}\right.
$$

(Obs: Neste presente trabalho o valor de $\alpha=0$ foi utilizado em todos os experimentos.)

Inicialmente, todos os neurōnios devem estar uncommitted ${ }^{7}$, pois estes só passarão ao estado de committed ${ }^{8}$ quando, em algum momento, tiverem seus pesos atualizados. Em seguida, encontre o neurônio $J$ com a maior ativaçāo, a partir de:

$$
y_{J}=\max \left\{y_{j}, j=1 \ldots n\right\} .
$$

Se houver mais que um $y_{J}$, entāo utilize o menor índice $j$, mantendo-se a ordem de $j=1,2,3 \ldots n$. Caso todos os $y_{j}$ sejam iguais a -1 , significa que os neurônios estāo inibidos, e aquele padrāo de entrada nāo será aprendido durante aquele ciclo de treinamento.

- Comparaçāo (ou Reset): após ter selecionado o índice do neurōnio com o maior $y_{J}$, e se este for Committed, então testa-se o sinal de Reset com:

$$
y_{J}>\rho
$$

\footnotetext{
${ }^{7}$ Neurónio que ainda nảo foi selecionado para o estágio de atualizaçăo dos pesos.

${ }^{8}$ Neurónio que foi selecionado, pelo menos uma vez, para o estágio de atualizaçāo dos pesos.
} 
Se a desigualdade for verdadeira, entāo vá para o próximo estágio. Caso contrário, faça $y J=-1$ (i.e., o neurônio ficará inibido durante a apresentação daquele padrão), sendo necessário que se repita o estágio de Busca;

- Adaptação: atualize os pesos da rede de acordo com a seguinte regra:

$$
\begin{gathered}
\mathbf{w}_{J}^{(\text {Novo })}=\left\{\begin{array}{l}
\mathbf{x}, \text { se } J \text { for uncommitted, } e \\
\aleph\left(\beta \aleph(\Psi)+(1-\beta) \mathbf{w}_{J}^{(\text {Velho })}\right), \text { se } J \text { for committed }
\end{array}\right. \\
\Psi=\left\{\begin{array}{l}
x_{i}, \text { se } w_{j i}^{(\text {Velho })}>\theta \\
0(\text { zero }), \text { caso contrário. }
\end{array}\right.
\end{gathered}
$$

O modelo ART2-A foi projetado para preservar as principais propriedades do modelo ART2. Mesmo assim, pode ser que, em alguns casos, o modelo ART2-A não seja tão bem aplicado quanto o modelo ART2. Todavia, o modelo ART2-A pode substituir o ART2 com eficiência na maioria das aplicaçōes, e com velocidade de processamento duas ou três vezes maior (Carpenter et al., 1991c). Na próxima seção será apresentado o modelo Fuzzy ART.

\subsection{Fuzzy ART}

O modelo Fuzzy ART incorpora todas as características básicas dos sistemas ART (Carpenter and Grossberg, 1987b). Assim como os demais modelos apresentados nas seções anteriores, este modelo trabalha com o paradigma de aprendizado não-supervisionado. Além disso, este modelo de RNA foi desenvolvido baseando-se no modelo ART1, mas adaptado ao tratamento de valores reais pertencentes ao intervalo $[0,1]$ (i.e, valores fuzzy) (Carpenter et al., 1991b). Mais detalhes a respeito deste modelo também podem ser encontrados nos trabalhos de (Frank et al., 1998) e (Baraldi and Blonda, 1999).

\subsubsection{Arquitetura da rede Fuzzy ART}

Os componentes da arquitetura da rede Fuzzy ART são: a camada $F_{1}$ (dividida em duas sub-camadas, entrada e interface, respectivamente, $F_{1(a)}$ e $\left.F_{1(b)}\right)$; a camada $F_{2}$ (cluster); a unidade de Reset; o conjunto de pesos, representados pela matriz W, que conecta a sub-camada $F_{1(b)}$ com a camada $F_{2}$. Entre as unidades da sub-camada $F_{1(a)}$ e as unidades da sub-camada $F_{1(b)}$ ocorre o pré-processamento dos dados de entrada. As unidades da sub-camada $F_{1}(b)$ também estão conectadas com a unidade de Reset. Isto está de acordo com a Figura (3.6). 


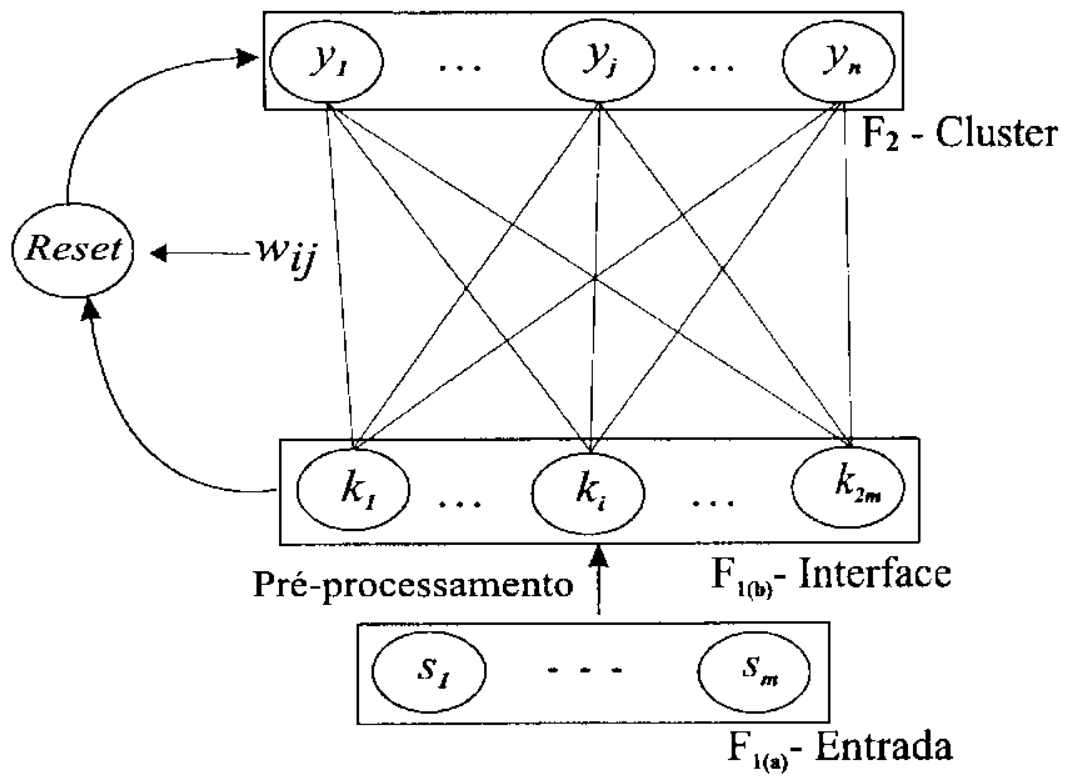

Figura 3.6: Arquitetura da rede Fuzzy ART.

\subsubsection{Algoritmo de treinamento da rede Fuzzy ART}

A rede Fuzzy ART, do mesmo modo que a ART2-A, implementa treinamento em modo rápido e em modo intermediário, apresentando ainda a opção de fast commitment e slow recode.

\subsubsection{Descriçāo do treinamento da rede Fuzzy ART}

O processo de treinamento da rede Fuzzy ART pode ser descrito assim como segue. O sinal de entrada migra da sub-camada $F_{1(a)}$ para a sub-camada $F_{1(b)}$, após sofrer um pré-processamento. Em seguida, o sinal atinge a camada $F_{2}$, reforçado pelo valor dos pesos contidos nas conexōes, e isto determina as ativaçōes em todas as unidades da camada $F_{2}$. Imediatamente após o estágio de busca, determina-se o neurônio com a maior ativação. O algoritmo segue avaliando se o neurônio vencedor, em $F_{2}$. é suficientemente similar ao padrāo de entrada $x$; se for verdadeiro, a rede entra em processo de atualização de pesos (ressonância).

\subsubsection{Resumo do algoritmo da rede Fuzzy ART}

No inicio do treinamento, os valores da matriz de pesos W são:

$$
w_{j 1}=\ldots=w_{j z}=1, \quad z=2 m
$$

e cada categoria, ou neurônio da camada $F_{2}$, deve ser iniciado na condição de uncommitted. Esta situaçāo será modificada, para committed, somente se o neurônio for selecionado para o estágio de Adaptaçāo. 


\begin{tabular}{|l|l|}
\hline \hline Parâmetros & Descriçấo \\
\hline$m$ & Número de componentes do vetor de entrada. \\
\hline$n$ & Número máximo de clusters que podem ser formados. \\
\hline$\varepsilon$ & $\begin{array}{l}\text { Parâmetro de escolha. Nos experimentos realizados } \\
\text { neste presente trabalho, foi utilizado um valor } \varepsilon \approx 0 .\end{array}$ \\
\hline$\beta$ & $\begin{array}{l}\text { Taxa de aprendizagem. Tem seus valores no intervalo } \\
{[0,1] . \text { Valor 1 determina treinamento no modo rápido; }} \\
\text { valor } \beta<1 \text { determina treinamento no modo interme- } \\
\text { diário. }\end{array}$ \\
\hline$\rho$ & $\begin{array}{l}\text { Parâmetro de vigilância. Determina quantos clusters } \\
\text { serāo formados. }\end{array}$ \\
\hline $\mathbf{W}$ & $\begin{array}{l}\text { Representa a matriz de pesos. Neste modelo, os pesos } \\
\text { top-down e bottom-up sāo iguais. Portanto, apenas } \\
\text { um destes conjuntos é usado. }\end{array}$ \\
\hline \hline
\end{tabular}

Tabela 3.5: Parâmetros da rede Fuzzy ART

- Inicialização: determine o tamanho das camadas $F_{1}$ e $F_{2}$, bem como os valores para os demais parâmetros da rede. Além disso, para cada vetor de entrada, é preciso ajustar todas unidades de $F_{2}$ para zero, ou seja, $y_{j}=0$, para todo $j$;

- Entrada: normalize o vetor de entrada s para que seus valores se encontrem no intervalo $[0,1]$. Para isto, a seguinte equaçāo é utilizada:

$$
\nu=\frac{\mathrm{s}}{\|\mathrm{s}\|}=\frac{\mathrm{s}}{\sqrt{\sum_{i=1}^{m} s_{i}^{2}}}
$$

onde $\nu$ é um vetor auxiliar, $\forall i s_{i} \geq 0$, e a norma Euclideana do vetor s é $\|\mathbf{s}\|>0$.

Em seguida, transforme cada vetor resultante $\nu m$-dimensional em um vetor $2 m$-dimensional $\left(k_{1}, \ldots, k_{2 m}\right)$. Isto é feito calculando-se o código complementar através da Equaçāo 3.29. Este cálculo é usado para evitar perda de informação e proliferaçāo de clusters em $F_{2}$ (Carpenter et al., 1991b) (Frank et al., 1998). Dessa forma, o vetor obtido após o estágio de pré-processamento, é dado por:

$$
\mathbf{k}=\left(\nu, \nu^{c}\right)=\left(\nu_{1}, \ldots, \nu_{n}, 1-\nu_{n}, \ldots, 1-\nu_{n}\right)
$$

- Busca: para cada vetor de entrada, calcule sua ativaçāo $y_{j}$ através de:

$$
y_{j}=\frac{\left\|\mathbf{k} \wedge \mathbf{w}_{j}\right\|_{2}}{\varepsilon+\left\|\mathbf{w}_{j}\right\|_{2}}
$$


sendo $\|\cdot\|_{2}$ a norma definida por:

$$
\|\mathbf{k}\|_{2}=\sum_{i=1}^{2 n} k_{i}
$$

que é a soma dos componentes de $\mathbf{k}$. O operador $\wedge$ é um operador fuzzy de conjunção (ou $A N D$ ), $\mathrm{e}$ isto significa que:

$$
a \wedge b \equiv \min (a, b)
$$

ou seja, o menor valor entre $a$ e $b$. Entāo para $\mathbf{k}$ e $\mathbf{w}_{\mathbf{j}}$, tem-se que:

$$
\mathbf{k} \wedge \mathbf{w}_{\mathbf{j}}=\left(k_{1} \wedge w_{i j}, \ldots, k_{i} \wedge w_{z j}\right), \quad z=2 m .
$$

O neurônio vencedor é indexado por $J$. Para encontrar este índice é necessário calcular a maior ativação de $y_{j}$ em $F_{2}$, que é o maior valor de $y_{j}$ considerando a Equação 3.30, ou seja,

$$
y_{J}=\max \left(y_{j}\right), \quad j=1 \ldots n .
$$

Se houver mais que um $y_{J}$, então utilize o menor indice $j$, mantendo-se a ordem de $j=1,2,3 \ldots n$. Caso todos os $y_{j}$ sejam iguais a -1 , significa que os neurônios estão inibidos, e aquele padrão de entrada não será aprendido durante aquele ciclo de treinamento.

- Comparação (ou Reset): após ter selecionado o índice do neurônio com o maior $y_{J}$, e se este for committed, então testa-se o sinal de Reset com:

$$
y_{J}>\rho .
$$

Se a desigualdade for verdadeira, entāo vá para o próximo estágio. Caso contrário, faça $y_{J}=-1$ (i.e., o neurônio ficará inibido durante a apresentaçāo daquele padrão), sendo necessário que se repita o estágio de Busca;

- Adaptação: atualize os pesos da rede de acordo com a seguinte regra:

$$
\mathbf{w}_{J}^{(N o v o)}=\beta\left(\mathbf{x} \wedge \mathbf{w}_{J}^{(\text {Velho })}\right)+(1-\beta) \mathbf{w}_{J}^{(\text {Velho })} .
$$

Na próxima seção sāo feitas algumas considerações a respeito dos modelos da família ART considerados relevantes no contexto deste trabalho. 


\subsubsection{Consideraçōes sobre os modelos ART estudados}

Vários estudos foram realizados para analisar o comportamento das RNAs ART que foram destacadas neste presente trabalho. Dentre os trabalhos que analisam o modelo ART2, pode-se destacar: (Hussain, 1993), (Fausett, 1994) e (Upal and Neufeld, 1996). No primeiro, o modelo ART2 é analisado como classificador, e a partir de seus experimentos, o autor observa algumas deficiências para este propósito, tais como:

- alta sensibilidade a pequenas mudanças no parâmetro de vigilância;

- sensibilidade na ordem de apresentação dos padrões de entrada.

Apesar de apontar algumas desvantagens do modelo, o autor destaca algumas caracteristicas que sāo üteis para o processo de classificação, e que faltam em RNAs adequadas para esta finalidade, como por exemplo a rede Multilayer Perceptron (MLP) (Rumelhart et al., 1986)). Tais características referem-se à capacidade de aprendizado on-line e incremental. No segundo trabalho a respeito do modelo ART2, o autor analisa a rede através de exemplos, tanto no modo de treinamento lento quanto no modo rápido, utilizando vários valores dos parâmetros de vigilância $\rho$ e de supressão de ruído $\theta$. As observações feitas a partir dos experimentos realizados foram:

- a rede é sensivel quanto à ordem de entrada dos padrōes de treinamento;

- no modo de treinamento lento, os pesos sāo atualizados de forma a procurar um valor médio (centróide) entre os padrōes classificados em cada cluster, o que não acontece no modo de aprendizado rápido. Neste último, após a apresentação de vários padrões, os protótipos associados a cada cluster armazenam o último padrão que foi classificado naquele cluster, perdendo quase todas as informações a respeito dos demais padrōes anteriormente atribuídos a aquele cluster. Por isso, o aprendizado modo rápido pode ser melhor aplicado em bases de dados pequenas;

- o modo de aprendizado lento é menos sensivel à ordem de entrada do que o modo de aprendizado rápido.

- a rede é sensivel ao parâmetro de supressão de ruido $\theta$, que pode ser determinante no processo de classificação.

No terceiro trabalho, os autores comparam o modelo ART2 com outros classificadores, tais como Autoclass e Snob. A partir dos experimentos, foram feitas algumas observações:

- a rede é sensivel à ordem de apresentação dos padrões de treinamento, o que leva a diferentes classificações;

- para padrões em ordem aleatória, o desempenho diminui com o aumento de volume dos dados; 
- a rede tem seu desempenho melhorado, considerando dados com alta dimensāo.

Nos experimentos analisados por Carpenter (Carpenter et al., 1991b), é mostrado que o desempenho, em termos de classificação, dos modelos ART2 e ART2-A são semelhantes.

O modelo de RNA ART2-A também foi analisado nos seguintes trabalhos: (Peper et al., 1993) e (Frank et al., 1998). No primeiro trabalho, o autores observam que 10 ciclos de treinamento são suficientes para estabilizar a rede $\mathrm{em}$ seus experimentos. Além disso, é observado que a classificaçāo desempenhada pela rede é sensível ao parâmetro $\theta$, pois, em comparaçāo com o modelo SOM, a rede ART2-A apresentou um desempenho melhor que aquela, sem a utilização deste mesmo parâmetro. Em contrapartida, com a utilizaçāo do parâmetro $\theta$, para o mesmo conjunto de dados, a rede ART2-A nāo superou o desempenho apresentado pela rede SOM.

No segundo trabalho, os autores analisam o modelo ART2-A, bem como algumas variaçōes deste modelo, tais como ART2A-C e ART2A-E. Nos experimentos realizados, foi observado que estes modelos são muito sensiveis ao parâmetro de vigilância $\mathrm{e}$ que o número de clusters pode variar com a ordem de apresentaçāo dos padrōes de treinamento. Apesar destas característica, observou-se que as redes AR'T2-A sāo mais coerentes na representação dos clusters com o espaço de padrões do que o modelo Fuzzy ART para dados com altas dimensões. Além disso, as redes ART2-A sāo menos sensiveis a ruídos nos padrões de entrada, e podem ser melhor aplicadas a tarefas gerais de classificação do que o modelo Fuzzy ART.

Dentre várias análises existentes na literatura a respeito do modelo Fuzzy ART, foram considerados, neste presente trabalho, os seguintes: (Frank et al., 1998) e (Baraldi and Alpaydin, 2002a). As conclusões a respeito das potenciais fraquezas do modelo podem ser resumidas nos seguintes itens:

- a rede é dependente da ordem de entrada dos padrōes de treinamento;

- a rede é altamente sensivel a ruídos no conjunto de dados de treinamento. Isto significa que a rede pode ser afetada por sobre-ajustamento (overffiting) no conjunto de pesos, fazendo com que aconteça proliferaçāo de clusters na camada de saida;

- nos experimentos foi observado um certo grau de incoerência no mapeamento dos clusters para dados com alta dimensão;

Tais considerações a respeito destes estudos foram levadas em conta para a realização e avaliaçāo dos experimentos feitos no decorrer deste presente trabalho. Os resultados referentes a tais experimentos são descritos e avaliados no Capítulo 5.

\subsubsection{Aplicaçōes das redes ART}

Os modelos da família ART foram acrescidos de uma série de novos conceitos para a teoria original e têm compreendido estes principios como sistemas quantitativos 
que podem ser aplicados a problemas que envolvem aprendizado, reconhecimento e previsão. Dentre as aplicaçōes das redes ART de paradigma não-supervisionado e as de paradigma supervisionado, pode-se citar: sistema de recuperação de partes de Boeing (Caudell et al., 1994); controle motor sensorial de robôs (Bachelder et al., 1993); navegação de robôs (Racz and Dubrawski, 1995); visāo computacional (Caudell and Healy, 1994); reconhecimento de objetos 3D (Seibert and Waxman, 1992); reconhecimento de face (Seibert and Waxman, 1993); processamento de imagens médicas (Soliz and Donohoe, 1996); reconhecimento de ondas de eletrocardiograma (Ham and Han, 1996) (Suzuki, 1995); reconhecimento automático de alvos (Bernardon and Carrick, 1995) (Waxman et al., 1995) (Moya et al., 1993); previsão da estrutura secundária da proteina (Mehta et al., 1993); verificação de assinaturas (Murshed et al., 1995); reconhecimento de caracteres chineses (Gan and Lua, 1992) (Kim et al., 1995), análise de partituras musicais (Perrott and Gjerdigen, 1999), e segmentação de imagens (Nakamura and Ogasawara, 1999) e (Oliveira et al., 2002).

\subsection{Considerações finais}

Este capitulo teve como objetivo de apresentar a idéia principal que fundamenta os modelos de RNAs da familia ART. Dentre os vários modelo ART existentes na literatura, somente os modelos ART relevantes para este presente trabalho foram apresentados, destacando-se suas características, arquiteturas e algoritmos de treinamento. Além disso, também foi destacados vários estudos realizados a respeito destes modelos.

No Capítulo 5 sāo realizadas análises e comparações entre os três modelos ART destacados neste capitulo, quanto às suas capacidades para detectar agrupamentos de dados, considerando diferentes bases de dados.

Com relação ao conteúdo apresentado a respeito das redes da familia ART, houve a preocupação em detalhar o funcionamento modelos que foram estudados neste trabalho para implementaçāo em uma linguagem de programação qualquer.

No próximo capítulo é realizado um levantamento a respeito dos principais métodos existentes para recuperação de informações, destacando-se o MAEM Slim-Tree 


\section{CAPÍTULO \\ Recuperação de Informaçōes}

\subsection{Introdução}

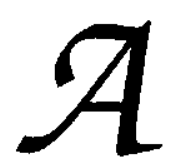

recuperaçāo de informaçōes é um problema fundamental em ciência da computação, estando presente, mesmo que indiretamente, na maioria das aplicaçōes nesta ârea. Aplicaçōes simples resumem-se a problemas de busca simples, enquanto que aplicaçōes complexas exigem, em geral, métodos de busca mais sofisticados. Os bancos de dados tradicionais sāo construídos baseados no conceito de busca exata, sendo divididos em registros que possuem uma chave ímpar que serve para comparação. As consultas nestes bancos de dados retornam toda a informação contida nos registros cuja chave é exatamente igual à chave submetida à busca. Consultas mais sofisticadas como consultas por abrangência ${ }^{1}$, usando chaves numéricas ou prefixos alfabéticos, baseiam-se em um procedimento que verifica se duas ou mais chaves sāo ou nāo iguais. Mesmo recentemente, quando os bancos de dados adquiriram a habilidade de armazenar novos tipos de dados, tais como imagens e audio digitalizado, as buscas por informaçōes ainda são feitas de forma exata.

Com a evolução da tecnologia de comunicação, e conseqüente aumento da quantidade de informações a serem armazenadas nos sistemas de computação, surgiram novos repositórios de informação. Uma vez que novos tipos de informação tais como texto, imagens, audio e video têm sido armazenados nestes repositórios, nāo é mais interessante estruturar as informações em chaves e registros devido ao elevado custo computacional de se manipular este tipo de informação. Além disso, este tipo de organizaçāo dos dados dificulta a realizaçāo do processo de data mining, pois este

\footnotetext{
${ }^{1}$ Do original $\mathrm{cm}$ inglès, range queries
} 
requer acesso à base de dados através de qualquer campo, e não somente aqueles designados como campos chaves. Esta situação conduziu a busca de novos modelos de repositórios de dados não-estruturados (Chávez et al., 2001).

O cenário descrito acima requer algoritmos de busca mais genéricos do que aqueles apresentados nos modelos de bancos de dados tradicionais. Para tanto, foi então introduzido o conceito de busca por similaridade ou busca por proximidade, o que significa buscar elementos que são semelhantes ou próximos a um certo elemento que é usado como referência. O conceito de similaridade entre os elementos é modelado por uma funçāo de distância e o conjunto de objetos ${ }^{2}$ que será analisado constitui o espaço métrico.

Este capítulo faz uma breve discussão a respeito de espaço métrico, na Seçāo 4.2. Os conceitos dos tipo de buscas por similaridade mais comuns, e que sāo usados neste trabalho, sāo apresentados na Seção 4.2.1. Um breve resumo a respeito dos métodos de acessos a dados multi-dimensionais é apresentado na Seção 4.3. Na Seçāo 4.3.2, sāo descritos de forma sucinta alguns exemplos de Métodos de Acesso a dados no Espaço Métrico (MAEMs), dentre os quais se destaca o método Slim-Tree, que é de fundamental importância dentro do contexto deste trabalho.

\subsection{Espaço métrico}

Há alguns trabalhos que abordam os conceitos, definiçōes e formas de busca um espaço métrico. Neste trabalho, o estudo feito a respeito do espaço métrico teve como base os trabalhos de (Brin, 1995), (Ciaccia et al., 1997) e (Chávez et al., 2001).

Um conjunto de objetos válidos $\mathbb{X}$ é chamado de espaço métrico se para qualquer par de pontos $x, y \in \mathbb{X}$ está associado um número real $d(x, y)$, sendo este chamado de distância de $x$ a $y$, e $d$ é denominada uma métrica ou funçāo de distância que rege o espaço métrico. Na definiçāo de espaço métrico, a funçāo de distância usada deve possuir as cinco propriedades seguintes:

$$
\begin{array}{lll}
\text { (p1) } \quad \forall x, y \in \mathbb{X}, d(x, y) \geq 0 & \text { positiva; } \\
\text { (p2) } \quad \forall x, y \in \mathbb{X}, d(x, y)=d(y, x) & \text { simétrica; } \\
\text { (p3) } \quad \forall x \in \mathbb{X}, d(x, x)=0 & \text { reflexiva; }
\end{array}
$$

e na maioria dos casos,

$$
\text { (p4) } \forall x, y \in \mathbb{X}, x \neq y \Rightarrow d(x, y)>0 \quad \text { estritamente positiva. }
$$

No caso particular, em que a função distância não atende à propriedade $(p 4)$, o conjunto é chamado de espaço semi-métrico ou pseudo-métrico. As propriedades de similaridades enumeradas anteriormente asseguram a consistência da funçāo

\footnotetext{
${ }^{2}$ Neste presente trabalho, o significado da palavra objeto diz respeito a qualquer dado indexado por uma estrutura de dados qualquer.
} 
distância e não podem ser usadas para assegurar comparaçôes em uma busca por similaridade. Para que, definitivamente, a função distância $d$ seja considerada uma métrica, é necessário que satisfaça a seguinte propriedade:

(p5) $\forall x, y, z \in \mathbb{X}, d(x, y) \leq d(x, z)+d(z, y)$ desigualdade triangular,

Como um exemplo de espaço métrico, pode-se considerar um par formado por um conjunto de palavras da lingua portuguesa, denotado por $\mathbb{U}$, e pela métrica de Lcvenshtein ou $L_{E d i t}(x, y)$ usada como função de distância $d()$. Considerando duas palavras $x$ e $y$, a distància $L_{E d i t}(x, y)$ retorna a quantidade de letras que precisam ser substituídas, removidas e inseridas em $x$ para convertê-la em $y$. Por exemplo, $L_{\text {Edit }}($ mesa, velas $)=3$.

Em muitas aplicaçōes envolvendo espaço métrico, o cálculo da métrica $d$ é muito custoso. Conseqüentemente, o número de cálculos de distância determinará a medida de complexidade computacional do algoritmo. As métricas mais comuns são as da família $L_{s}$ (ou Minkowski), definidas pela equaçāo:

$$
L_{s}\left(\left(x_{1}, \ldots, x_{k}\right),\left(y_{1}, \ldots, y_{k}\right)\right)=\left(\sum_{i=1}^{k}\left|x_{i}-y_{i}\right|^{s}\right)^{1 / s} .
$$

Dentre as métricas da família $L_{s}$, as mais conhecidas são: a métrica da Chebychev (ou Infinity) ( $\left.L_{0}\right)$, a métrica de Manhattan $\left(L_{1}\right)$ e a métrica Euclideana $\left(L_{2}\right)$. A Figura 4.1 mostra as diferentes regiões de cobertura possiveis para um objeto $O$, dado um raio $r$ que pode ser calculado a partir destas três métricas. A métrica $L_{1}$ corresponde ao somatório do módulo das diferenças entre as coordenadas. Na representação da métrica $L_{2}$, o conjunto de pontos de mesma distāncia para $L_{2}$ forma uma circunferência.

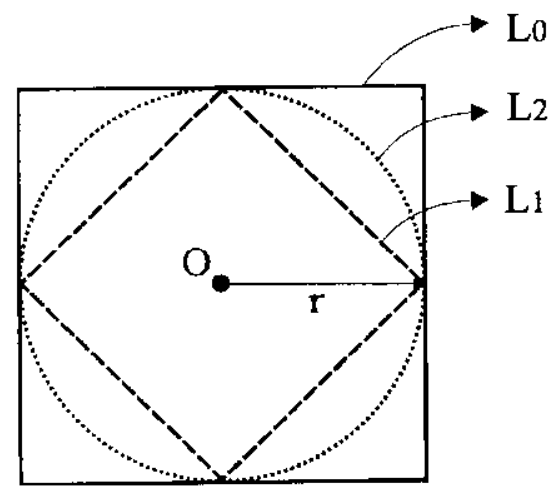

Figura 4.1: Regiões de cobertura de (3) três métricas familia $L_{s}$.

Uma outra é a métrica utilizada é $L_{\infty}$ (ou $L_{0}$ ), que corresponde a calcular o limite da Equação 4.4 quando $s$ tende ao infinito. Neste caso, o resultado da consulta é aquele item cuja distância entre dois pontos é a máxima diferença entre as coordenadas:

$$
L_{\infty}\left(\left(x_{1}, \ldots, x_{k}\right),\left(y_{1}, \ldots, y_{k}\right)\right)=\max \left|x_{i}-y_{i}\right| \forall i / 1 \leq i \leq k .
$$


Uma busca com a métrica $L_{\infty}$ corresponde a uma consulta clássica, na qual o conjunto de pontos a ser recuperado é aquele que se encontra dentro dos limites de um hiper-retângulo, assim como mostra a Figura 4.1. Além das métrica citadas aqui, outras métrica podem ser obtidas a partir da Equação 4.4.

Em muitas aplicações, o espaço métrico é realmente um espaço vetorial, conseqüentemente os dados são coordenadas de pontos $k$-dimensionais, ou seja, $k$ coordenadas de valores reais $\left(x_{1}, \ldots, x_{k}\right)$, e a similaridade ê interpretada geometricamente. Em outras palavras, se os objetos do espaço métrico $(\mathbb{X}, d)$ são tuplas de números reais, então este mesmo par, que define o espaço métrico, pode ser chamado de espaço vetorial com dimensāo finita. Um espaço vetorial $k$ dimensional é um caso particular de espaço métrico. Na Seçāo 4.3, serāo apresentados alguns métodos que interpretam os objetos de forma espacial, tentando aproveitar a propriedade geometrica dos dados.

\subsubsection{Consultas por similaridade}

Há basicamente dois tipos de operadores de consultas por similaridade que podem ser realizadas:

- Consulta por abrangência (Range Query ou (RQ)): uma $R Q\left(O_{q}, r_{q}\right.$ ) busca lou recupera) todos os objetos menor ou igual a uma distância máxima $r_{q}$ (raio de abrangência) a partir de um objeto de referência $O_{q}$;

- Consulta por $k$-vizinhos mais próximos ( $k$-nearest neighbor query) ou $k$-NN: uma $k-N N\left(O_{q}, k\right)$ busca (ou recupera) $k$ objetos mais próximos ao objeto de referência $O_{q}$.

A Figura 4.2 mostra um exemplo de consulta por abrangência. $O$ par $\left(O_{q}, r_{q}\right)$ com $O_{q}$ representando um elemento de referência pertencente ao espaço métrico $\mathbb{X}$, e $r_{q}$ um número real que indica o raio de de abrangência. O conjunto $\left\{u \in \mathbb{X}, d\left(O_{q}, r\right) \leq r\right\}$ é o resultado desta busca, ou seja, os seguintes objetos: $u 3, u 9, u 5, u 13, u 12$ e $u 1$.

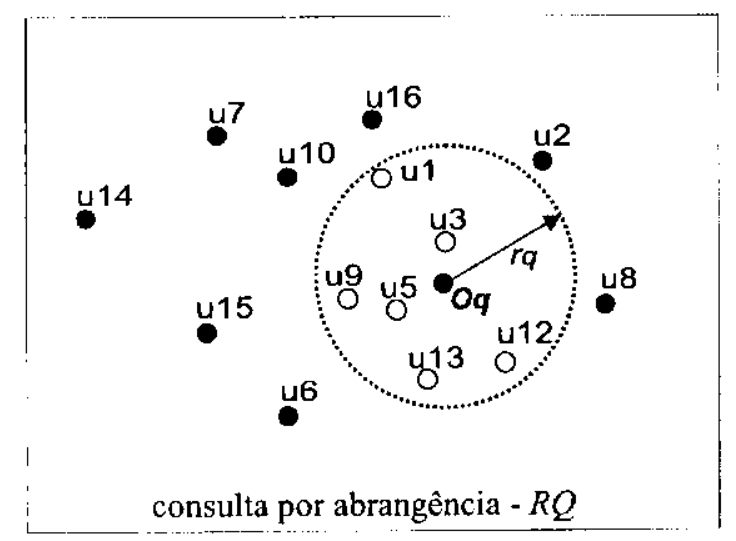

Figura 4.2: Exemplo de consulta por abrangência.

A Figura 4.3 mostra um exemplo do tipo de busca por $k$-vizinhos mais próximos. A consulta, neste caso, é representada pelo par $\left(O_{q}, k\right)$, em que $O_{q}$ representa um 
elemento de referência que pertence ao espaço métrico $\mathbb{X}$ e $k$ é um número real que indica o número de objetos mais próximos a $O_{q}$ que se deseja buscar. O resultado da busca com $k=2$ (2-vizinhos mais próximos) sāo os seguintes objetos: $u 3, u 5$. Se $k=3$, o resultados seria os mesmos dois objetos $(u 3, u 5)$ mais um terceiro objeto selecionado de acordo com uma política que deve ser definida no caso de empate. Neste mesmo exemplo, tem-se o empate de três objetos $(u 9, u 13 e u 12)$, ou seja, com a mesma distância em relação $\left(O_{q}\right)$. Como política de desempate pode-se selecionar aletoriamente apenas um dos objetos empatados a partir de uma lista de empates.

Na próxima seção será apresentada uma revisāo dos principais métodos existentes para indexação de dados multi-dimensionais.

\subsection{Métodos de acesso a dados multi-dimensionais}

Realizar consultas por similaridade não é uma tarefa simples devido, principalmente, ao tempo gasto em comparações de objetos, e ao elevado número de acessos a dispositivos de armazcnamento (Chávez et al., 2001). Os dados de tipos complexos (ou dados multimidia) requerem mais espaço do que os dados de tipos convencionais (texto), conseqüentemente o número de acessos a disco é maior naqueles do que nestes. Portanto, a estrutura de armazenamento deve ser mais sofisticada ao se trabalhar com dados multimídia. Além disso, é importante considerar que comparar dois dados desta natureza pode ser uma operação muito custosa, sendo conseqüentemente responsável por uma porcentagem considerável no tempo total da consulta.

Uma das maneiras de simplificar o processo de indexação dos dados multimídia é através da aplicação de técnicas de extraçāo de características, tais como, Fastmap (Faloutsos and Lin, 1995), Análise de Componentes Principais (PCA, Principal Component Analysis) (Ng and Sedighian, 1996), (Johnson and Wichern, 1998). Espera-se que as características extraídas representem, de forma confiável, o objeto original. Após extrair as características dos dados multimidia a representação destes passa entāo a ser feita por vetores de características, ou seja, representações

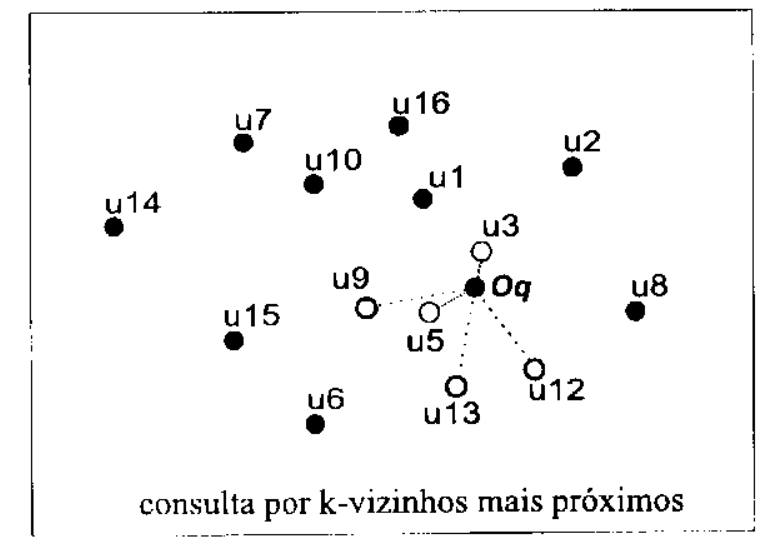

Figura 4.3: Excmplo de consulta por $k$-vizinhos mais próximos. 
multi-dimensionais. A indexação destes dados pode então ser melhor representada através dos Métodos de Acesso Espacial (MAEs) ${ }^{3}$ e dos Métodos de Acesso Métrico ${ }^{4}$.

Antes de fazer uma discussão a respeito dos MAEs, é importante, primeiramente, considerar algumas estruturas de dados clássicas que, mesmo projetadas para trabalhar com dados de uma dimensão, inspiraram o projeto de outras estruturas classificadas como MAEs e MAMs. Uma destas estruturas de dados clássicas bastante conhecida é a árvore binária de busca. Nesta estrutura, cada nó possui no máximo duas ramificações, e é construída de forma que os elementos com valores menores sempre sāo inseridos à esquerda e os elementos com valores maiores sempre à direita. Desta forma, esta estrutura garante que o elemento mais a esquerda na árvore é o de menor valor, e o elemento mais a direita na árvore é o de maior valor. Na Figura 4.4 pode-se observar a posiçāo onde seria inserida uma nova chave em uma árvore que tem o elemento $s$ na raiz. Os elementos menores ou iguais a $s$ sāo inseridos na sub-árvore da esquerda e os maiores na sub-árvore da direita.

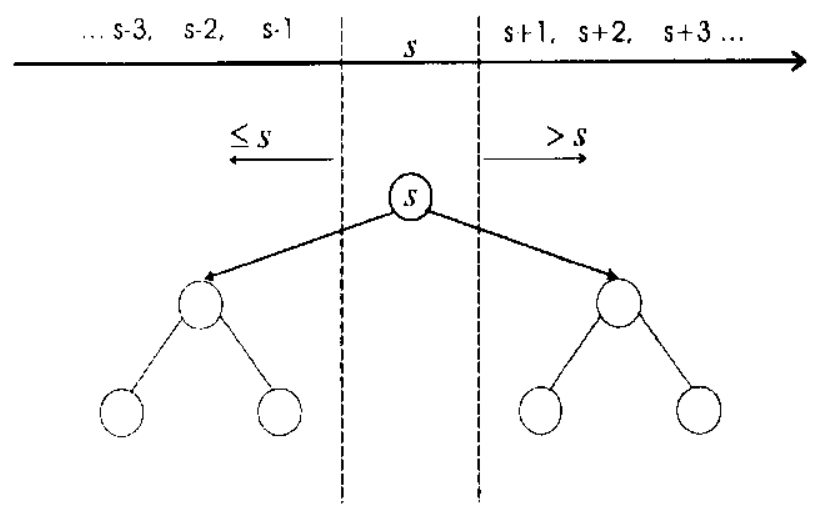

(a) Esquerda e Direita

Figura 4.4: Critério de inserção em uma ârvore binária de busca.

Este tipo de estrutura é apropriada para realizar consultas de forma exata (exact matching). Quando uma busca nesta estrutura é solicitada, a chave é comparada com a raiz e, dependendo da relação de ordem em relaçāo a esta (maior ou menor), o procedimento será repetido até encontrar a chave solicitada ou alcançar um nó folha. Uma busca em uma árvore binária, no caso médio, é de ordem logarítmica; por outro lado, no pior caso, a complexidade de busca para encontrar o maior ou o menor elemento na árvore é sempre $O(h)$, onde $h$ é a altura ${ }^{5}$ da árvore.

Outra estrutura de fundamental importância é a ârvore $B$ (BTree) (Bayer and McCreight, 1972) (Comer, 1979), sendo esta estrutura considerada padrão e base para diversos métodos de acesso a dados multi-dimensionais. A BTree é uma estrutura de árvore balanceada por altura, projetada para trabalhar com dados unidimensionais e

\footnotetext{
${ }^{3}$ Do original em inglês, Spatial Access Methods (SAM)

${ }^{4}$ Do original em inglês, Metric Access Methods (MAMs)

${ }^{5} \mathrm{~A}$ altura de uma árvore é o máor caminho que pode ser feito a partir da raiz até as folhas (nós que não tem ramificaçōes).
} 
em grandes volumes, isto porque ela foi desenvolvida para trabalhar com dispositivos de armazenamento secundários, tais como discos magnéticos, caso não seja desejado ou viável manter a estrutura inteira em armazenamento primários (memória RAM-Random Access Memory). Estas estruturas visam otimizar as operaçōes de entrada-saída em discos, jả que o tempo de acesso a informaçōes em um disco é prejudicado principalmente pelo tempo de posicionamento do braço de leitura. Uma vez que o braço esteja posicionado no local correto, a leitura pode ser feita de forma bastante rápida. Desta forma, é interessante minimizar o número de acessos a disco. A árvore BTree difere, em termos estruturais, da árvore binária convencional, pois é um exemplo de árvore multi-vias ${ }^{6}$, além disso ela é construída de forma ascendente, ou seja, das folhas para a raiz. O processo de construção da árvore se inicia com um nó, que receberá elementos. Guando nāo houver mais espaço para inserir elementos, este nó se dividirá em dois novos nós ligados a um outro nó contendo um elemento central. Este processo se repete caso o nó central (nó pai) também estiver totalmente ocupado. O algoritmo de construção garante que na sub-ärvore esquerda de um nó nunca existirá uma chave maior que aquela contida no próprio nó, e que na sub-árvore direita nunca existirá uma chave menor do que este. Desta forma, o conjunto de dados é dividido em subconjuntos disjuntos, e a interseç̧ão de sub-árvores do mesmo nivel sempre é vazia. Na Figura 4.5, observa-se um exemplo deste tipo de árvore. Mais detalhes sobre a estrutura da BTree e outras estruturas podem ser encontrados em (Folk et al., 1998).

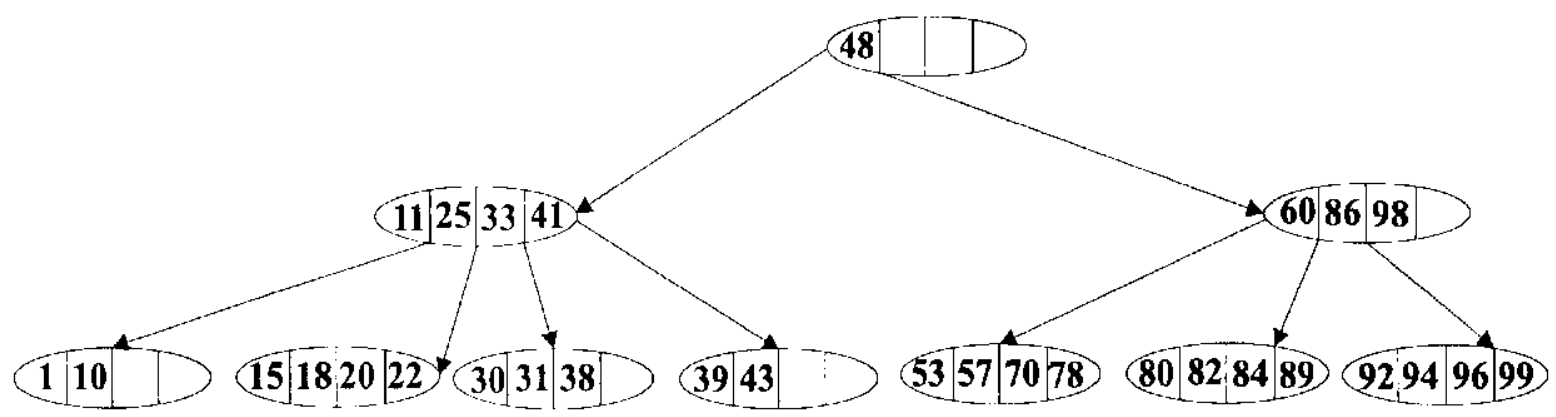

Figura 4.5: Exemplo de uma ärvore B (B-Tree)

\subsubsection{Métodos de acesso a dados espaciais}

Os métodos descritos, até agora, sāo estruturas clássicas e muito úteis para dados simples, isto é, de uma única dimensāo. Porém, para indexaçāo de chaves compostas por mais de um valor, ou dados multi-dimensionais, existem outros métodos tais como os MAEs, que são estruturas de busca em espaços vetoriais. Os MAES fazem uso de informações como coordenadas espaciais para agrupar e classificar pontos no espaço. Um dos MAEs mais conhecidos é a $k$ - $d$-Tree, sendo uma estrutura de árvore de busca binária para indexar coordenadas de pontos ou dados compostos, dividindo

\footnotetext{
${ }^{6}$ Isto significa que em cada nó contém mais que um elemento.
} 
o espaço em $k$ dimensōes usando diferentes coordenadas, uma de cada vez em cada nivel da árvore. A estrutura $k$ - $d$-Tree também foi projetada para funcionar usando memória primária (RAM), portanto, inadequada a grande volumes de dados. Uma das desvantagens desta estrutura é a sensibilidade desta com relação à ordem na qual os pontos são inseridos. Outra desvantagem é que, para certas distribuições dos dados, nāo é possivel encontrar um hiperplano que divida igualmente os pontos (Lomet and Salzberg, 1989). Neste caso, um esquema mais flexível de divisāo do espaço pode resolver o problema por completo (Fuchs et al., 1980).

O MAE $k$ - $d$-Tree bem como seus variantes BSP-Tree (Fuchs et al., 1980) e QuadTrees (Finkel and Bentley, 1974), (Samet., 1995) sāo estruturas projetadas para trabalhar usando dispositivos de armazenamento primário (memória RAM). Na tentativa de expandir a aplicação dos MAEs a grandes volumes de dados, Robinson (Robinson, 1984) propôs a $k$-d-B-Tree. Esta é uma estrutura hierárquica em forma de árvore multi-vias, isto é, cada nó da árvore é capaz de armazenar mais de um elemento, incorporando algumas propriedades da $k$ - $d$-Tree e da estrutura $B$-tree (Comer, 1979) para gerenciar pontos em coordenadas multi-dimensionais. Assim como a $k$ - $d$-Tree, a $k$ - $d$-B-Tree divide o espaço $\mathrm{cm} k$ regiōes (hiperplanos) que possuem representações nos nós internos da estrutura. As regiōes correspondentes aos nós que estāo no mesmo nivel na árvore sāo mutuamente disjuntas. Cada nó folha da estrutura corresponde a uma partiçāo dos nós internos e armazena os dados contidos na respectiva partição. Alêm disso, a $k$ - $d$-B-Tree ć uma estrutura perfeitamente balanceada que se adapta bem a distribuiçāo dos dados. Na Figura 4.6, pode-se observar um exemplo de $k$-d-B-Tree.

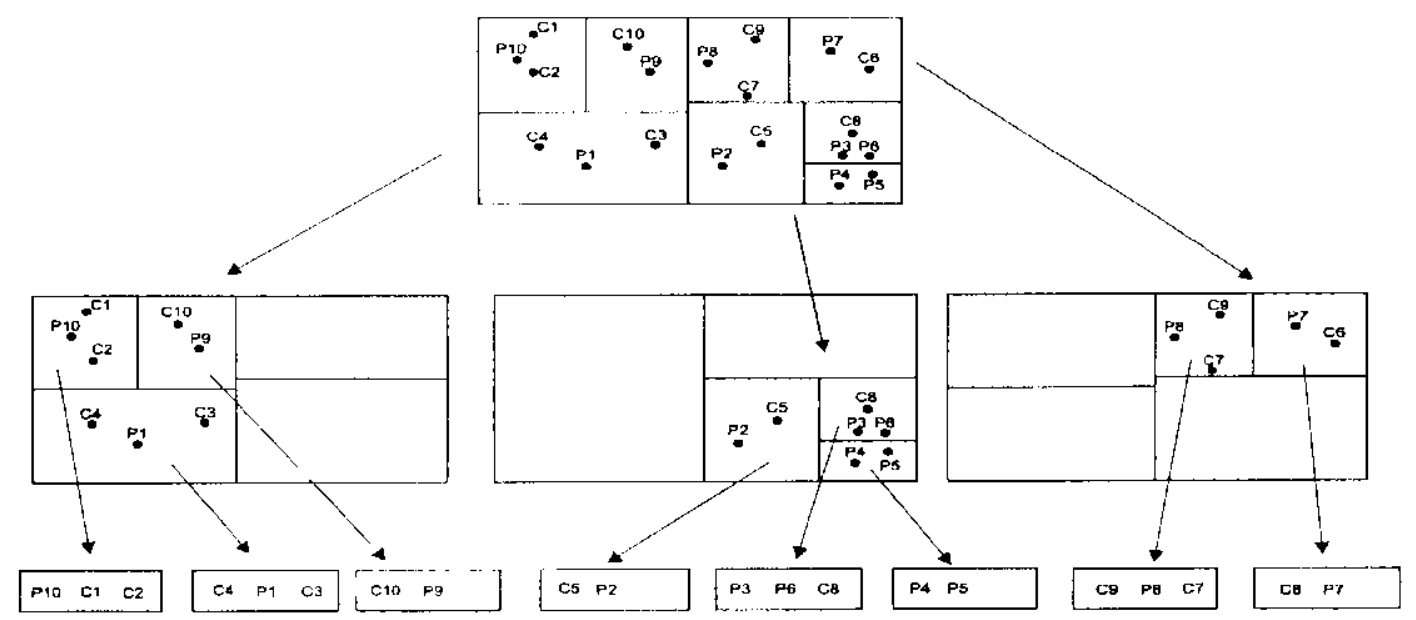

Figura 4.6: Exemplo de uma estrutura K-d-B-Tree.

Para inserir uma nova coordenada (ou ponto) na estrutura, primeiro é feita uma busca para localizar a partiçāo mais à direita do nó. Caso ela não esteja cheia, o ponto é inserido. Por outro lado, quando o nó não possui espaço suficiente para receber mais elementos, é alocada uma nova página ocorrendo a divisão da partição por um hiperplano. Em seguida, os pontos sāo divididos entre as duas páginas, 


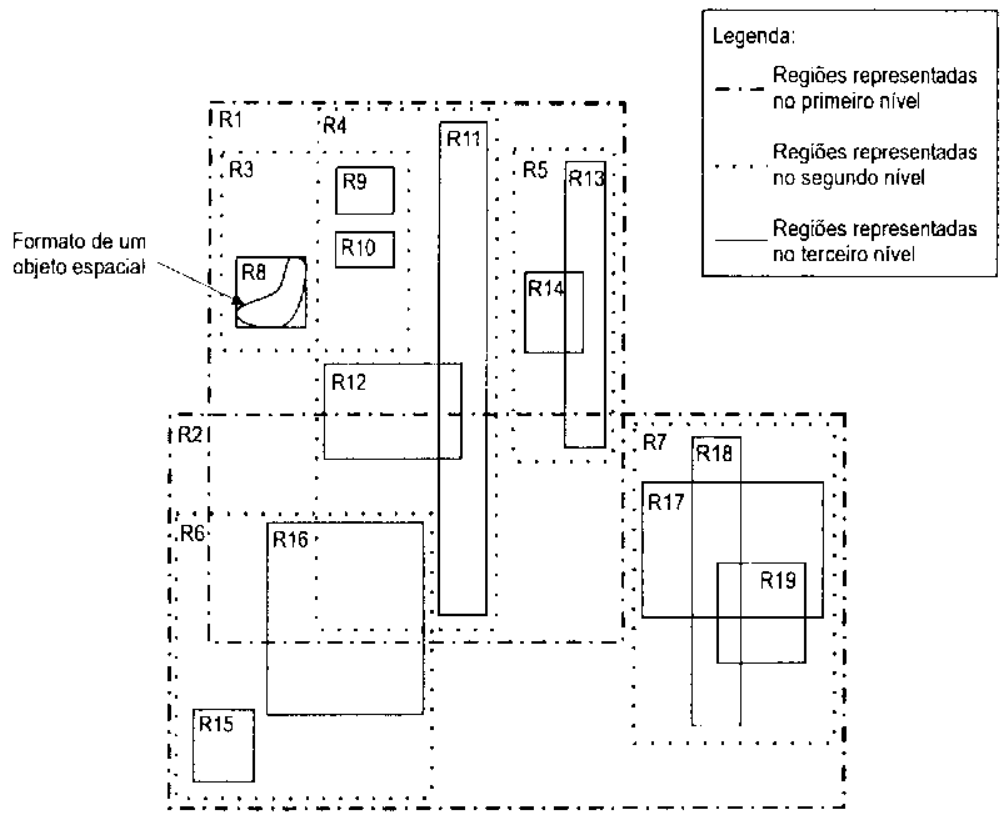

Figura 4.7: Representaçāo de uma estrutura R-Tree através de MBRs.

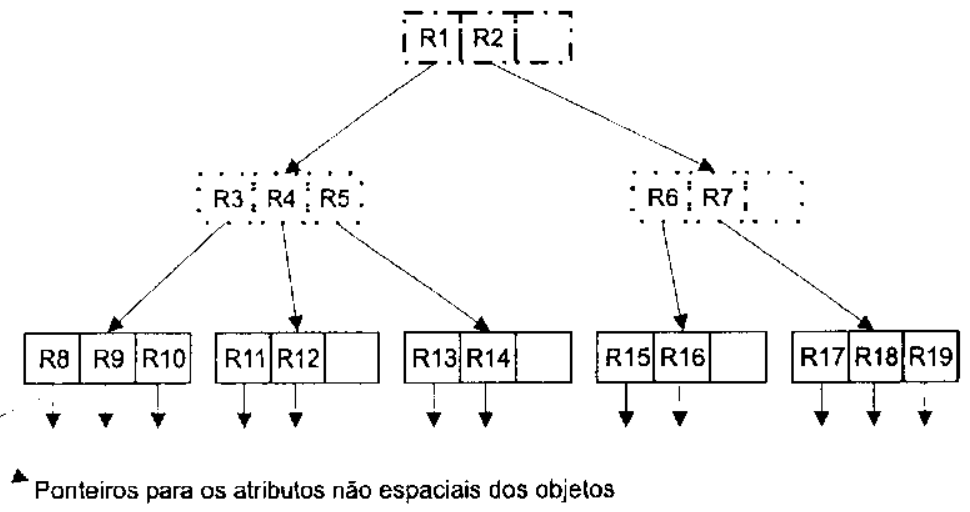

Figura 4.8: Representação uma estrutura $R$-Tree em forma árvore segundo a Figura 4.7 .

um ponto pertence à mais de uma intersecçāo de MBRs, nenhuma das sub-árvores representadas pelos MBRs podem ser descartadas. Isto faz com que mais de um caminho tenha que ser verificado para buscar um determinado objeto, implicando em um número maior de acessos a memória secundária. Uma abordagem muito útil relacionada à consultas do tipo $k$-vizinhos mais próximos utilizando $R$-Tree pode ser encontrada em (Roussopoulus et al., 1995).

Na tentativa de resolver essas limitaçōes da $R$-Tree, outras estruturas foram projetadas com o intuito de melhorar o seu desempenho. As mais conhecidas são $R^{*}$-Tree (Beckmann et al., 1990) e $R^{+}$-Tree (Sellis et al., 1987). Uma outra estrutura que evoluiu da $R$-Tree é a $X$-Tree (Berchtold et al., 1996). Esta estrutura define um super - $n$ (super node) para tentar resolver o problema da sobreposição de MBRs. Se o índice de sobreposição é alto, os nós são concatenados em um super - $n$ de tamanho variável (geralmente um múltiplo do tamanho original). Essa abordagem 
é interessante só se for possível acessar o disco com páginas de tamanho variável. Dessa forma, há realmente uma diminuiçāo no número de acessos a disco. Se isso nāo acontecer, o número de acessos aumenta e o desempenho pode ser próximo ao da $R$-Tree. Existem outras variaçōes da $R$-Tree original que podem ser observadas com maiores detalhe em (Hellerstein et al., 1995) e (Papadias et al., 1999).

Infelizmente, os MAEs são muito sensiveis a dimensão do espaço vetorial, isto significa que os algoritmos que buscam pontos mais próximos têm uma dependência da dimensão do espaço (Maldição da Dimensionalidade) (Chávez et al., 2001). Para superar esta limitação algumas técnicas foram propostas para reduzir a dimensāo dos dados tais como: a transformada de Karhunen-Loève ('K-L') (Duda and Hart, 1973) (Fukunaga, 1990), Decomposição de Valor Singular Singular Value Decomposition (SVD) (Strang, 1980) (Press et al., 1988) (Golub and Loan, 1989) e FastMap (Faloutsos and Lin, 1995).

\subsubsection{Métodos de Acessos a dados no Espaço Métricos}

O princípio básico dos métodos criados para indexação no espaço métrico é utilizar a distância entre dois elementos para decidir a posição deles na estrutura. Desta forma, é possivel formar estruturas hierárquicas, nas quais cada nó possui um objeto representativo, ou ponto de referência, para todo o conjunto ao qual ele pertence, e cada um dos elementos inseridos naquele conjunto tem a distância em relação ao seu representativo.

O primeiro trabalho encontrado na literatura envolvendo a indexaçāo de dados métricos é o de Burkhard e Keller (Burkhard and Keller, 1973). Nesse trabalho os autores propõem uma estrutura, em forma de uma árvore hierárquica e multi-vias, também chamada na literatura de BKT. O objetivo desta estrutura é permitir que possa encontrar o melhor par entre duas palavras, dada uma consulta textual em un arquivo ASCII. Para comparar as palavras, a métrica utilizada retorna como valor da distância, valores inteiros. A construção desta estrutura é baseada em pivôs, ou seja, todo elemento colocado na raiz de uma sub-árvore é chamado de pivô, sendo ele é usado para divisāo espacial dos objetos. Para construir esta estrutura, um objeto $p \in \mathbb{U}$ escolhido de forma aleatória é colocado na raiz da árvore. Assim. defini-se $\mathbb{U}_{i}=\{u \in \mathbb{U}, d(u, p)=i\}$ como sendo o conjunto de todos os objetos que estão à distância $i>0$ em relação à raiz, e este processo se repete até que o número de objetos nāo seja maior do que o número permitido pelo bucket ${ }^{7}$ da estrutura. Para efetuar uma busca, do tipo Range Guery, em uma BKT, primeiramente, é necessário fornecer um objeto $q$ e uma distância $r$, que è o raio de cobertura. A busca começa na raiz da estrutura e segue por todos os filhos $i$, tal que $d(p, q)-r \leq i \leq d(p, q)+r$, e continua recursivamente. Se uma folha (ou Bucket de um ou mais elementos) for alcançada então compara-se seqüencialmente todos os seus elementos. Cada vez que

\footnotetext{
${ }^{7}$ estrutura que representa os nós árvore e que armazena os objetos que têm a mesma distância em relação ao seu representativo.
} 
é feita uma comparação com os pivôs ou com os elementos de um bucket, recupera-se os elementos onde $d(q, u) \leq r$, ou seja, os elementos cuja distância é menor ou igual ao raio de cobertura.

A partir do trabalho de Burkhard e Keller surgiram outros, tambêm relacionados à funçōes distâncias que retornam valores discretos, tais como Fixed-Query Trees (ou FQTs) de (Baeza-Yates et al., 1994), que é uma estrutura de ârvore semelhante à BKT, mas, diferente com relação à organizaçāo dos pivôs, pois, na FQT, há um pivô diferente por nível, ou seja, o mesmo para todos os nós em cada nível, e os elementos reais estão armazenados nas folhas. A vantagem desta construção é que as consultas são guardadas durante backtracking que ocorre na árvore; se, durante as consultas, visita-se vários nós do mesmo nivel, então não é necessário que se faça mais que uma comparação, pois os pivôs que estão naquele nivel sāo iguais. Esta característica diminui a complexidade computacional em relação à FQT. Uma outra estrutura, a Fixed-Height FGT(ou FHQTs), também proposta em (Chávez et al., 2001), é uma variante da FQT, mas com a principal diferença de que todos os nós folhas estāo na mesma altura $h$, e, diferente da estrutura BKT, não se considera o tamanho do Bucket e, semelhante à FQT, utiliza-se um pivô diferente por nível. Outra estrutura, as FQA Fixed Queries Array (Chávez et al., 1999), não sāo árvores, mas sim representaçōes compactas da FHQT em forma de array. O tipo de organizaçāo das estruturas FGAs faz com que ela possua uma eficiência computacional maior que as FHQT. A representaçāo destas estruturas está na Figura 4.9.

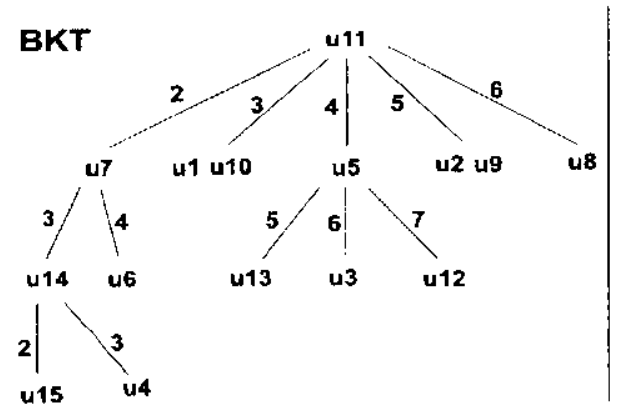

(a) $b=2$

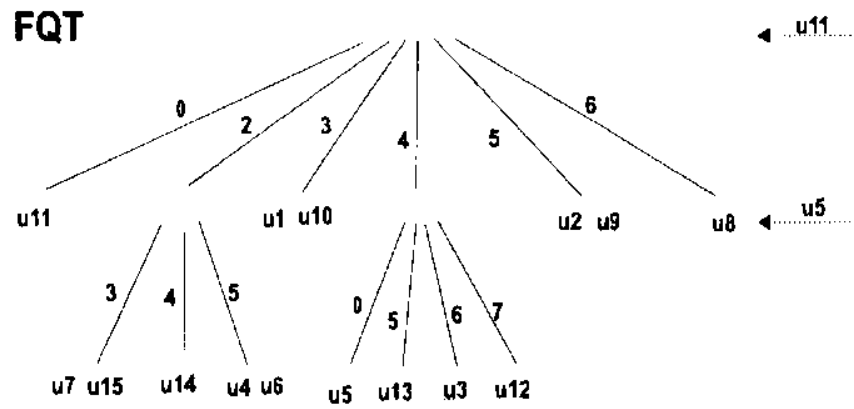

(b) $\mathrm{b}=2$

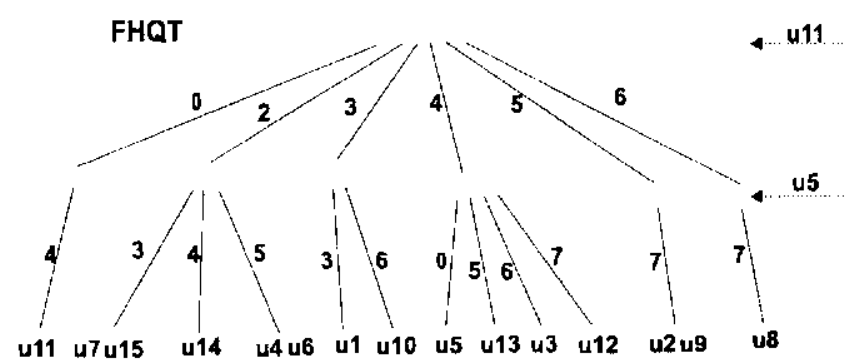

(c) $\mathrm{h}=2$

\section{FQA}

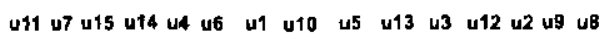

$\begin{array}{llllllllllllllll}0 & 2 & 2 & 2 & 2 & 2 & 3 & 3 & 4 & 4 & 4 & 4 & 5 & 5 & 6\end{array}$

$\begin{array}{lllllllllllllll}4 & 3 & 3 & 4 & 5 & 5 & 3 & 6 & 0 & 5 & 6 & 7 & 7 & 7 & 7\end{array}$

(d) $\mathrm{h}=2$

Figura 4.9: Exemplo de representaçāo das estruturas BKT, FQT, FHQT e FQA

Em 1991, Uhlmann propôs o MAEMs Vantage-Point Tree (VPT) (Uhlmann, 1991). Diferente dos trabalhos apresentados anteriormente, essa estrutura foi projetada para 
trabalhar com métricas que lidam com valores contínuos. Além disso, essa estrutura é uma ârvore binária em que cada nó armazena um objeto e um raio para particionar o espaço, ou seja, o raio é usado como critério para decidir em qual sub-árvore um novo objeto deve ser inserido. Nesse trabalho, Uhlmann ressalta que a VPT também pode ser generalizada para uma árvore multi-vias.

Um outro algoritmo proposto em (Uhlmann, 1991) foi o Generalized Hyper-plane Tree (GHT); a construçāo desta estrutura é idêntica a Bisector Trees (BST), proposta por (Kalantari and McDonald, 1983). Entretanto, a GHT utiliza um hiperplano como critério para divisão espacial no momento da busca, diferente da BST que utiliza o raio de cobertura de cada "dois centros" escolhido para fazer o mesmo trabalho. A GHT, como a BST, é uma árvore binária, sendo esta construída da seguinte forma: cada nó é composto por dois objetos $s_{1}$ e $s_{2}$ escolhidos arbitrariamente; os objetos mais próximos ao primeiro objeto, $s_{1}$, são armazenados na sub-árvore esquerda do nó, os objetos mais próximos a $s_{2}$ são armazenados na sub-árvore direita do nó. $O$ processo é repetido de forma recursiva até que todos os objetos tenham sido inseridos. Dependendo da boa seleção dos objetos chaves, a árvore tende a ser balanceada. Em seu trabalho, Ulmann, garante que a GHT poderia ter desempenho melhor que as VPT em dados com alta dimensão, mas os resultados experimentais mostram que o desempenhos das GH'Ts não supera o desempenho das VPTs.

Uma outra estrutura, variante da GHT, chamada GNAT (Geometric Near-Neighbor Access Tree), foi proposta por Brin (Brin, 1995). A diferença básica em relação à GHT é que, nesta árvore, são escolhidos mais de dois representativos por nó. O processo de inserçāo é similar, isto é, o objeto é comparado com todos os representativos e é inserido naquela sub-árvore correspondente ao mais próximo. Além disso, cada sub-árvore armazena, no nó pai, as distâncias minima e máxima dos objetos em relaçāo aos seus respectivos representativos. A recuperaçāo de informaçōes nesta estrutura é feita da seguinte forma: como em cada nó representativo $c_{i}$ ficam armazenadas as distâncias mínima e máxima, um objeto a ser consultado, $q$, é comparado com alguns centros $c_{i}$ e são descartados, através da propriedade de desigualdade triangular, aqueles que estão fora da faixa de distāncia armazenada no representativo. O processo é repetido de forma aleatória escolhendo os centros (representativos) atê que nenhum nó possa ser descartado, e segue de forma recursiva, visitando cada sub-árvore e recuperando os nós suficientemente próximos ao objeto de referência $q$. O desempenho da estrutura GNAT superou em algumas situaçōes o desempenho das VPTs.

Bozkaya e Ozsoyoglu (Bozkaya and Ozsoyoglu, 1997) apresentam a Multi-Vantage-Point Tree (MVPT) como uma estrutura baseada na VPT, que utiliza muitos elementos em um único nó, e todos os objetos das sub-árvores subseqüentes sāo armazenados junto com a sua distância para cada objeto representativo. Esta informação adicional permite reduzir, através da desigualdade triangular, em até $80 \%$ a quantidade de cálculos de distâncias em consultas por abrangência (Range Query) em comparaçāo 
com à VPT. A complexidade computacional da MVPT é menor do que na referente VPT, mas isto nāo se repete em todos os casos (Chávez et al., 2001) (Bozkaya and Ozsoyoglu, 1997). Uma outra generalização da VPT é a Vantage Point Forest (VPF) (Yianilos, 1999), que é uma estrutura projetada para fazer consultas do tipo $k$ - $N N$ ( $k$-Nearest Neighbors) com raio máximo, o que é análoga uma consulta do tipo Range Query.

Todas as estruturas mencionadas nesta seção são estáticas, isto é, não é possivel inserir ou remover elementos após a árvore ter sido construída. Além disso, como estas árvores são construídas através de um processo recursivo que nāo garante a permanência da estrutura balanceada por altura, esta situação exige reorganizaçōes custosas da estrutura para evitar a perda de desempenho. Estas deficiências estruturais foram superadas por outras estruturas, os MAEMs dinâmicos, que são as estruturas $M$-Tree e a Slim-tree, que são apresentadas a seguir.

\subsubsection{Os MAEMs dinâmicos}

\subsection{M-Tree}

O MAEM M-Tree (Ciaccia et al., 1997) é uma adaptaçāo das árvores $R$-Tree para dados métricos. Esta estrutura tem a forma de árvore balanceada por altura, ou seja, a diferença de nivel dos nós folhas é no máximo 1 (um), sendo apropriada para lidar com bases de dados em ambientes dinâmicos. Outra propriedade desta estrutura refere-se a sua capacidade para indexar objetos utilizando comparaçāo de atributos, através de funções de distância restritas a postulados métricos, que nāo são adequados a espaços vetoriais.

Na estrutura $M$-Tree, o nó interno não possui o mesmo conteúdo que o nó folha. Cada elemento de um nó folha contém a informação que compõe o objeto propriamente dito, o identificador do objeto $(O I d)$ e o valor representando a distáncia entre este nô e o objeto representativo daquele grupo. O nó interno, com exceção da raiz, contém o objeto propriamente dito, um ponteiro relacionado à sua sub-árvore, um raio de cobertura abrangendo toda a sub-árvore e o valor da distância entre este nó e o seu objeto representativo. O objeto representativo de cada nó armazena seu raio de cobertura e deve ser aquele que está mais próximo ao centro em relaçāo aos outros, isto é, o objeto mais similar aos outros elementos do mesmo nó. O elementos mais próximos aos representativos são organizados dentro de uma sub-ârvore que tem aquele representativo como raiz.

A M-Tree armazena todos os objetos indexados, representados por suas chaves e seus atributos, em qualquer um dos seus nós folha. De forma similar às $R$-Tree, o particionamento do espaço métrico não gera, necessariamente, regiões disjuntas, o que significa que podem ocorrer sobreposições. O particionamento dos objetos utiliza como base suas distâncias relativas, medidas através de uma métrica específica, armazenando os objetos dentro de nós de tamanho fixo. 
A operação de busca na $M$-Tree é acelerada através da utilizaçāo de uma propriedade dos espaços métricos, chamada de desigualdade triangular. Esta propriedade utiliza os raios de cobertura dos objetos representativos, e a distância entre estes objetos representativos e os demais objetos pertencentes a aquele nó. A inserçāo de objetos na $M$-Tree será descrita na próxima seção, uma vez que esta operação é semelhante àquela realizada no MAEM Slim-tree.

\subsection{Slim-tree}

O MAEM Slim-Tree foi proposto por Traina em (Traina Jr. et al., 2000b). Esta estrutura foi baseada nos modelo do MAE R-Tree e do MAEM M-Tree. A Slim-Tree consiste de uma árvore balanceada, dinâmica e que cresce de baixo para cima, assim como a BTree, $R$-Tree e $M$-Tree. O funcionamento desta estrutura é semelhante ao da $M$-Tree, porém a ordem de complexidade do algoritmo de particionamento é menor, o que melhora o desempenho das consultas. Assim como em outras árvores métricas, os objetos são armazenados em disco e em pãginas de tamanho fixo (cada nó tem um número máximo elementos) e cada página corresponde a um nó da ârvore. A Slim-Tree possui dois tipos de nó: o nó-índice e o nó-folha. O nó-índice é um registro que ć definido por:

$$
\text { nó-indice }=\text { Entidade }_{\text {Representativo }}+\text { Entidade }[1] \cdots \text { Entidade }[N] \text {. }
$$

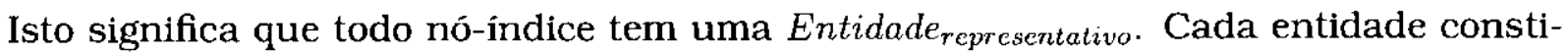
tuinte deste nó, sendo esta um nó representativo ou não, é definida por:

$$
\text { Entidade }=[O b j, \text { Dist, Sub, Raio, Num }]
$$

onde cada campo é definido por:

- Obj: corresponde ao objeto que está definido dentro do espaço métrico;

- Dist: distãncia entre este objeto e o representativo do nó ao qual pretence. Se esta entidade é um nó representativo, entāo, o valor de Dist $=0$;

- $S u b$ : referência para o nó do nivel inferior, ou nó filho (um nivel abaixo);

- Raio: raio de cobertura, pode ser obtido somando-se a maior distância entre uma entidade, pertencente a um nó-índice, e uma outra entidade do nó-índice do nível inferior (nó filho) com o maior raio de cobertura armazenado nestes nós. Se o nó-indicc está indexando nós-folhas entāo, para este nó, o raio de cobertura corresponde à maior distância entre este nó e dos objetos indexados nas folhas;

- Num: número de objetos indexados nos nós-folhas do seu nó filho, ou seja, da sub-árvore a qual referencia. 
A Entidade representativo armazena o objeto representativo de um nó-indice e indexa (engloba) todas as entidades pertencentes aos nós de níveis inferiores a esta, sendo tal informação armazenada no campo Raio de seu registro. No momento de uma consulta por abrangência ou $k$-vizinhos mais próximos, esta entidade é usada como referência para verificar qual ramo da árvore deve-se investigar para localizar o conjunto de objetos (ou o objeto) que se deseja buscar. O nó-indice tem como principal objetivo organizar a árvore de forma hierárquica de modo a facilitar a recuperaçāo dos objetos armazenado nas nos nós-folhas. Uma representação deste tipo de nó pode ser observada na Figura 4.10,

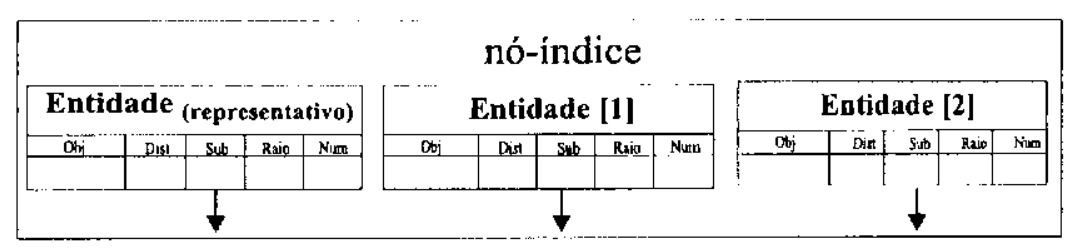

Figura 4.10: Estrutura do nó-índice da Slim-Tree

No último nivel dos nós da árvore encontram-se os nós-folhas, que são definidos como segue:

$$
\text { nó-folha }=\text { Entidade[1] } \cdots \text { Entidade[N]. }
$$

Cada entidade constituinte de um nó folha é definida por:

$$
\text { Entidade }=[\text { Obj, Oid, Dist }]
$$

onde cada campo significa:

- Obj: objeto que está definido dentro do espaço métrico;

- Oid: identificador do objeto. Utilizado para encontrar o objeto na base em que está armazenado;

- Dist: distância entrem este objeto e o representativo do nó ao qual pretence. Se esta entidade é o objeto representativo do nó que está referenciando este nó-folha então o valor de Dist $=0$. Deve-se ressaltar que não existe Entidade representativo nos nós-folhas, tal entidade existe até o nivel anterior a esses nós.

A principal função dos nós-folhas é armazenar os objetos propriamente ditos, é a partir dos nós-folhas que os objetos são recuperados.

O mecanismo de inserção de objetos na Slim-Tree e na $M$-Tree é o mesmo, sendo tal mecanismo, descrito de forma resumida a seguir.

\section{Descrição do algoritmo de inserção da Slim-tree}




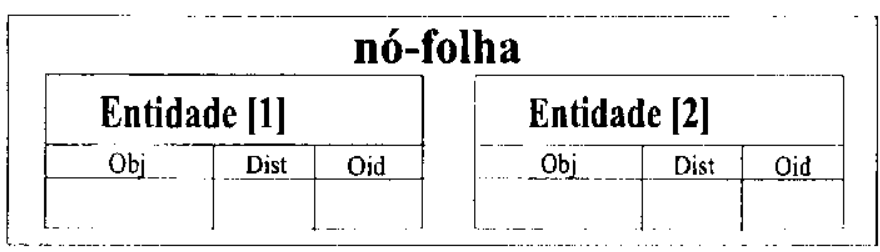

Figura 4.11: Estrutura de um nó-folha da Slim-Tree

A partir do nó raiz, o algoritmo tenta alocar um nó para abrigar o novo objeto. Esta busca é feita verificando se o centro (ou representativo) de determinado nó está mais próximo do novo objeto. Assim que o nó é encontrado, aumenta-se o raio de cobertura do objeto representativo do nó escolhido a fim de cobrir o novo objeto. Por outro lado, se as condiçōes de similaridades são satisfeitas em mais de um nó, entāo, é executa um algoritmo chamado ChooseSubtree para escolher um novo objeto representativo. Esse processo é aplicado em todos os niveis da árvore até que a inserçāo do objeto seja feita na sub-árvore que possui o menor grau de ocupação.

A estrutura da Slim-Tree possui três opções para o algoritmo ChooseSubtree:

- Random: escolhe aleatoriamente um dos nó que se dentre aqueles que satisfazem as condiçōes de similaridade;

- Mindist: escolhe o nó que possui menor distância em relação ao novo objeto e em relação ao representativo daquele nó;

- Minocup: escolhe o nó que possui menor ocupação dentre aqueles que satisfazem as condições de similaridades. Este método é default no algoritmo da Slim-Tree, devido a melhor performance frente aos outros métodos sugeridos.

A opçāo Minocup utiliza o campo Num presente no registro do nó-índice para selecionar o nô com menor número de entidades. Os resultados, utilizando esta opção para o algoritmo ChooseSubtree, foram bastante satisfatórios, pois as árvores obtidas apresentaram-se mais compactas, o que resultou em um número de acessos a disco e cálculos de distância menor para responder a consultas por similaridade.

Durante o processo de inserçāo pode ocorrer uma situaçāo na qual o nó escolhido já está com sua taxa de ocupação máxima. Neste caso, deve-se alocar um novo nó e dividir (quebrar) este nõ em dois. Algumas políticas são efetuadas para fazer a quebra de nós, sendo estas executadas através dos seguintes algoritmos:

- Random: seleciona aletoriamente dois objetos representativos para os novos nós. Os demais objetos, pertencentes ao nó que será dividido, serão distribuídos entre estes dois nós, pelo critério de menor distância entre o objeto e o objeto representativo de cada destes. Esta não é a melhor estratégia, mas é a mais rápida; 
- minMax todos os possívcis pares de objetos são considerados como potenciais representativos. Desta forma, o algoritmo avalia cada um destes pares, considerando a associaçāo dos demais elementos a cada um dos representativos que compõem o par em questão. O par de objetos que minimizar o raio de cobertura de cada uma de suas sub-árvores será o escolhido. A complexidade do algoritmo, no caso médio, é de $\Theta\left(C^{3}\right)$ usando $\Theta\left(C^{2}\right)$ cálculos de distância, onde $C$ é o número médio de objetos armazenados em nós que não é o nó raiz. Este algoritmo é usado pelo MAEM M-Tree e, apesar de ser muito custoso, permite um desempenho satisfatório na realização de consultas (Ciaccia et al., 1997);

- Minimal Spanning Tree (MST): a partir dos objetos presentes no nó que será quebrado, constrói-se uma árvore geradora mínima, ou seja, uma árvore de caminho minimo cujo arco mais longo (de maior distância) deverá ser removido. Assim, obtém-se dois agrupamentos (clusters) compostos pelos dois novos nós resultantes da quebra, sendo que cada um dos dois nós possuirá um representativo que será colocado no novo nó que foi criado. Nos testes realizados por Traina em (Traina Jr. et al., 2000b), o algoritmo MST permitiu a construção da Slim-Tree de forma equivalente às construídas pelo algoritmo minMax, porém com um tempo bem menor. Isto pode ser notado pela complexidade do algoritmo, para o caso médio, que é $\Theta\left(C^{3}\right)$ usando $\Theta\left(C^{2}\right)$ cálculos de distância. Este método é default na Slim-Tree.

\section{Representação da estrutura Slim-tree}

A Figura 4.14 apresenta uma representação, em forma de árvore, de uma Slim-Tree com seus nós-índices e scus nós-folhas. Vale notar que estrutura indexa 13 (treze) vetores com valores reais, sendo estes encontrados no último nivel da árvore, ou seja, nos nó-folhas. Os dois vetores que estāo no primeiro nivel da ärvore sāo exatamente os representativos dos dois nós-índices resultantes da quebra de um dos nós. É comum haver repetições de objetos nos nô-îndices em vários niveis da estrutura, contanto que estes objetos sejam representativos de algum nó. Nos nós-folhas, não há repetiçāo de objetos, qualquer que seja a situaçāo. Alguns objetos sāo repetidos por representarem regiōes de abrangência que indexam outros objetos. A utilização de objetos representativos para cada nó-índice é importante, pois, no momento de uma consulta, as informaçōes, armazenadas nos registros dos nós dos objetos representativos sāo utilizadas para comparaçāo, a partir dos primeiros níveis da árvore até chegar nos nós-folhas. A Figura 4.12 apresenta um representaçāo conceitual da Slim-Tree, apresentada na Figura 4.14. Esta representação mostra como os dados estão distribuidos espacialmente entre as regiões de abrangência de cada nó-indice. A informação das regiōes de abrangência de cada nó-indice está guardada no campo Raio. Neste caso, a métrica utilizada é a $L 2$ (Distância Euclidiana), por isso a representação das regiōes de abrangência tem a forma circular. Vale observar que 
as linhas em negrito correspondem às es de abrangência dos nó-índices do primeiro nivel, que são os vetores $L$ e $F$. Como, no primeiro nível da árvore, o nó raiz nāo possui objetos represcntativos, os objetos que lá estāo armazenados são exatamente os representativos dos nós do nível abaixo, ou seja, do segundo nível.

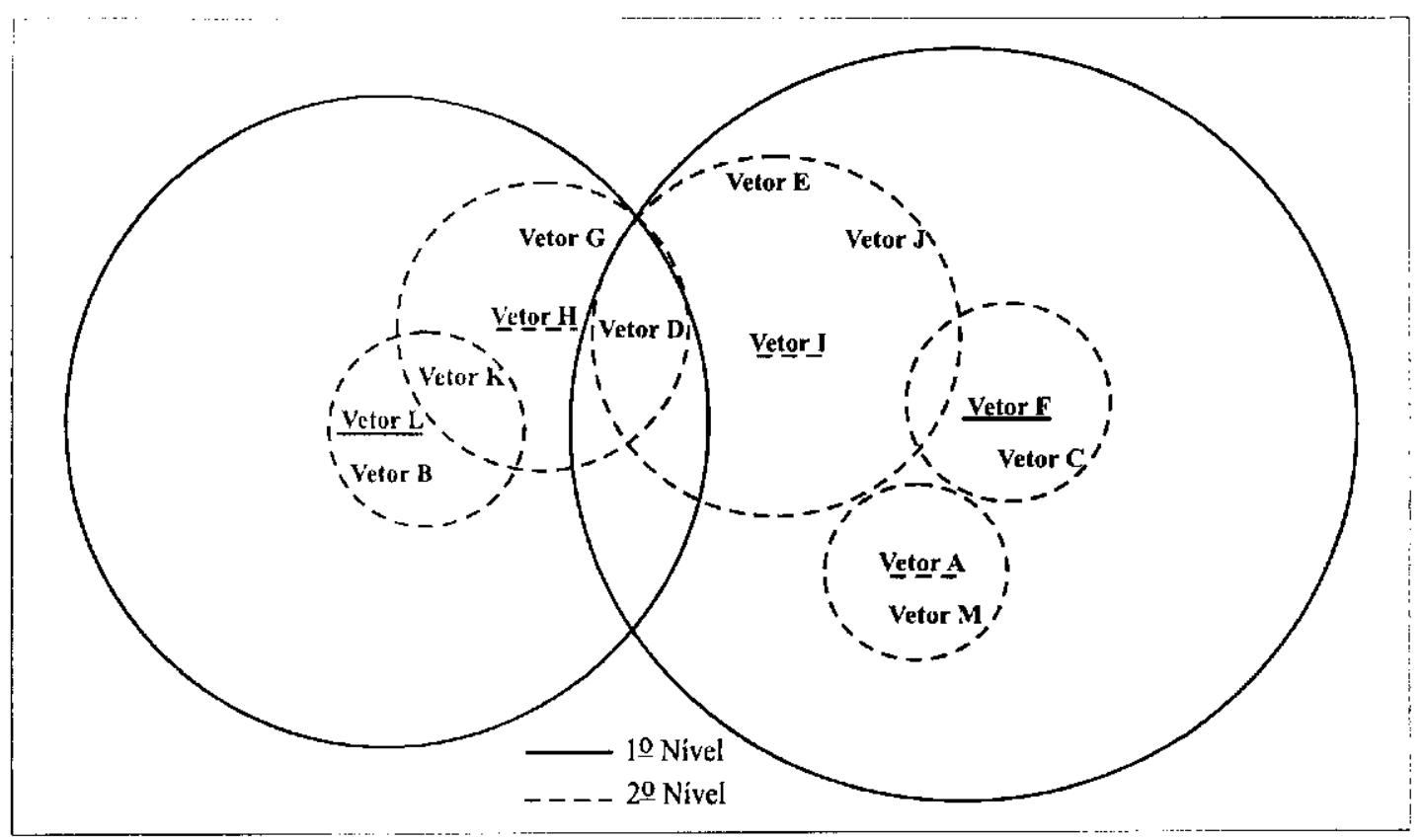

Figura 4.12: Representação conceitual da estrutura Slim-Tree.
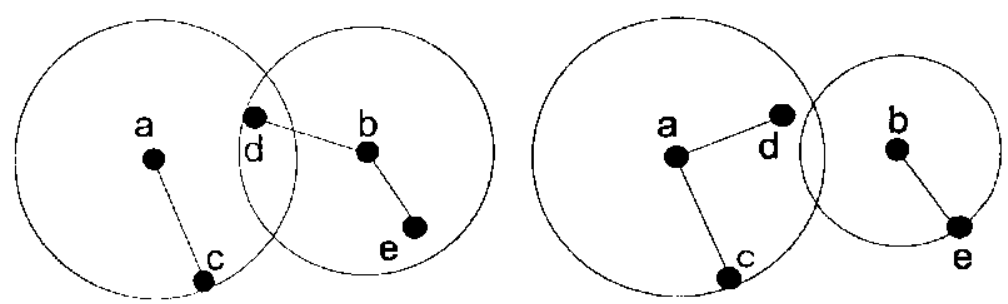

(a) Situação de sobreposição an- (b) Sobreposiçāo eliminada detes da aplicação do Slim-down. pois da aplicação do Slim-down.

Figura 4.13: Efeitos do algoritmo Slim-down: antes e depois.

Serve-se observar que, na representação conceitual da Slim-Tree, as regiōes de abrangência dos vetores $L$ e $F$ abrigam todos os demais vetores indexados pela estrutura. O vetor $L$ indexa os vetores $K, B, H, G$ e $D$; o vetor $F$ indexa os vetores $C, A$, $M, I, J, E$ e $D$. Descendo um nível, ou seja, passando para o segundo nivel (linha pontilhada), tem-se o vetor $I$ indexando os vetores $D, E$ e $J$; o vetor $F$ indexando o vetor $C$; o vetor $A$ indexando o vetor $M$. Agora, na sub-árvore, que tem como representativo o vetor $L$ no primeiro nivel, tcm-se a seguinte configuração para o segundo nivel: o vetor $H$ indexa os vetores $K,(K$ e 1$)$; o vetor $L$ indexa os vetores $K$ e $B$. Os vetores $K, B, G, E, J, D, C$ e $M$ não possuem regiōes de abrangência porque não indexam 
objeto algum. Uma outra situação, que pode ser melhor observada na Figura 4.12, é a existência de sobreposiçōes (Overlapping) das regiōes de abrangência.

$\mathrm{O}$ vetor $D \mathrm{e}$, ao mesmo tempo, indexado por duas regiões diferentes, $L$ e $F$, no primeiro nível; o vetor $K$ é indexado, ao mesmo tempo, por duas regiōes de abrangência diferentes, ou seja, as regiões de do vetores $H$ e $L$, no segundo nível. Desta forma nota-se que as sobreposiçōes são identificadas a partir de regiōes de abrangência pertencentes a objetos representativos diferentes, localizados em um mesmo nivel da árvore.

A situação de sobreposição de regiões de abrangência é significativa, principalmente, no momento da consulta, pois esta leva ao aumento do número de acessos a disco e de cálculos de distância, o que se deve ao fato de que haverá um número maior de sub-árvores para consultar. Por exemplo, se em uma consulta por abrangência, o nó onde está localizado o vetor $D$, tiver que ser acessado, o algoritmo vai avaliar, primeiramente, em qual das sub-árvores o objeto está. Neste caso, o objeto procurado está em duas sub-árvores, isto é, na sub-árvore que tem como representativo o vetor $L$ e na sub-árvore que tem como representativo o o vetor $F$. Portanto, a busca será feita, primeiramente, em uma sub-árvore e, depois, na outra. Esta situação, como já foi dito, aumenta significativamente o custo computacional da consulta.

Como uma alternativa para minimizar as sobreposiçōes entre regiões em cada nivel da árvore, a aplicaçāo do algoritmo Slim-down da Slim-Tree pode ser uma solução satisfatória. Na figura 4.13(a) as regiōes de cobertura do objeto $a$ e $b$ sobrepõem-se, ambas envolvendo o objeto $d$. Depois da aplicaçāo do algoritmo Slim-down, o objeto $d$ é alocado na sub-árvore do objeto $a$ e a região de cobertura do objeto $b$ é reduzida para eliminar a situação de sobreposição. Após a aplicaçāo do Slim-down, a operaçāo de busca será feita com uma complexidade computacional menor, pois a consulta será realizada somente pelo caminho do objeto $a$, e nāo mais pelos dois caminhos $a \mathrm{c}$ $b$, como na situação anterior. A aplicação do algoritmo Slim-down pode ser muito custosa, dependendo do volume de dados indexados pela Slim-Tree. Portanto, é interessante, primeiramente, verificar o grau de sobreposições existentes na estrutura antes de aplicar o Slim-down. Umas das contribuições do MAEM Slim-Tree é o cálculo do fat-factor (Traina Jr. et al., 2000b), que torna possivel avaliar a se árvore métrica em questāo é considerada "boa" ou "ruim" para realizar uma consulta por similaridade. Este cálculo é feito a partir da estimativa do número de acessos a disco ou número de cálculos de distância que podem ser realizados em uma consulta, por exemplo, por abrangència. O cálculo do fat-factor retorna valores no intervalo $[0,1]$, isto significa que a pior árvore para se fazer uma consulta por similaridade tem o fat-factor igual a $1(\mathrm{um})$ e a árvore ideal tem o fat-factor igual a 0 (zero). 


\subsection{Considerações finais}

Considerando as contribuiçōes apresentadas pelo MAEM Slim-Tree, tais como o desenvolvimento do Minocup, MST, Slim-down e fat-factor, quando comparada com a $M$-Tree, nas mesmas condiçōes, a primeira mostrou desempenho superior, tanto em número de acessos a disco quanto em número de cálculos de distância para responder a consultas por abrangência (Traina Jr. et al., 2000b).

Apesar de não terem sido abordados neste trabalho, os algoritmos de consultas por abrangência e de consultas por $k$-vizinhos mais próximos utilizados pela estrutura Slim-Tree são considerados importantes. Detalhes sobre estes podem ser encontrados em (Ciaccia et al., 1997).

A partir dos estudos realizados a respeito de estruturas de dados para indexação e recuperaçāo de informaçōes e também por possuirmos o código fonte e uma versão funcional do MAEM Slim-Tree implementada em linguagem $\mathrm{C}++$, gentilmente cedidos pelo GBDI-ICMC-USP, que tem como coordenadores os Prof. Drs. Caetano Traina Jr. e Agma J. Traina, podemos concluir que o MAEM Slim-Tree mostrou-se mais adequado aos propósitos descritos neste trabalho.

Neste capítulo, foram apresentados, de uma maneira resumida, os MAEs e MAEMs mais comuns para indexaçāo e recuperaçāo de informaçōes. No próximo capítulo será apresentado, de maneira detalhada, um sistema que combina um modelo da família ART com o MAEM Slim-Tree como uma forma alternativa para indexação e recuperação de informaçōes por medidas de similaridade. 


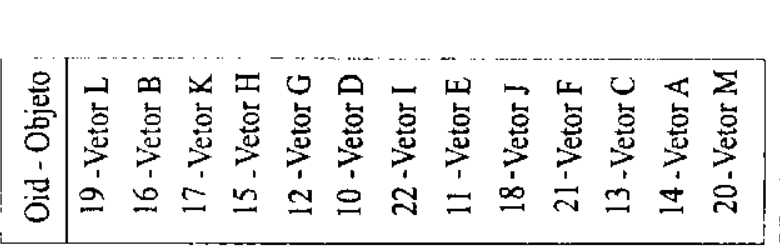

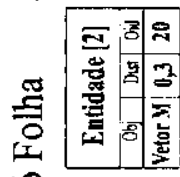

识
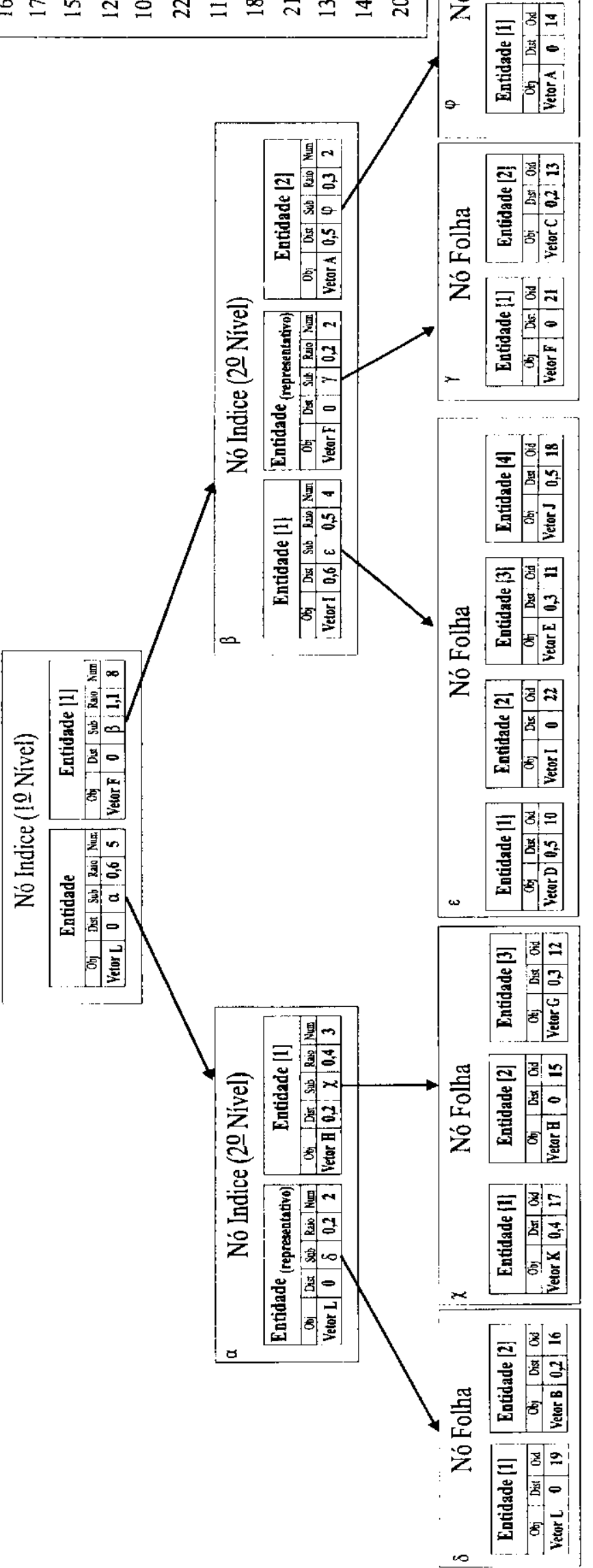

Figura 4.14: Representação de uma Slim-Tree com seus nós-índices e seus nńc-fnlhac 
Recuperação de Informações Utilizando um Modelo da família ART

\subsection{Introduçāo}

Como o objetivo principal deste presente trabalho é avaliar a possibilidade de aplicação de um modelo da familia ART em combinação com a estrutura Slim-Tree afim de se obter um modelo hibrido capaz de responder a consultas por similaridade, resolveu-se analisar a capacidade de cada um dos modelos estudados, isto é, os modelo ART2, ART2-A e Fuzzy ART, com relação à classificaçāo de dados em diferentes bases de dados. O objetivo desta análise faz parte do aprofundamento de estudo e compreensão do funcionamento destes modelos ART, para que se possa aplicar da melhor forma possivel suas características. Na próxima seção, é descrita uma metodologia de como foram realizados os experimentos com os modelos da familia ART estudados no Capitulo 3.

\subsection{Os experimentos com os modelos da família ART estudados}

Os experimentos com os modelos familia ART foram realizados considerando-os como se fossem classificadores, apesar de estes modelos serem implementados com o paradigma de aprendizado não-supervisionado. Além disso, o modo de treinamento utilizado para os três modelos foi o modo lento, com taxa de aprendizagem $\beta=0.01$. Partindo destas consideraçōes, foram executados os passos descritos a seguir. Inicialmente, para as bases de dados da Tabela 5.1 que possuem valores reais positivos, 
foi necessário padronizar seus valores para que estes pertencessem ao intervalo $[0,1]$. . Isto foi feito através da seguinte equaçāo (Weiss and Indurkhay, 1998):

$$
\nu(i)^{\prime}=\frac{\nu(i)-\operatorname{mean}(\nu)}{\operatorname{std}(\nu)}
$$

onde $\nu$ é o componentc do vetor coluna que será normalizado, mean( ) è a média aritmética do vetor $\nu, \operatorname{std}\left(\right.$ ) é o desvio padrão do vetor $\nu$ e $\nu(i)^{\prime}$ é o novo componente do vetor coluna padronizado. Segundo (Weiss and Indurkhay, 1998), dados padronizados desta forma sāo mais adequados para aplicaçōes que envolvem cálculos de distância.

Por outro lado, para as bases de dados com valores reais positivos e negativos, foi aplicada a Equação 5.1, para padronizar seus valores para o intervalo $[-1,1]$. Em seguida, também foi necessário transformar estes valores em valores que pertencem ao intervalo [0, 1]. Isto foi feito utilizando a scguinte equação (Masters, 1993):

$$
\nu(i)^{\prime \prime}=r *\left(\nu(i)^{\prime} \cdot \text { RowMin }\right)+\text { RangeMin }
$$

onde o valor de $r$ é obtido através da equação:

$$
r=\frac{\operatorname{Range} M a x-\operatorname{RangeMin}}{\operatorname{Row} \operatorname{Max}(\nu)-\operatorname{Row} \operatorname{Min}(\nu)}
$$

onde RangeMax e RangeMin corresponde aos valores máximo e minimos do novo intervalo, e, RowMax( ) e RowMin( ) correspondem, respectivamente aos valores máximo e minimo do vetor coluna.

A maioria dos conjuntos de dados testados nos experimentos (Tabela 5.1) realizados neste trabalho sāo do repositório (UCI) (Blake and Merz, 1998), exceto o conjunto de dados Eigenfaces (Wactlar et al., 1996) que pertence ao projeto Infomedia da Universidade Carnegie Mellon, Estados Unidos. com exceçāo da base de dados Eigenfaces

Em seguida os dados foram rotulados como pertencentes as sua respectivas classes e submetidos como entrada às redes ART. Foram realizadas de 10 (dez) cxecuções, utilizando no mínimo 10 (dez) ciclos de treinamento e acrescentando 1 (um) ciclo para cada execuçāo, para os quais os padrōes de entrada foram apresentados à rede de forma aleatória, i.e., cada ciclo com uma ordem diferente. Como a criação dos clusters na camada de saída das redes AR' é feita dinamicamente, o algoritmo é que vai determinar quantos cluster devem ser criados. Considerando o fato de se conhecer o número de classes cxistentes (o que nem sempre ocorre de antemāo, como é o caso da base de dados Eigenfaces), o número de clusters foi fixado de acordo com aquele que cada base de dados deve possuir. Isto significa, que se os padrōes de uma determinada base são classificados em 2 (duas) classes apenas, então, o número de clusters foi fixado em 2 (dois). 


\begin{tabular}{|l|l|}
\hline \hline Bases de Dados & Descrição \\
\hline Iris & $\begin{array}{l}\text { Conjunto de } 150 \text { vetores com } 4 \text { atributos } \\
\text { (valores reais) cada e } 3 \text { classes de flores } \\
\text { Iris. }\end{array}$ \\
\hline Vinhos & $\begin{array}{l}\text { Conjunto de } 178 \text { vetores com } 13 \text { atributos } \\
\text { (valores reais) cada e } 3 \text { classes de vinhos. }\end{array}$ \\
\hline $\begin{array}{l}\text { Wisconsin Diagnostic } \\
\text { Breast Cancer (WDBC) }\end{array}$ & $\begin{array}{l}\text { Conjunto de } 569 \text { vetores (valores reais) com } \\
31 \text { atributos cada e 2 classes: maligno ou } \\
\text { benigno. }\end{array}$ \\
\hline $\begin{array}{l}\text { Wisconsin Breast Can- } \\
\text { cer (WBC) }\end{array}$ & $\begin{array}{l}\text { Conjunto de 683 vetores com 9 atributos } \\
\text { (valores reais) cada e } 2 \text { classes: maligno ou } \\
\text { benigno. }\end{array}$ \\
\hline $\begin{array}{l}\text { Pima Indian Diabetes } \\
\text { (PID) }\end{array}$ & $\begin{array}{l}\text { Conjunto de 768 vetores com 8 atributos } \\
\text { (valores reais) cada e 2 classes: positivo ou } \\
\text { negativo para diabetes. } \\
\text { Waveform }-\cdots \text { Conjunto de 5000 vetores com 21 atributos } \\
\text { (valores reais) cada e 3 classes de ondas. }\end{array}$ \\
\hline Eigenfaces & $\begin{array}{l}\text { Conjunto de 11900 vetores de faces com 16 } \\
\text { atributos (valores reais no intervalo [0, 1]) } \\
\text { cada. Cada face foi processado com o } \\
\text { método Eigenfaces. }\end{array}$ \\
\hline \hline
\end{tabular}

Tabela 5.1: Bases de dados utilizadas nos experimentos.

A avaliação da classificaçāo foi feita através de uma matriz de confusão (Peper et al., 1993), que indica quantos elementos, de cada classe, foram agrupados nos cluster formados pela rede.

A Tabela 5.2 mostra a média aritmética dos resultados, extraidos da matriz de confusão, a partir 10 (dez) execuções com 10 (dez) ciclos de treinamento, considerando como conjunto de treinamento todos os elementos constituintes de cada base de dados.

\begin{tabular}{|c|c|c|c|c|}
\hline & & \multicolumn{3}{|c|}{ Modelos } \\
\hline Bases de Dados & Clusters & $\overline{A R T 2}$ & ART2-A & Fuzzy ART \\
\hline Iris & 3 & $72 \%$ & $94 \%$ & $85 \%$ \\
\hline Vinhos & 3 & $70 \%$ & $70 \%$ & $53 \%$ \\
\hline WDBC & 2 & $86 \%$ & $89 \%$ & $61 \%$ \\
\hline WBC & 2 & $86 \%$ & $86 \%$ & $61 \%$ \\
\hline Waveform & 3 & $52 \%$ & $51 \%$ & $35 \%$ \\
\hline$P I D$ & 2 & $54 \%$ & $56 \%$ & $64 \%$ \\
\hline
\end{tabular}

Tabela 5.2: Desempenho das redes ART2, ART2-A e Fuzzy ART.

A Tabela 5.3, do mesmo modo que a Tabela 5.2, mostra a média aritmética dos resultados, extraidos da matriz de confusão, a partir de 10 (de $z$ ) execuçōes com, no minimo, $10(\mathrm{de} z)$ ciclos de treinamento, considerando como conjunto de treinamento todos os elementos constituintes de cada bases de dados. A diferença é que, para 
os experimentos da Tabela 5.3 os modelos ART2 e ART2-A tiveram o paràmetro para supressāo de ruido $(\theta)$ ativado. Neste caso, seus valores deste parâmetro foram experimentalmente determinados para cada conjunto de dados testado.

\begin{tabular}{|c||c||c|c|}
\cline { 3 - 4 } \multicolumn{2}{c|}{} & \multicolumn{2}{c|}{ Modelos } \\
\hline Bases de Dados & Clusters & ART2 & ART2-A \\
\hline Iris & 3 & $90 \%$ & $94 \%$ \\
\hline Vinhos & 3 & $85 \%$ & $84 \%$ \\
\hline WDBC & 2 & $89 \%$ & $82 \%$ \\
\hline WBC & 2 & $90 \%$ & $86 \%$ \\
\hline Waveform & 3 & $57 \%$ & $72 \%$ \\
\hline$P I D$ & 2 & $56 \%$ & $63 \%$ \\
\hline
\end{tabular}

Tabela 5.3: Desempenho das redes ART2 e ART2-A, com a ativação do parâmetro $\theta$ (supressāo de ruído).

A Tabela 5.4 mostra a média aritmética dos resultados, extraídos da matriz de confusāo, a partir 10 (dez) execuçōes com, no mínimo, 10 (dez) ciclos de treinamento, considerando como conjunto de treinamento apenas $50 \%$ dos elementos constituintes de cada base de dados, escolhidos aleatoriamente e o conjunto todo para classificação dos dados. Além disso, neste experimento, os modelos AR'T2 e AR'T2-A foram treinados com o parāmetro de supressāo de ruído e comparados com o modelo Fuzzy ART.

\begin{tabular}{|c|c|c||c||c|}
\cline { 3 - 4 } \multicolumn{1}{c|}{} & \multicolumn{3}{c|}{ Modclos } \\
\hline Bases de Dados & Clusters & ART2 & ART2-A & Fuzzy ART \\
\hline Iris & 3 & $91 \%$ & $94 \%$ & $88 \%$ \\
\hline Vinhos & 3 & $89 \%$ & $84 \%$ & $60 \%$ \\
\hline WDBC & 2 & $89 \%$ & $83 \%$ & $61 \%$ \\
\hline WBC & 2 & $88 \%$ & $82 \%$ & $63 \%$ \\
\hline Waveform & 3 & $57 \%$ & $72 \%$ & $38 \%$ \\
\hline PID & 2 & $56 \%$ & $66 \%$ & $66 \%$ \\
\hline
\end{tabular}

Tabela 5.4: Desempenho dos modelos ART2, ART2-A e Fuzzy ART.

Observe que na Tabela 5.4, o modelo Fuzzy ART apresentou melhoras significativas na classificaçāo em relaçāo à Tabela 5.2, mas ainda nāo foram suficientes para superar os outros dois modelos. O desempenho dos modelos ART2 e ART2-A podem ser considerados bem parecidos, tanto na Tabela 5.4 quanto na Tabela 5.2. Outra característica, que pode ser observada, pelos resultados apresentados na Tabela $5.2 \mathrm{e}$ na Tabela 5.4, é que o treinamento da rede ART2-A nāo precisa ser, necessariamente, realizado com todos os dados da base.

Considerando os resultados obtidos com as experimentações nos modelos ART, os estudos realizados a respeito destes modelos (de acordo com o apresentado no Capítulo 3), e por apresentar um tempo de pré-processamento menor do que o modelo 
ART2, escolheu-se o modelo ART2-A como o mais adequado para a implementação do modelo híbrido.

A próxima seção descreve como foi feita a combinaçāo do modelo ART2-A com o MAEM Slim-Tree.

\subsection{Construção de um modelo híbrido}

A Figura 5.1 apresenta um modelo hibrido que combina a rede neural ART2-A com o MAEM Slim-Tree. Neste modelo, cada neurônio da camada de saída implementa uma Slim-Tree correspondente. Na implementação do modelo ART2-A, bem como dos

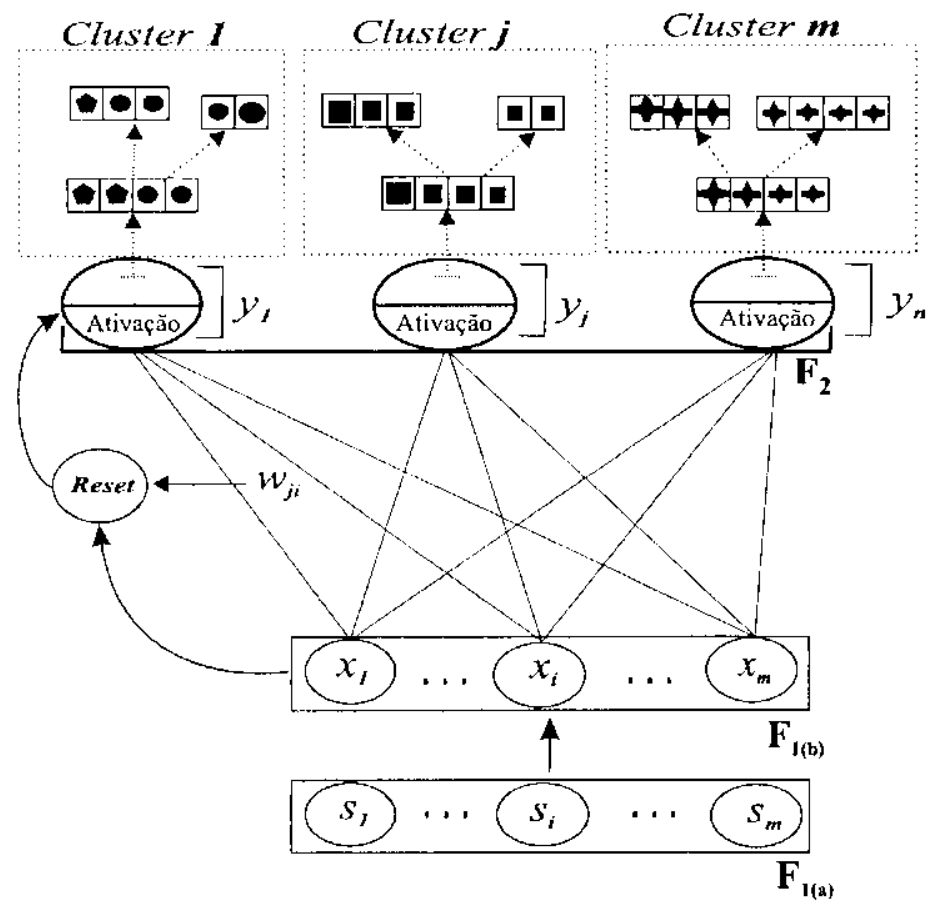

Figura 5.1: Combinando a Arquitetura da Rede ART2-A com o MAEM Slim-Tree.

outros modelos descritos em detalhes no Capítulo 3 , cada neurônio da camada $F_{2}$ é criado como um registro contendo dois campos: um campo para guardar o valor de ativaçāo do neurônio e o outro campo para armazenar o nó raiz da Slim-Tree, que será criada durante o processo de agrupamento dos dados.

O processo de agrupamento e recuperação de informações ocorre como descrito a seguir. Inicialmente, um conjunto de padrōes deve ser submetido à rede ART2-A para treinamento. Em seguida, submete-se ao sistema híbrido, todo o conjunto de dados que se pretende consultar, o qual poderá ou nāo ser o mesmo conjunto utilizado para treinamento. Através do processamento do sistema hibrido, os dados são automaticamente agrupados cada qual em seu respectivo cluster.

A inserção dos objetos nos scus respectivos clusters é feita da mesma maneira como foi descrita no capitulo 4, Seção 4.3.2.1.2, $\mathrm{cm}$ que é feita umá descriçāo a respeito da estrutura Slim-Tree. 
Após o término do processo de agrupamento dos dados, o novo modelo (ART2-A+Slim-tree) estará pronto para receber o conjunto de dados referente às consultas desejadas. Na forma em que foi implementado, no conteúdo do arquivo correspondente a estes dados, deve constar o vetor de atributos de cada objeto que se deseja consultar, mais os parâmetros necessários para o tipo de consulta desejado e o tipo de métrica usada. Estes parāmetros indicam o tipo de consulta a ser realizada, que pode ser: consultas por abrangência ou consulta por $k$-vizinhos mais próximos. Neste trabalho foi utilizada somente a métrica $L 2$, ou seja, a distāncia Euclideana. Neste texto, cada padrāo pertencente ao conjunto de consultas, será denominado objeto de referência.

O processo de recuperação de informações é realizado como segue. O objeto de referência é submetido ao sistema híbrido que, por sua vez, selecionará, através de medidas de similaridade, em qual dos clusters deverá ser feita a busca. Uma vez determinado o cluster, a consulta será realizada na Slim-Tree correspondente àquele cluster. Da forma como foi implementado, as estatísticas da busca, que consiste no número de acesso a disco e no nümero de cálculos de distância efetuados, são armazenados num arquivo corresponde a aquele cluster.

Na próxima seção, é descrito a metodologia que foi usada para obtenção dos resultados das consultas realizadas, a partir do modelo híbrido proposto, para comparaçāo deste com o MAEM Slim-Tree nas mesmas condiçōes, isto é, considerando os mesmos conjuntos de dados.

\subsection{Resultados dos experimentos}

Nessa seçāo, sāo apresentados os resultados dos experimentos realizados neste presente trabalho, assim como a metodologia que foi utilizada. Deve ser observado, que para os testes de recuperação de informaçōes, as bases de dados usadas foram: Iris, Waveform e Eigenfaces. Além disso, a implementação do sistema híbrido foi realizada utilizando o software Microsoft Visual $\mathrm{C}++$ em ambiente operacional Windows $2000 /$ NT.

Para explicar a metodologia utilizada, resolveu-se adotar como referência os experimentos realizados no MAEM Slim-Tree com a base de dados Iris. Vale lembrar que a metodologia é a mesma para as outras duas bases de dados.

Para as consultas por abrangência, foram criados 4 (quatro) arquivos, um para cada raio de abrangência. Assim, todos os objetos de cada arquivo foram consultados com o mesmo raio de abrangência. Além do raio de abrangência, também foi necessário identificar uma métrica a ser usada. Em todos os experimentos realizados neste trabalho, a métrica usada foi a Euclideana ( $L 2)$. Uma vez obtidos os resultados da busca, calculou-se a média aritmética dos números de acessos a disco e dos números de cálculos de distância, para cada um dos 4 (quatro) raios de abrangências. Os seguintes valores foram considerados como raio de abrangēncia: 0.001, 0.01, 0.1 e 1.0. 
Para realizar consultas por $k$-vizinhos mais próximos, o mesmo procedimento foi adotado, ou seja, foram criados 4 arquivos, um para cada $k$ de vizinhos mais próximos. Os seguintes valores foram tomados para $k: 300,600,900$ c 1200 , exceto para a base Iris, para a qual foi adotada os seguintes valores de $k: 10,20,30$ e 40. Além do número de vizinhos mais próximos, também foi necessário identificar métrica a ser usada. Uma vez obtido os resultados da busca, calculou-se a média aritmética dos números de acessos a disco e dos números de cálculos de distância, para cada número $k$, de vizinhos mais próximos.

Em todos os gráficos apresentados, o nümero médio de acessos a disco e distâncias calculadas para os seus respectivos raios de abrangência (ou de $k$-vizinhos adotados) aparecem dentro dos retângulos mostrados nas Figuras. Quanto maior for esse número maior o custo computacional envolvido.

Os experimentos realizados com o modelo híbrido ( $A$ RT2-A+Slim-tree) procederam da seguinte forma. Inicialmente, o treinamento da rede foi realizado, para as base de dados, Iris e Waveform, com $50 \%$ de todo o conjunto, fixando-se o número de saidas da rede de acordo com o número de suas respectivas classes.

A metodologia de coleta dos resultados difere um pouco daquela usada nos experimentos com a estrutura Slim-Tree, pois, cada cluster apresenta suas próprias estatísticas, em termos de acessos a disco e cálculos de distância, a respeito da consulta realizada. Uma vez obtidos estes resultados, é preciso juntar o número de acessos a disco e o número de cálculos de distância, das consultas realizadas em cada um dos clusters e calcular a média aritmética para obter uma medida de desempenho das consultas. O mesmo foi feito para a estrutura Slim-Tree, com a diferença que, esta utiliza apenas 1 (um) arquivo para apresentar as estatisticas de cada consulta realizada.

Os gráficos mostrados nas Figuras 5.2 a Figura 5.9 apresentam uma comparaçāo entre os desempenhos, em termos do número de acessos a disco e do número de distâncias calculadas, tanto para consultas por abrangência quanto para consultas do tipo $k$-vizinhos mais próximos, para a estrutura Slim-Tree e para o modelo híbrido (ART2-A+Slim-tree).

Nota-se que, em todos esses gráficos, o desempenho do modelo híbrido (ART2-A+Slim-tree) foi sempre superior ou igual ao desempenho da Slim-Tree.

Considerando os experimentos realizados com a base de dados Eigenfaces, Figura 5.10 a Figura 5.13, inicialmente, o treinamento da rede foi realizado com todos padrões da base e foi fixado um número máximo de saídas para a rede, por exemplo, 10 (dez) neurônios. Isto foi feito porque o númcro de classes nāo é conhecido a priori. Após o treinamento e indexação dos dados, houve a formação de 4 (quatro) clusters (isto é, 4 (quatro) Slim-Trees no sistema hibrido) na camada de saida. O processo de indexação, recuperação e coleta dos resultados foi feito da mesma maneira daquele realizado para as duas bases de dados usadas anteriormente, com exceçāo do 
Conjuntos de Dados: Iris

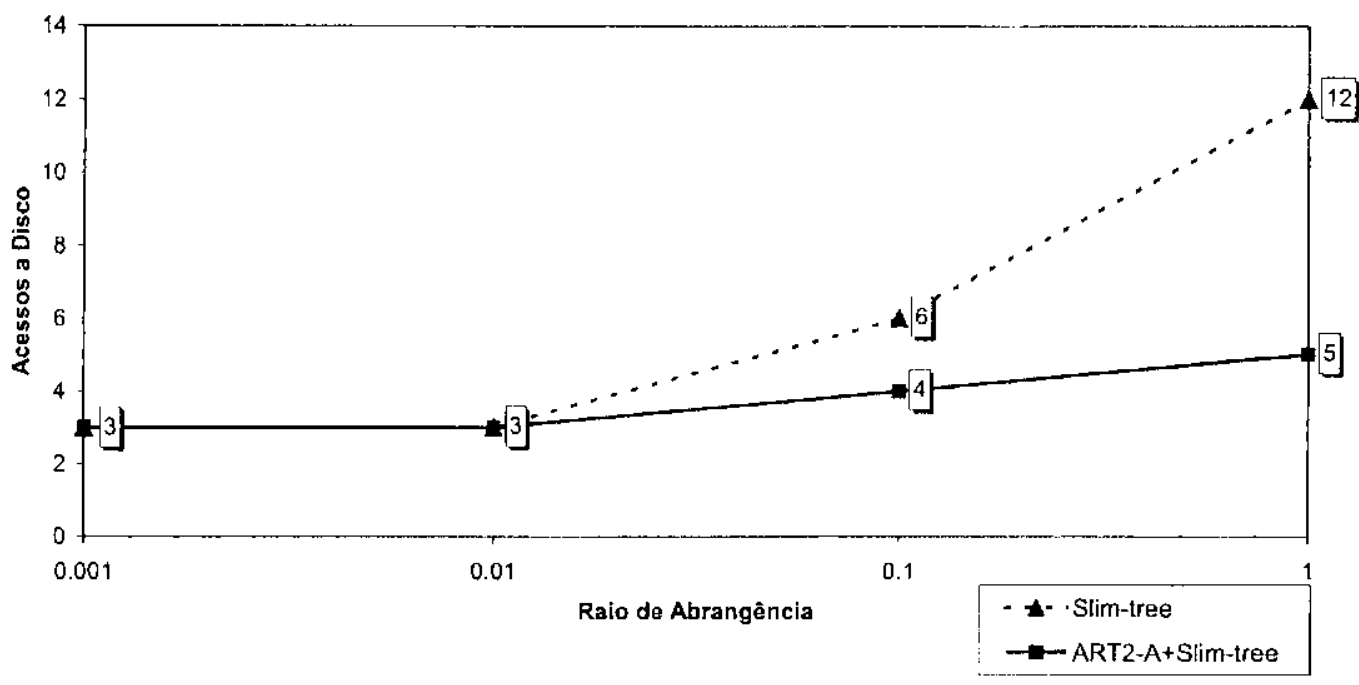

Figura 5.2: Desempenho, em número de acessos a disco, do MAEM Slim-Tree e do modelo híbrido (ART2-A+Slim-tree), em consultas por abrangência realizadas na base de dados Iris.

Conjunto de Dadas: Iris

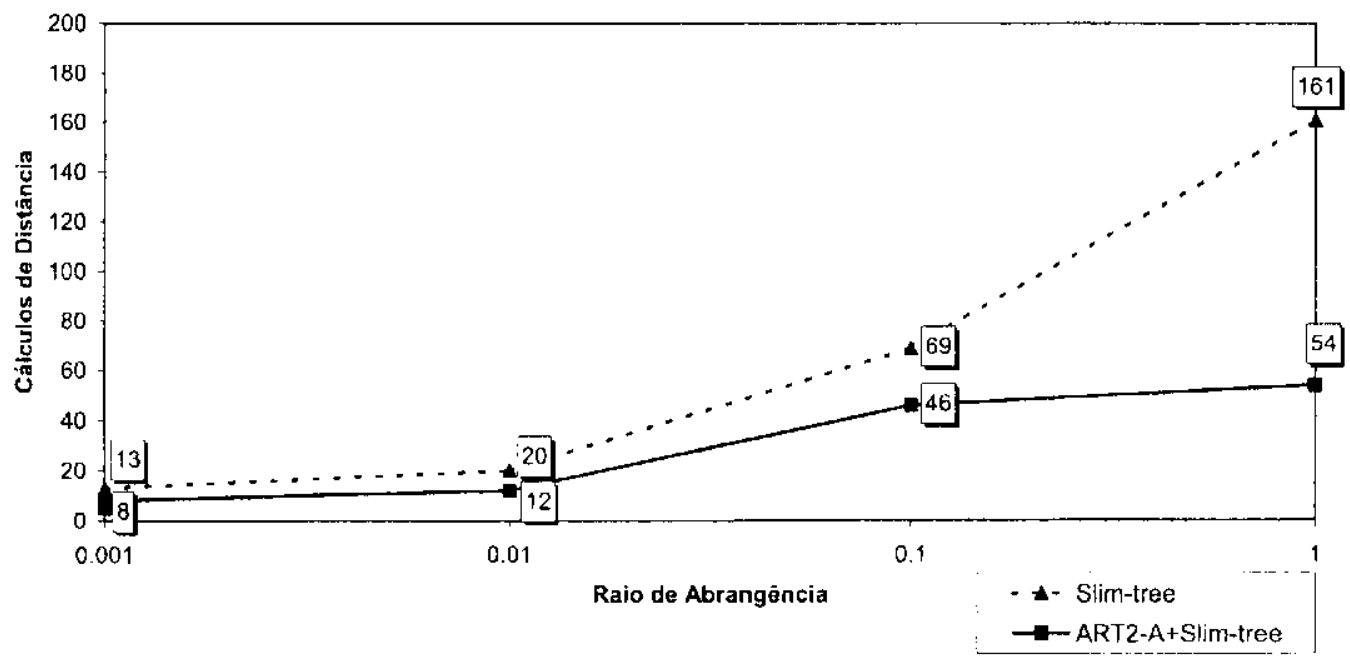

Figura 5.3: Desempenho, em número de cálculos de distância, do MAEM Slim-Tree e do modelo hibrido (ART2-A+Slim-tree), em consultas por abrangência realizadas na base de dados Iris.

número de exemplos de treinamento. Neste caso, considerou-se, para conjunto de treinamento, a base de dados completa.

Nota-se que para esta base de dados, que não contém nenhuma informaçāo sobre as classes, o desempenho do modelo hibrido foi bem superior ao da Slim-Trees (ver 5.10 a Figura 5.13), tanto em relaçāo ao número de acessos a disco quanto ao número de cálculos de distância. 
Conjunto de Dados: tris

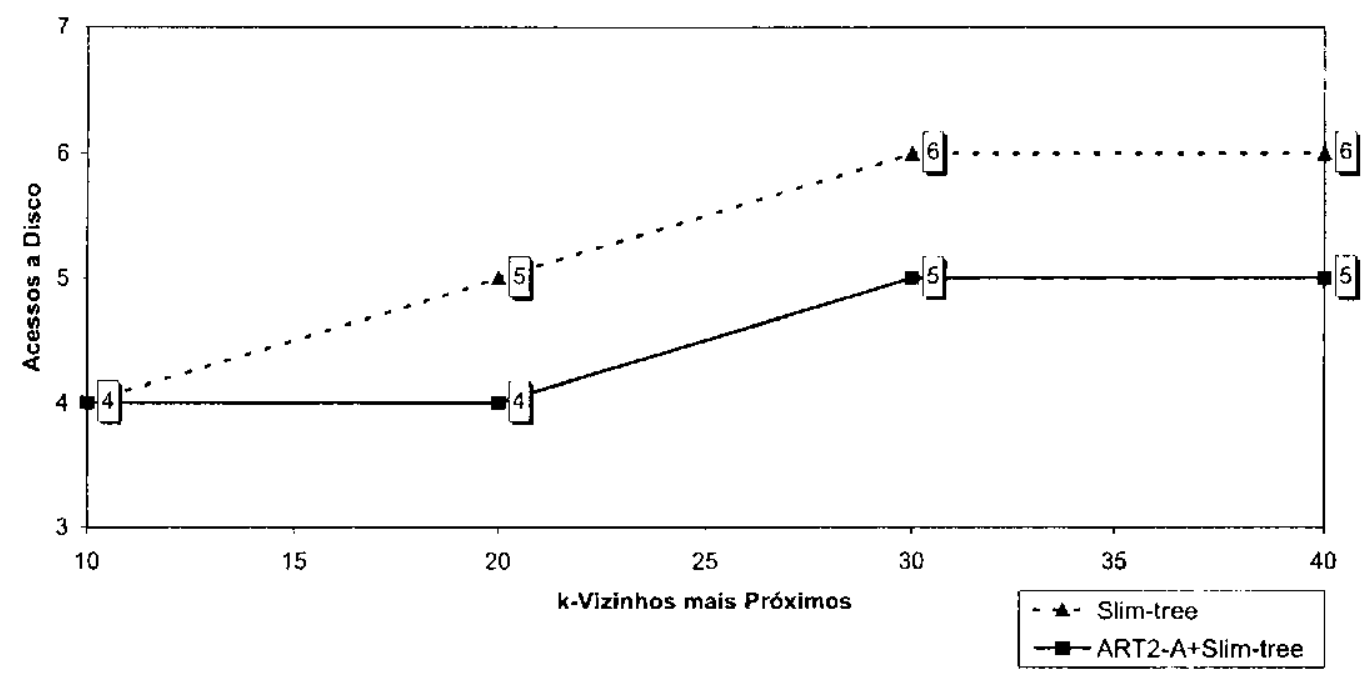

Figura 5.4: Desempenho, em números de acessos a disco, do MAEM Slim-Tree e do modelo híbrido (ART2-A+Slim-tree), em consultas por $k$-vizinhos mais próximos realizadas na base de dados Iris.

Conjunto de Dados: Iris

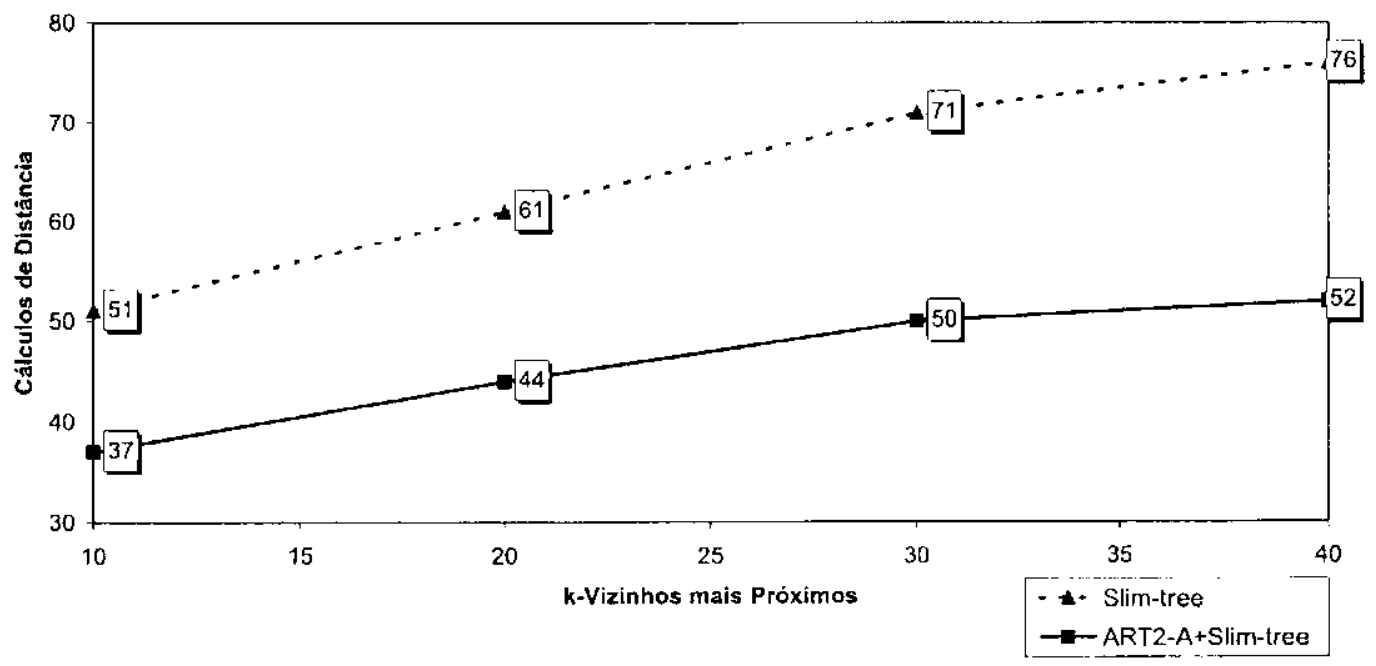

Figura 5.5: Desempenho, em número de cálculos de distância, do MAEM Slim-Tree e do modelo hibrido (ART2-A+Slim-tree), em consultas por $k$-vizinhos mais próximos realizadas na base de dadosiris. 
Conjunto de Dados - Waveform

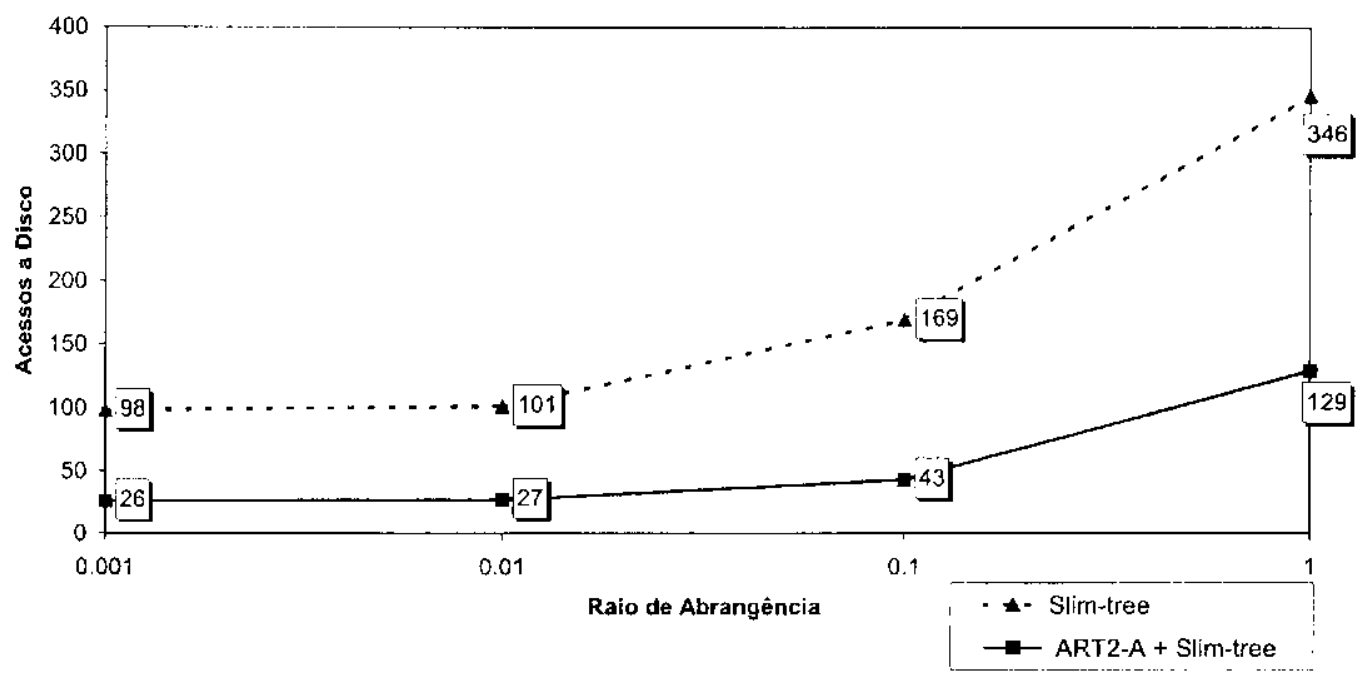

Figura 5.6: Desempenho, em número de acessos a disco, do MAEM Slim-Tree e do modelo hibrido (ART2-A+Slim-tree), em consultas por abrangência realizadas na base de dados Waveform.

Conjunto de Dados- Waveform

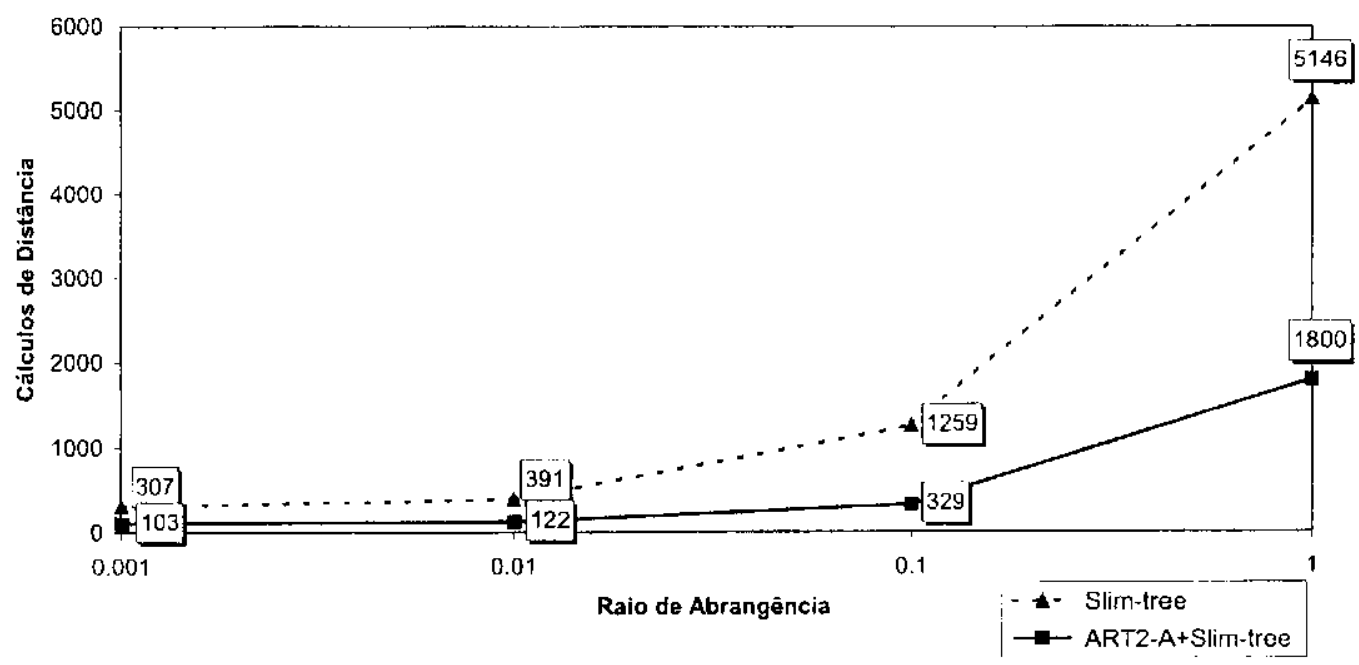

Figura 5.7: Desempenho, em número de cálculos de distância, do MAEM Slim-Tree e do modelo híbrido (ART2-A+Slim-trce), em consultas por abrangência realizadas na base de dados Waveform. 
Conjunto de Dados- Waveform

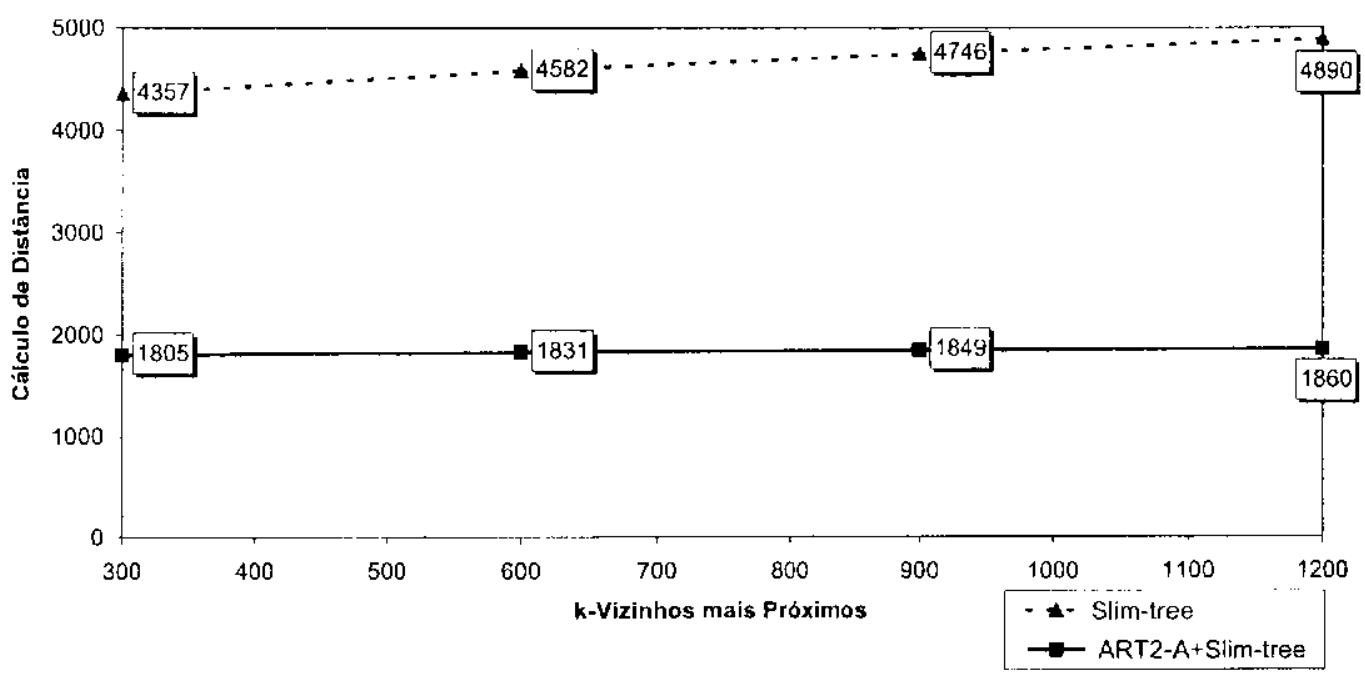

Figura 5.8: Desempenho, em número de números de acessos a disco, do MAEM Slim-Tree e do modelo híbrido (ART2-A+Slim-tree), em consultas por $k$-vizinhos mais próximos realizadas na base de dados Waveform.

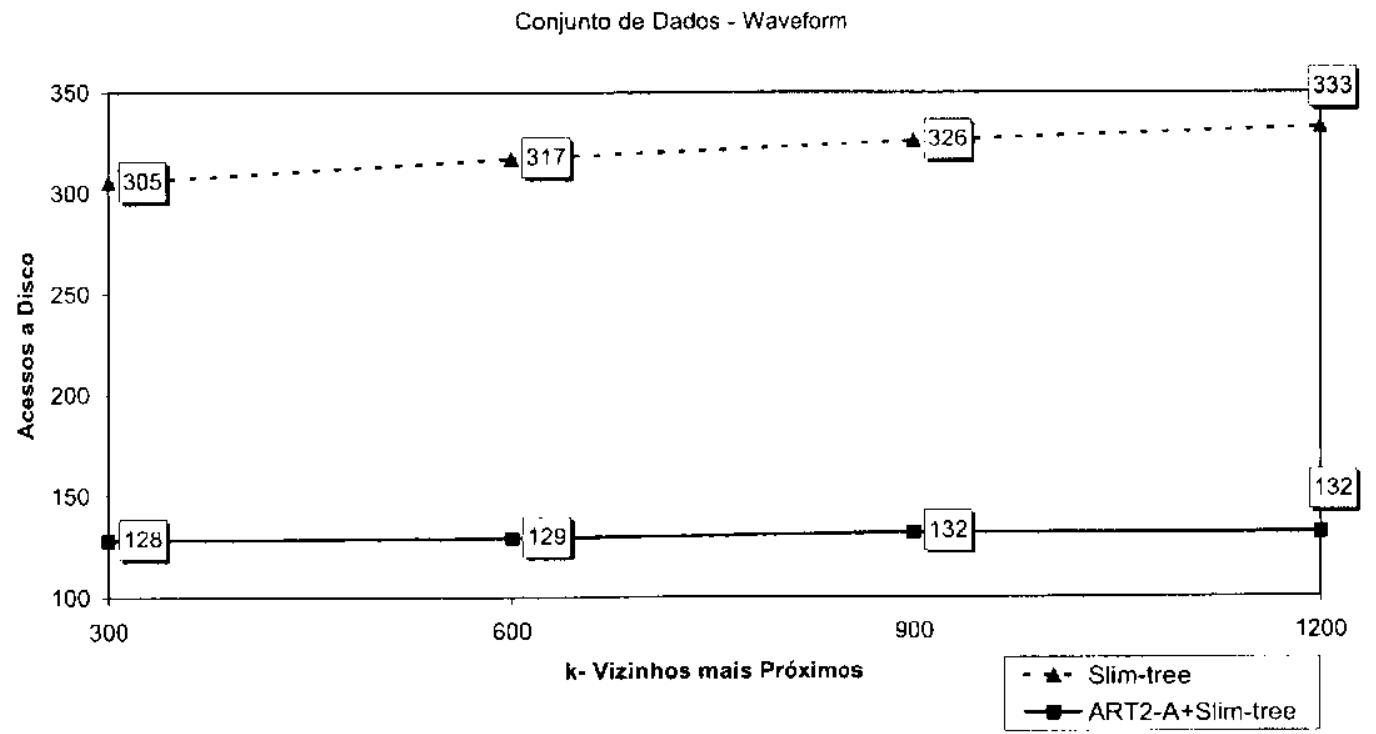

Figura 5.9: Desempenho, em número de cálculos de distāncia, do MAEM Slim-Tree e do modelo hibrido ( $\Lambda$ RT2-A+Slim-tree), em consultas por $k$-vizinhos mais próximos realizadas na base de dados Waveform. 
Conjunto de Dados: Eigenfaces

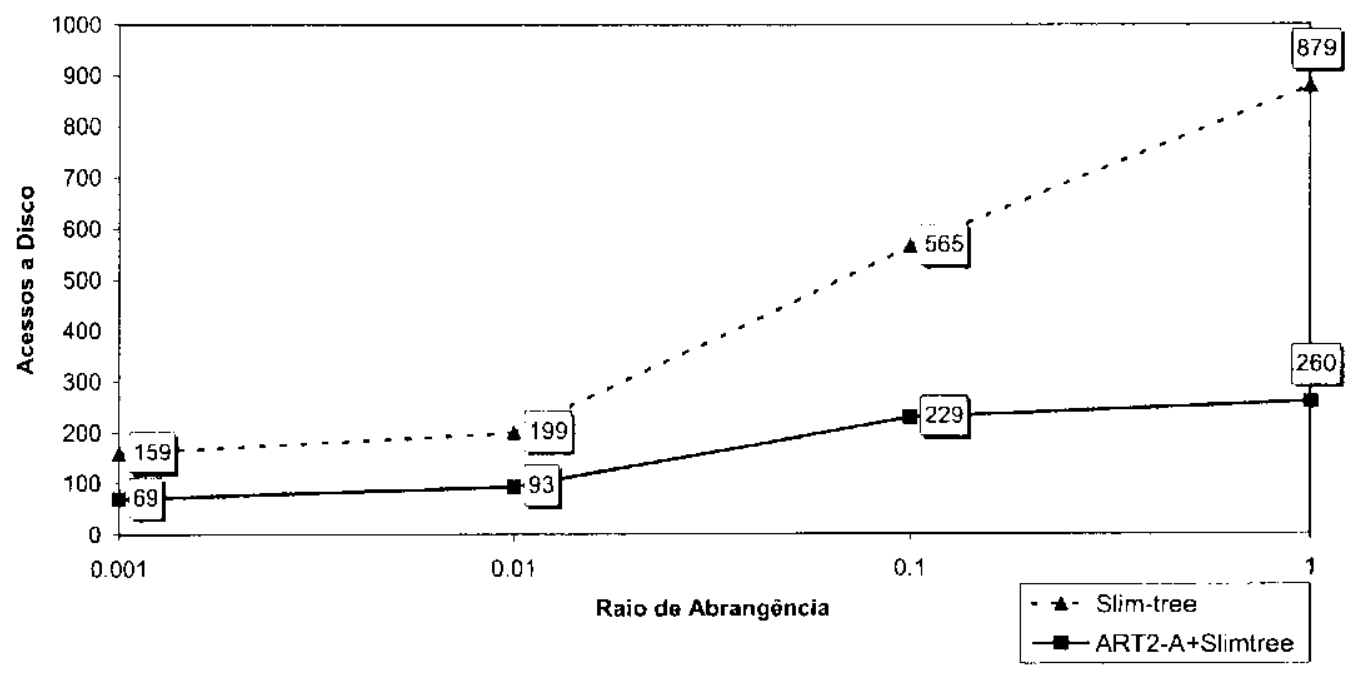

Figura 5.10: Desempenho, em número de acessos a disco, do MAEM Slim-Tree e do modelo híbrido (ART2-A+Slim-tree) em consultas por abrangência realizadas na base de dados Eigenfaces.

Conjunto de Dados: Eigenfaces

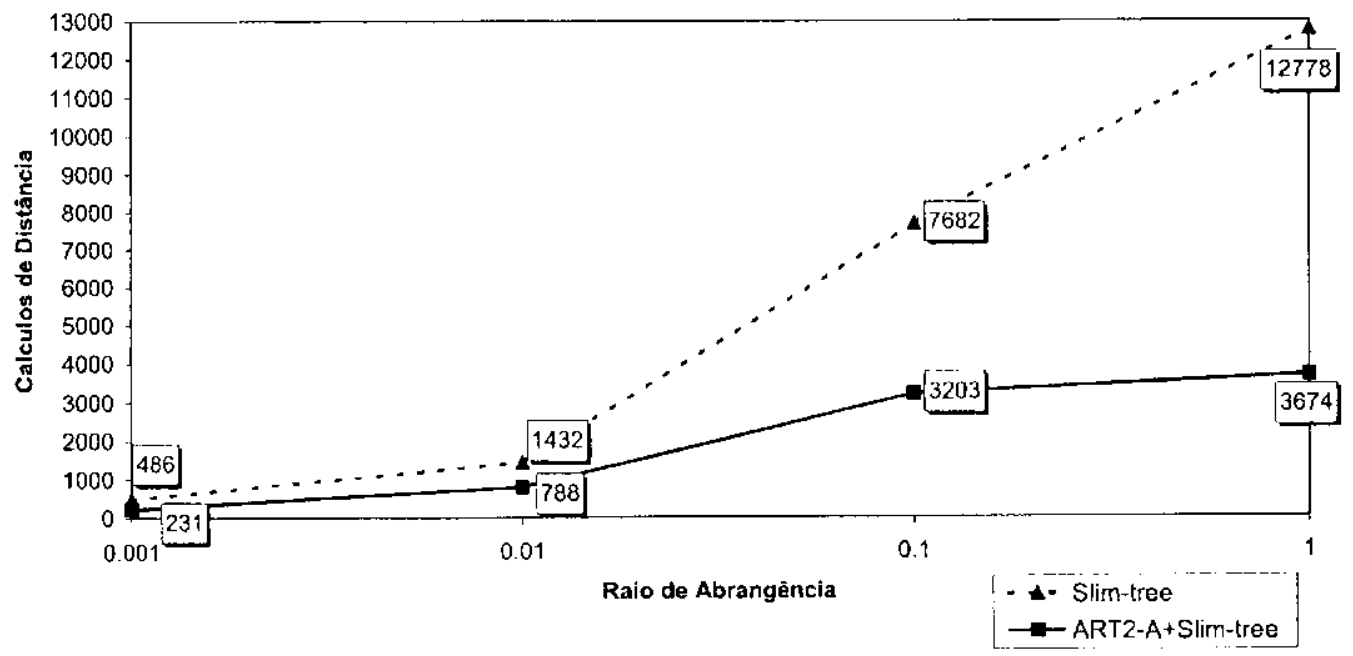

Figura 5.11: Desempenho, em número de cálculos de distância, do MAEM Slim-Tree e do modelo hibrido (ART2- $\Lambda+S l i m$-tree) em consultas por abrangência realizadas na base de dados Eigenfaces. 
Conjunto de Dados: Eigenfaces

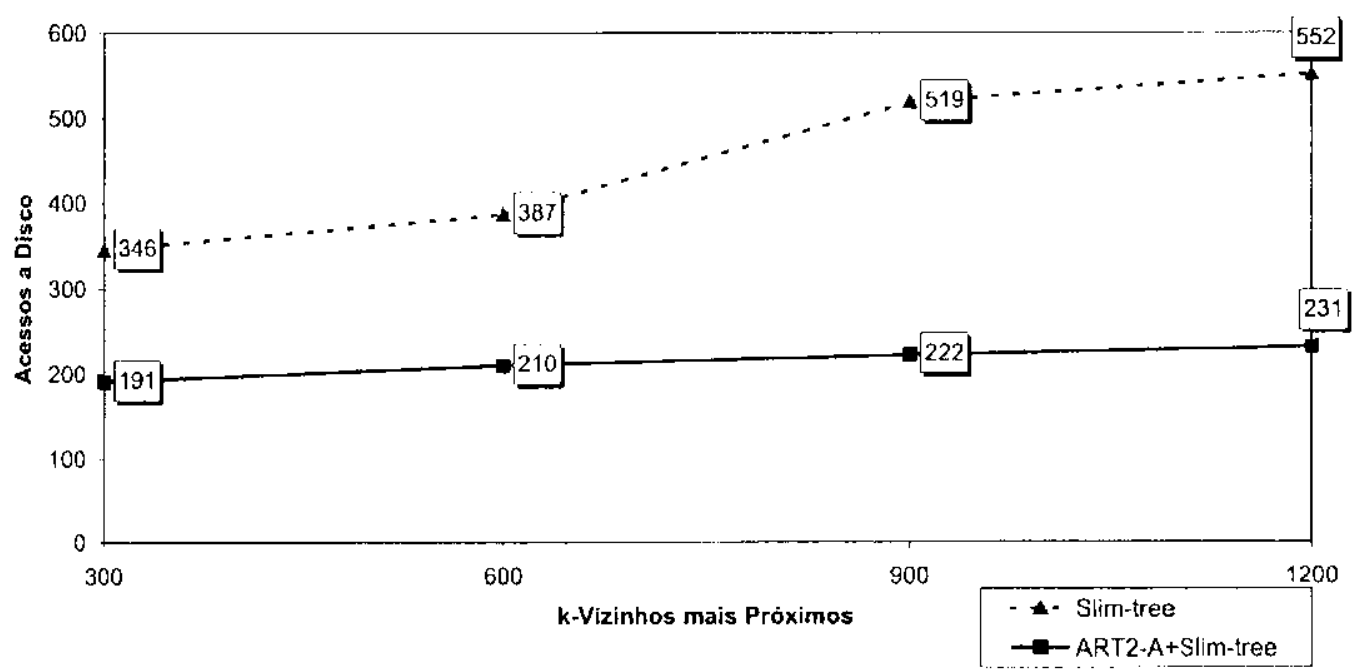

Figura 5.12: Desempenho, em número de accssos a disco, do MAEM Slim-Tree e do modelo híbrido (ART2- $A+S l i m$-tree) em consultas por $k$-vizinhos mais próximos realizadas na base de dados Eigenfaces.

Conjunto de Dados: Eigenfaces

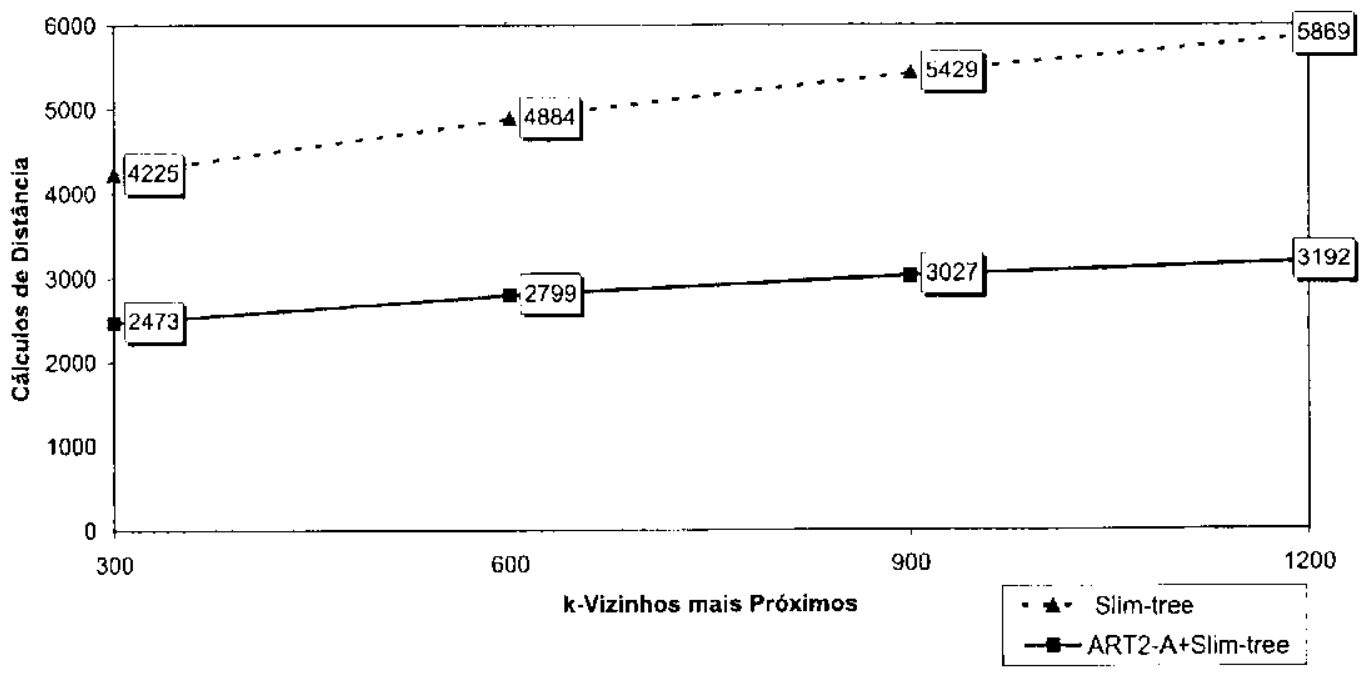

Figura 5.13: Desempenho, em número de cálculos de distância, do MAEM Slim-Tree e do modelo híbrido (ART2-A+Slim-tree) em consultas por $k$-vizinhos mais próximos realizadas na base de dados Eigenfaces. 


\section{Conclusão e Trabalhos Futuros}

O modelo desenvolvido neste trabalho, tem como principais caracteristicas ser dinâmico e robusto, considerando-se aplicação para dados multi-dimensionais. Isto é devido às características dinâmicas tanto da rede ART2-A quanto da estrutura Slim-Tree. A rede tem a caracteristica de incorporar novo conhecimento sem perder aquele previamente adquirido, e a Slim-Tree permite que novos dados sejam inseridos no modelo híbrido, mesmo depois de já haver sido realizado algum tipo de consulta.

Mesmo que nāo se conheça nenhuma informação a respeito dos dados e que se opte por fazer o treinamento com o conjunto de dados completo, com certeza o espaço de busca será reduzido, devido a formação de clusters que ocorre graças ao processamento da rede neural. Assim sendo, mesmo que o treinamento seja demorado, ainda valerá a pena utilizar o sistema híbrido para consulta, pois, uma vez treinada a rede, podc-sc fazer uso do conjunto de pesos para se fazer buscas, sem necessidade de novo treinamento da rede. Além disso, se houver a necessidade de armazenar novos dados, estes poderão ser inseridos no sistema híbrido de forma incremental, isto é, o treinamento da rede neural será feito apenas com o novo conjunto de dados, considerando um treinamento prévio para o conjunto de pesos da rede neural. Isto permite um ganho de tempo em relaçāo a aquele que se teria, caso fosse realizado com toda a base de dados, anteriormente usada para treinamento, acrescida do novo conjunto de dados.

O desempenho do modelo teve considerável melhora graças à redução do espaço de busca, proporcionada pelo agrupamento dos dados a partir do modelo neural. Cada neurônio da rede neural funciona como um objeto rcpresentativo da Slim-Tree $\mathrm{e}$ isto faz com que algumas sub-árvores sejam podadas antes que a busca prossiga em frente. Esses representativos foram encontrados graças ao processo de treinamento da rede neural e ficam armazenados na memória principal, uma vez que estes correspondem aos protótipos armazenados nos pesos da rede neural. No caso de se utilizar apenas a Slim-Tree, seria necessário montar a árvore completa e fazer a poda considerando a árvore toda (isto é, todos os objetos da árvore armazenados em disco), o que innplica um custo computacional maior. 
Este modelo apresenta duas contribuições importantes. Para área de RNAs, tem-se um modelo de RNA capaz de fazer recuperação de informações baseadas em conteúdo, isto é, utilizando objetos de referència, e com capacidade de responder a operações de consultas sofisticadas, tais como consultas por abrangência e $k$-vizinhos mais próximos, o que não é caracteristica comum em modelos de RNAs.

Para a área de Data Mining, foi desenvolvido um modelo de busca que apresenta um custo computacional menor do que aquele apresentado pela estrutura Slim-Tree.

Além disso, o sistema híbrido será interligado ao projeto IMiMD (Indexing and Data Mining in Multimedia Databases), financiado pelo Programa ProTem/NSF;

No entanto, estas conclusões levam em consideração apenas os testes apresentados. Para uma conclusão mais geral, será necessário que mais testes com bases de dados diferentes sejam considerados.

A seguir são indicadas algumas propostas futuras para a continuidade deste trabalho:

- Utilizar outras bases de dados com diferentes tipos de dados multimídia, tais como vídeo digitalizado, audio, moléculas de DNA e impressōes digitais, e validar do sistema híbrido quando à capacidade de agrupamento e recuperação destes tipos de informaçōes.

- Avaliar a possibilidade de combinar o MAEM Slim-Tree com outros modelos de redes neurais da família ART, tanto modelos que implementam o paradigma de aprendizado não-supervisionado quanto modelos que implementam o paradigma de aprendizado supervisionado;

- Incorporar ferramentas para visualização da estrutura Slim-Tree formada nos cluster criados pela RNA. Isto pode ser útil para se fazer análise dos clusters, já que a estrutura pode fornecer a relação de similaridade que cada objeto tem um com outro dentro de cada unidade de cluster.

- Inserir o modelo híbrido proposto em uma base de dados conectada a um SGBDM (Sistema de Gerenciamento de Banco de dados Multimidia). Assim, pretende-se tornar possível que um usuário possa efetuar consultas do tipo: "Encontre um conjunto de imagens que diferem de uma dada imagem em no máximo $20 \%$ ", ou ainda, "Encontre todas as imagens que estāo dentro de uma faixa de 10 unidades de uma dada imagem". É esperado que o modelo também possa responder a consultas do tipo: "Encontre os padröes mais freqüentes que aparecem em imagens de tomografia abdominal".

- Incorporar os módulos de implementaçāo dos modelos ART ao simulador de Redes Neurais Kipu (Cuadros, 1998). 


\section{Referências Bibliográficas}

Aghbari, Z., OH, K.-S., Feng, Y., and Makinouchi, A. (2002). Som-based k-nearest neighbors search in large databases. In Sixth Working Conference on Visual Database Systems, pages 51-65, Brisbane, Autralia.

Albrecht, R. and Merkl, D. (1999). Extracting information from text data bases. ASP Conferense Series, 172. http://citeseer.nj.nec.com/352778.html.

Amari, S. I. (1983). Field theory of self-organizing neural nets. IEEE Transactions on Systems, Man, and Cybernetics, SMC-13:741-748.

Bachelder, I., Waxman, A., and Seibert, M. (1993). A neural system for mobile robot visual place learning and recognition. In In Proceedings of the World Congress on Neural Networks, volume I, pages 512-517, Hillsdale. NJ: Erlbaum Associates.

Baeza-Yates, R. A., Cunto, W., Manber, U., and Wu, S. (1994). Proximity matching using fixed-queries trees. In Crochemore, M. and Gusfield, D., editors, Proceedings of the 5th Annual Symposium on Combinatorial Pattern Matching, volume 807, pages 198-212, Asilomar, CA. Springer-Verlag, Berlin.

Baldi, P. and Hornik, K. (1989). Neural networks and principal component analysis: learning from examples without local minima. Neural networks, 2:53-58.

Baraldi, A. and Alpaydin, E. (1998). Simplified ART: A new class of ART algorithms. Technical Report TR-98-004, International Computer Science Institute, Berkeley, CA.

Baraldi, A. and Alpaydin, E. (2002a). Constructive feedforward art clustering networks - part i. IEEE Transaction on Neural Networks, 13(3):645-661.

Baraldi, A. and Alpaydin, E. (2002b). Constructive fecdforward art clustering networks - part ii. IEEE Transaction on Neural Networks, 13(3):662-677. 
Baraldi, A. and Blonda, P. (1999). A survey of fuzzy clustering algorithms for pattern recognition - part ii. IEEE Transactions on Systems, Man and Cybernetics, Part B (Cybernetics), 29(6):786-801.

Barlow, H. B. (1989). Unsupervised learning. Neural Computation, 1(3):295-31 1.

Bartfai, G. (1994). Hierarchical clustering with art neural networks. In IEEE International Conference on Neural Networks, volume 2, pages 940-944. IEEE Press.

Bartfai, G. (1995). An art-based modular architecture for learning hierarchical clusterings. TR, CS-TR-95/3.

Bayer, R. and McCreight, E. (1972). Organization and maintenance of large ordered indexes. Acta Informatica, 3(1):173-189.

Beckmann, N., Kriegel, H., and Schnei, R. (1990). The $r^{*}$-tree: an efficient and robust access method for points and rectangles. In Proceedings of ACM SIGMOD Conference.

Berchtold, S., Keim, D., and Kriegel, H. (1996). The x-tree: an index structure for high-dimensional data. Proceedings, International Conference on Very Large Data Bases, 22, pages 28-39. Mumbai (Bombay).

Bernardon, A. M. and Carrick, J. E. (1995). A neural system for automatic target learning and recognition applied to bare and camoulflaged sar target. Neural Networks, 8:1103-1108.

Bezdek, J. C. (1992). Integration and generalization of LVQ and c-means clustering. In SPIE Vol. 1826, Intelligent Robots and Computer Vision XI: Biological, Neural Net, and 3-D Methods, volume 1826, pages 280-299, Bellingham, WA. SPIE.

Blake, C. L. and Merz, C. J. (1998). UCI repository of machine learning databases. University of California, Irvine, Dept. of Information and Computer Sciences.

Blonda, P., Baraldi, A., Bafunno, G., Satalino, G., and Ria, G. (1997). Experimental comparison of FOSART and F LVQ in a remotely sensed image classification task. Proceedings of the SPIE-The International Society for Optical Engineering, 3165:113-22. Applications of Soft Computing Conf. Date: 28-29 July.

Bose, S. and Murthy, C. (1996). New LVG model, technical rept.

Bozkaya, T. and Ozsoyoglu, M. (1997). Distance-based indexing for high-dimensional metric spaces. http://citeseer.nj.nec.com/67185.html.

Brin, S. (1995). Near neighbor search in large metric spaces. In The VLDB Journal, pages 574-584. http://citeseer.nj.nec.com/brin95near.html. 
Burkhard, W. and Keller, R. (1973). Some approaches to best-match file searching. Communications of the ACM, 16(4):230-236.

Carpenter, A. and Grossberg, S. (1990). Art 3 hierarchical search: Chemical transmitter in selforganizing pattern recognition architectures. Neural Networks, 3:129-152.

Carpenter, G., Grossberg, S., Markuzon, N., Reynolds, J. H., and Rosen, D. B. (1992). Fuzzy ARTMAP: A neural network architecture for incremental supervised learning of analog multidimensional maps. IEEE Transactions on Neural Networks, 3(5):698-713.

Carpenter, G., Grossberg, S., Neurophysiol, C., and Reynolds, S. (1991a). Artmap: Supervised real-time learning and classification of nonstationary data by a self-organizing neural network. Neural Networks, 4:565-588.

Carpenter, G., Grossberg, S., and Rosen, D. (1991b). Fuzzy art: Fast stable learning and categorization of analog patterns by an adaptive resonance system. Neural Networks, 4:759-771.

Carpenter, G. A. and Grossberg, S. (1987a). Art 2 : self-organization of stable category recognition codes for analog input patterns. Applied Optics, 26(23):4919-4930.

Carpenter, G. A. and Grossberg, S. (1987b). A massively parallel architecture for a self-organizing neural pattern recognition machine. Computer Vision, Graphics, and Image Processing, 37(1):54-1 15.

Carpenter, G. A., Grossberg, S., and Rosen, D. B. (199lc). Art2-a: An adaptive resonance algorithm for rapid category learning and recognition. Neural Networks, 4:493-504.

Caudell, T., Smith, S., Escobedo, R., and Anderson, M. (1994). Nirs: Large scale art-1 neural architectures for engineering design retrieval. Neural Networks, 7(9).

Caudell, T. P. and Healy, M. J. (1994). Adaptive resonance theory networks in the encephalon autonomous vision system. In Proceedings of the IEEE International Conference on Neural Networks, pages 1235-1240, Orlando, Florida. IEEE.

Celsia, G. G. (1976). Organization of auditory cortical areas in man. Brain, 99:403-414.

Celsia, G. G., Broughton, R. J., Rasmussen, T., and Branch, C. (1968). Auditory evoked responses from the exposed human cortex. Electroencephalography and Clinical Neurophysiology, 24:458-466.

Changeoux, J. P. and Danchin., A. (1976). Seletive stabilization of developing sinpases as a mechanism for the specification of neural network. Nature(London), 264:705-712. 
Chávez, E., Marroquín, J. L., and Navarro, G. (1999). Overcoming the curse of dimensionality. In Workshop on Content-Based Multimedia Indexing (CBMI'99), pages 57-64.

Chãvez, E., Navarro, G., Baeza-Yates, R., and Marroquín, J. (2001). Searching in metric spaces.

Chiuch, T. (1994). Content-based image indexing. In Proceedings of the Twentieth International Conference on Very Large Databases, pages 582-593, Santiago, Chile.

Ciaccia, P., Patella, M., and Zezula, P. (1997). M-tree: An efficient access method for similarity search in metric spaces. In In Proc. of the 23rd Intl. Conf. on Very Large Data Bases - VLDB, pages 426-435.

Comer, D. (1979). The ubiquitous b-tree. ACM Computing Surveys, 1 1(2):121-137.

Cuadros, E. (1998). Kipu: Simulador de redes neurais construtivas. Master's thesis, Universidade de São Paulo - USP, São Carlos - SP. Tese de mestrado - ICMC-USP.

der Malsburgs, C. V. (1973). An automation with brain-like properties. Kibernets, 14:85-100.

Duda, R. and Hart, P. (1973). Pattern Classification and Scene Analysis. Wiley, New York.

Faloutsos, C. and Lin, K. (1995). Fastmap: A fast algorithm for indexing, data-mining and visualization of traditional and multimedia data. In Int. Conf. on Management of Data-ACM SIGMOD, pages 163-174, San Jose, CA.

Fausett, L. (1994). Fundamental of Neural Network: Architectures, Algorithms, and Applications. Prentice Hall.

Finkel, R. and Bentley, J. (1974). Quadtrees: A data structure for retrieval of composite keys. Acta Informatica, 4(1):1-9.

Folk, M., Zoellick, B., and Riccardi, G. (1998). File Structures, An Object Oriented Approach Using $\mathrm{C}++$. Addison-Wesley, 3 edition.

Frank, T., Kraiss, K.-F., and Kuhlen, T. (1998). Comparative analysis of fuzzy art and art2-a network clustering performance. IEEE Transactions on Neural Networks, $9(3)$.

Freeman, J. A. and Skapura, D. M. (1991). Neural Networks - Algorithms, Applications, and Programing Techniques. New York: Addison-Wesley.

Fuchs, II., Kedem, Z., and Naylor, B. (1980). On visible surface generation by a priori tree structures. In ACM SIGGRAPH - Computer Graphics, volume 14, pages 124-133. 
Fukunaga, K. (1990). Introduction to Statistical Pattern Recognition. Academic Press. 2nd Edition.

Fukushima, K. (1975). Cognitron: a self-organizing multilayered neural network. Biological Cybernetics, 23:121-134.

Fukushima, K. (1980). Neocognitron: a self-organizing neural network model for a mechanism of pattern recognition unaffected by shift in position. Biological Cybernetics, 36:196-202.

Gaede, V. and Gunther, O. (1998). Multidimensional access method. ACM Computing Surveys, 30(2):170-231.

Gan, K. and Lua, K. (1992). Chinese character classification using adaptive resonanse network. Pattern Recognition, 25:877-888.

Golub, G. H. and Loan, C. F. V. (1989). Matrix Computations. The Johns Hopkins University Press, Baltimore, second edition.

Guttman, A. (1984). R-trees: $\Lambda$ dynamic index structure for spatial searching. In $A C M$ SICMOD Conference, pages 47-57, Boston.

Ham, F. and Han, S. (1996). Classification of cardiac arrhythmias using fuzzy artmap. IEEE Transactions on Biomedical Engineering, 43(4):425-430.

Haring, S., Viergever, M. A., and Kok, J. N. (1994). Kohonen networks for multiscale image segmentation. Image and Vision Computing, 12(6):339-44.

Haykin, S. (1994). Neural networks-a comprehensive foundation. Macmillan And Ieee Press.

He, J., Tan, A.-H., and Tan, C.-L. (2002). Art-c : $\Lambda$ neural architecture for self-organization under constraints. In Proceedings of International Joint Conference on Neural Networks (IJCNN), pages 2550-2555, Hawaii, USA.

Hebb, D. O. (1949). The Organization of Behavior. John Wiley \& Sons, New York, NY.

Hellerstein, J. M., Naughton, J. F., and Pfeffer, A. (1995). Generalized search trees for database systems. In Proc. 21st Int. Conf. Very Large Data Bases, VLDB, pages 562-573. Morgan Kaufmann. editors Umeshwar Dayal and Peter M. D. Gray and Shojiro Nishio, isbn 1-55860-379-4.

Hopfield, J. J. (1982). Neural networks and systems with emergent selective computational abilities. In National Academy of Sciences of the USA, volume 79, pages 3088-3082.

Hrönel, D. and Ragg, T. (2000). Learning musical structure and style by recognition, prediction and evolution. citeseer.nj.nec.com/370243.html. 
Hussain, T. S. (1993). Artstar: A supervised modular adaptive resonance network classifier. Master's thesis, Quenn's University, Kingston, Ontario - Canada. URL http://citeseer.nj.nec.com/70535.html.

Johnson, R. and Wichern. D. (1998). Applied Multivariate Statistical Analysis. Prentice Hall, New Jersey, fourth edition edition.

Kalantari, I. and McDonald, G. (1983). A data structure and an algorithm for the nearest point problem. IEEE Transactions on Software Engineering, 9(5):631-634.

Kaski, S. (1999). Fast winner wearch for SOM-based monitoring and retrieval of high-dimensional data. In In Proceedings of ICANN99, Ninth International Conference on Artificial Neural Networks, volume 2, pages 940-945, London. IEE Conference Publication. http://citeseer.nj.nec.com/kaski99fast.html.

Kim, J. W., Jung, K. C., Kim, S. K., and Kim, J. H. (1995). Shape classification of on-line chinese character strokes using art 1 neural network. In In Proceedings of World Congress on Neural Networks (WCNN'95), Hillsdale. NJ:Erlbaum.

Kohonen, T. (1982). Self-organized formation of topologically correct feature maps. Biological Cybernetics, 43:59-69.

Kohonen, T. (1984). Self-organization and associative memory. Springer Series of Information Science, 8.

Kohonen, T. (1989a). The 'neural' phonetic typewriter. In The Second European Seminar on Neural Networks, London, UK. British Neural Networks Society.

Kohonen, T. (1989b). Self-organization and associative memory. Springer Series of Information Science, 3rd Ed.

Kohonen, T. (1990). The self-organizing map. In New Concepts in Computer Science: Proc. Symp. in IIonour of Jean-Claude Simon, pages 181-190, Paris, France. AFCET.

Kohonen, T. (1997). Exploration of very large databases by self-organizing maps. In Proceedings of ICNN'97, International Conference on Neural Networks, pages PL1-PL6, Piscataway, NJ. IEEE Service Center.

Kohonen, T., Kangas, J., Laaksonen, J., and Torkkola, K. (1992). LVQ_PAK: A program package for the correct application of Learning Vector Quantization algorithms. In Proc. IJCNN'92, International Joint Conference on Neural Networks, volume I, pages 725-730, Piscataway, NJ. IEEE Service Center.

Kohonen, T. and Somervuo, P. (1997). Self-organizing maps of symbol strings with application to speech recognition. In Proceedings of WSOM'97, Workshop on Self-Organizing Maps, pages 2-7, Espoo, Finland. Helsinki University of Technology, Ncural Networks Research Centre. 
Koskela, M. (1999). Content-based image retrieval with self-organizing maps. Master's thesis, Helsinki University Of Technology Department of Engineering Physics and Mathematics, Helsinki, Finland. http://citeseer.nj.nec.com/369758.html.

Laaksonen, J., Koskela, M., and Oja, E. (1999). PicSOM: Self-organizing maps for content-based image retrieval. In International Joint Conference on Neural Networks (IJCNN'99), Washington, D.C.,USA. citeseer.nj.nec.com/article/laaksonen99picsom.html.

Linsker, R. (1986). From basic network principles to neural architecture: Emergence of spacial-opponent cells / orientation-selective cells / orientation columns. Proceedings of the National Academy of Sciences, 83:7508-7512, 8390-8394, 8779-8783.

Lomet, D. and Salzberg, B. (1989). A robust multi-attribute search structure. In Fifth International Conference on Data Engineering, pages 296-304, Los Angeles, CA. IEEE.

Masters, T. (1993). Practical Neural Network Recipes in C++. Academic Press. Inc.

Matsuoka, Y. (1995). Embodiment and manipulation learning process for a humanoid hand. Technical Report AITR-1546, Massachusetts Institute of Technology. http://citeseer.nj.nec.com/matsuoka95embodiment.html.

Mehta, B., Vij, L., and Rabelo, L. (1993). Prediction of secondary structures of proteins using fuzzy artmap. Lawrence Erlbaum Ass., Inc., Hillsdale, NJ.

Moya, M., Koch, M., and Hostetler, L. (1993). One-class classifier networks for target recognition applications. In World Congress on neural networks, pages 797-801, Portland, OR. International Neural Network Society, INNS.

Murre, J. M., Pfaf, R. H., and Wolters, G. (1989). Calm networks: A modular approach to supervised and unsupervised learning. In In Proceedings of the IJCNN-89.

Murshed, N. A., Bortozzi, F., and Sabourin, R. (1995). Off-line signature verification without a priori knowledge of class $\omega 2$. In NJ:IEEE, editor, In proceedings of The International Conference on Document Analysis and Recognition, Piscataway.

Nakamura, T. and Ogasawara, T. (1999). On-line visual learning method for color image segmentation and object tracking. In International Conference on Intelligent Robots and Systems (IROS' 99), pages 222-228. IEEE/RSJ.

Ng, R. and Sedighian, A. (1996). Evaluating multi-dimensional indexing structure for images transformed by principal component analysis. In (SPIE IST) Conf. on Storage and Retrieval for Image and Video Databases $V$, volume 2670, pages 50-61, San Jose, CA. 
Oliveira, P. R., Vicentini, J. F., and Romero, R. A. F. (2002). Combining fuzzy art network clustering and sparce code shrinkage for image segmentation. 9th International Conference on Neural Information Processing (ICONIP'2002). Singapore, (to appear).

Papadias, D., Mamoulis, N., and Theodoridis, Y. (1999). Processing and optimization of multiway spatial joins using R-trees. In Procedings of ACM PODS, pages 44-55.

Papadias, D., Theodoridis, Y., Sellis, T., and Egenhofer, M. (1995). Topological relations in the world of minimum bounding rectangles: A study with $r$-trees. In ACM SIGMOD International Conference on Management of Data, pages 92-103. San Jose - California, USA.

Peper, F., Zhang, B., and Noda, H. (1993). A comparative study of art2-a and the self-Organizing feature map.

Perrott, D. and Gjerdigen, R. (1999). Scanning the dial: An exploration of factors in the identification of musical style.

Press, W. H., Flannery, B. P., Teukolsky, S. A., and Vetterling, W. T. (1988). Numerical Recipes in C. Cambridge University Press.

Racz, J. and Dubrawski, A. (1995). Artificial neural network for mobile robot topological localization.

Robinson, J. T. (1984). he k-d-b tree: A search structure for large multidimensional dynamic indexes. In ACM SIGMOD l Conference on Management of Data, volume 177, pages 10-18, Ann Arbor, Michigan.

Roussopoulus, N., Kelley, S., and Vincent, F. (1995). Nearest neighbor queries. Proceedings ACM Sigmod International Conference On Management of Data, pages 71-79.

Rumelhart, D. E., Hinton, G. E., and Williams, R. J. (1986). Learning internal representations by error propagation. In Rumelhart, D. E. and McClelland, J. L., editors, Parallel Distributed Processing: Explorations in the Microstructure of Cognition. Vol. I: Foundations, pages 318-362. Bradford Books/MIT Press, Cambridge, MA.

Samet, H. (1995). Spatial Data Structures. Modern Database Systems. Reading, Addison-Wesley/ACM, kim, w., ed. edition.

Schieber, M. H. and Hibbard, L. S. (1993). How somatotopic is the motor cortex hand area?. Science, 261:489.

Schomaker, L. and Teulings, H. (1990). A handwriting recognition system based on the properties and architectures of the human motor system. In Proc. Int. Workshop on Frontiers in Handwriting Recognition, volume 168, pages 195-211, Montreal. 
Seibert, M. and Waxman, A. (1993). An approach to face recognition using saliency maps and caricatures. In Proceedings of the World Congress on Neural Networks (WCNN-93), volume III, pages 661-664, Hillsdale. NJ:Earlbaum.

Seibert, M. and Waxman, A. M. (1992). Adaptive 3-d object recognition from multiplc vicws. IEEE Transactions on Pattern Analysis and Machine Intelligence, 14(2): 107-124.

Sellis, T. K., Roussopoulos, N., and Faloutsos, C. (1987). The R+-tree: A dynamic index for multi-dimensional objects. In International Conference on Very Large Data Bases (VLDB), pages 507-518, Brighton, England. ht.tp://citeseer.nj.nec.com/sellis87tree.html.

Serratosa, F., Vergés-Llahi, J., Alquezar, R., and Sanfeliu, A. (1999). Face recognition: Graph matchingversus neuraltechniques. http://citeseer.nj.nec.com/404515.html.

Soliz, P. and Donohoe, G. W. (1996). Adaplive resonance theory neural network for fundus image segmentation. In NJ:Earlbaum, editor, In Proceedings of the World Congress on Neural Networks WCNN'96, pages 1180-1183, IIIlsdale.

Stent, G. S. (1973). A physiological mechanism for Hebb's postulate of learning. Proceedings of the National Academy of Sciences, 70:997-1001.

Strang, G. (1980). Linear Algebra and its Applications. Academic Press. 2nd edition.

Suzuki, Y. (1995). Self-organizing gRS-wave recognition in ECG using neural networks. IEEE Transactions on Neural Networks, 6(6):1469-1477.

Traina Jr., C., J. M. Traina, A., Seeger, B., and Faloutsos, C. (2000a). Slim-trees: High performance metric trees minimizing overlap between nodes. In Advances in Database Technology - EDBT 2000, 6th International Conference on Extending Database Technology, Konstanz, Germany, March 27-31, 2000, Proceedings, volume 1777 of Lecture Notes in Computer Science, pages 51-65. Springer. editor by Carlo Zaniolo and Peter C. Lockemann and Marc H. Scholl and Torsten Grust, bibsource at http://dblp.uni-trier.de, isbn(3-540-67227-3).

Traina Jr., C., J. M. Traina, A., Seeger, B., and Faloutsos, C. (2000b). Slim-trees: High performance metric trees minimizing overlap between nodes. In Advances in Database Technology, volume 1777, pages 51-65. Springer.

Uhlmann, J. K. (1991). Satisfying general proximity/similarity queries with metric trees. Information Processing Letters, 40(4): 175-179.

Ulrich Nehmzow, T. S. and Hallam, J. (1991). Location recognition in a mobile robot using self-organising feature maps. In Schmidt, G., editor, Information Processing 
in Autonomous Mobile Robots. Proc. of the Int. Workshop, pages 267-277. Berlin, Heidelberg. Springer.

Upal, M. A. and Neufeld, E. M. (1996). Comparison of Unsupervised Classifiers. In ISIS Information, Statistics and Induction in Science, pages 342-353, Singapore. World Scientific.

Vargas, E. C. and Romero, R. A. F, (2002). A sam-som family: Incorporating spatial access methods into constructive self-organizing maps. In International Conference on Neural Networks - IEEE, pages 1172-1177, Honolulu, Haway (USA).

Vesanto, J. (2000). Using som in data mining. Master's thesis, Department of Computer Science and Engineering, Helsinki University, Helsinki, Finland. http://citeseer.nj.nec.com/vesantooousing.html.

Wactlar, H., Kanade, T., Smith, M., and Stevens, S. (1996). Intelligent access to digital video: Infomedia project. IEEE Computer, 29(3):46-52.

Waxman, A. M., Seibert, M. C., Gove, A., Fay, D. A., Bernardon, A. M., Lazott, C., Steele, W. R., and Cunningham, R. K. (1995). Neural processing of targets in visible, multispectral IR and SAR imagery. Neural Networks, 8(7-8):1029-1051.

Weber, R. (1998). Similarity search in high-dimensional data spaces. In Grundlagen von Datenbanken, pages 138-142, Germany.

Weiss, S. M. and Indurkhay, N. (1998). Predictive Data Mining: A Practical Guide. Morgan Kaufmann Publishers Inc., San Francisco, California, USA.

Williamson, J. R. (1997). Gaussian artmap: A neural network for fast incremental learning of noisy multidimensional maps. Neural Networks, 9(5):881-897.

Woolsey, C. N. (1958). Organization of somatic sensory and motor areas of the cerebral cortex. In Harlow and Woolsey, editors, In Biological and biochemical bases of behaviour, pages 63-81, Madison. University Wisconsin Press.

Yianilos, P. N. (1999). Excluded middle vantage point forests for nearest neighbor search. Technical report, NEC Research Institute. Presented at the Sixth DIMACS Implementation Challenge: Near Neighbor Searches workshop. 